\title{
Calcium orthophosphate-based biocomposites and hybrid biomaterials
}

\author{
Sergey V. Dorozhkin
}

Received: 4 July 2008/ Accepted: 20 November 2008/Published online: 15 January 2009

(C) Springer Science+Business Media, LLC 2009

\begin{abstract}
In this review article, the state-of-the-art of calcium orthophosphate-based biocomposites and hybrid biomaterials suitable for biomedical applications is presented. This subject belongs to a rapidly expanding area of science and research, because these types of biomaterials offer many significant and exciting possibilities for hard tissue regeneration. Through the successful combinations of the desired properties of matrix materials with those of fillers (in such systems, calcium orthophosphates might play either role), innovative bone graft biomaterials can be designed. The review starts with an introduction to locate the reader. Further, general information on composites and hybrid materials including a brief description of their major constituents are presented. Various types of calcium orthophosphate-based bone-analogue biocomposites and hybrid biomaterials those are either already in use or being investigated for various biomedical applications are then extensively discussed. Many different formulations in terms of the material constituents, fabrication technologies, structural and bioactive properties, as well as both in vitro and in vivo characteristics have been already proposed. Among the others, the nano-structurally controlled biocomposites, those with nanosized calcium orthophosphates, biomimetically fabricated formulations with collagen, chitin and/or gelatin, as well as various functionally graded structures seem to be the most promising candidates for clinical applications. The specific advantages of using
\end{abstract}

S. V. Dorozhkin $(\bowtie)$

Kudrinskaja sq. 1-155, 123242 Moscow, Russia

e-mail: sedorozhkin@yandex.ru calcium orthophosphate-based biocomposites and hybrid biomaterials in the selected applications are highlighted. As the way from a laboratory to a hospital is a long one and the prospective biomedical candidates have to meet many different necessities, the review also examines the critical issues and scientific challenges that require further research and development.

$\begin{array}{ll}\text { Abbreviations } \\ \text { EVOH } & \text { Ethylene-vinyl alcohol copolymer } \\ \text { IBS } & \text { Injectable bone substitute } \\ \text { HDPE } & \text { High-density polyethylene } \\ \text { HPMC } & \text { Hydroxypropylmethylcellulose } \\ \text { PAA } & \text { Polyacrylic acid } \\ \text { PBT } & \text { Polybutyleneterephthalate } \\ \text { PCL } & \text { Poly(c-caprolactone) } \\ \text { PDLLA } & \text { Poly-DL-lactic acid } \\ \text { PEEK } & \text { Polyetheretherketone } \\ \text { PEG } & \text { Polyethylene glycol } \\ \text { PGA } & \text { Polyglycolic acid } \\ \text { PHB } & \text { Polyhydroxybutyrate } \\ \text { PHBHV } & \text { Poly(hydroxybutyrate-co-hydroxyvalerate) } \\ \text { PHEMA } & \text { Polyhydroxyethyl methacrylate } \\ \text { PHV } & \text { Polyhydroxyvalerate } \\ \text { PLA } & \text { Polylactic acid } \\ \text { PLGA } & \text { Poly(lactic-co-glycolic) acid } \\ \text { PLLA } & \text { Poly(L-lactic acid) } \\ \text { PMMA } & \text { Polymethylmethacrylate } \\ \text { PPF } & \text { Poly(propylene-co-fumarate) } \\ \text { PS } & \text { Polysulfone } \\ \text { PSZ } & \text { Partially stabilized zirconia } \\ \text { PTFE } & \text { Polytetrafluoroethylene } \\ \text { PVA } & \text { Polyvinyl alcohol } \\ \text { PVAP } & \text { Polyvinyl alcohol phosphate } \\ \text { SEVA } & \text { Starch/ethylene vinyl alcohol copolymer }\end{array}$




\section{Introduction}

The fracture of bones due to various traumas or natural aging is a typical type of a tissue failure. An operative treatment frequently requires implantation of a temporary or a permanent prosthesis, which still is a challenge for orthopedic surgeons, especially in the cases of large bone defects. A fast aging of the population and serious drawbacks of natural bone grafts make the situation even worse; therefore, there is a high clinical demand for bone substitutes. Unfortunately, a medical application of xenografts (e.g., bovine bone) is generally associated with potential viral infections. In addition, xenografts have a low osteogenicity, an increased immunogenicity and, usually, resorb more rapidly than autogenous bone. Similar limitations are also valid for human allografts (i.e., tissue transplantation between individuals of the same species but of non-identical genetic composition), where the concerns about potential risks of transmitting tumor cells, a variety of bacterial and viral infections, as well as immunological and blood group incompatibility are even stronger [1-3]. Moreover, harvesting and conservation of allografts (exogenous bones) are additional limiting factors. Autografts (endogenous bones) are still the "golden standard" among any substitution materials because they are osteogenic, osteoinductive, osteoconductive, completely biocompatible, non-toxic, and do not cause any immunological problems (non-allergic). They contain viable osteogenic cells, bone matrix proteins, and support bone growth. Usually, autografts are well accepted by the body and rapidly integrated into the surrounding bone tissues. Due to these reasons, they are used routinely for a long period with good clinical results [3, 4]; however, it is fair to say on complication cases, those frequently happened in the past $[5,6]$. Unfortunately, a limited number of donor sites restrict the quantity of autografts harvested from the iliac crest or other locations of the patient's own body. Also, their medical application is always associated with additional traumas and scars resulting from the extraction of a donor tissue during a superfluous surgical operation, which requires further healing at the donation site and can involve long-term postoperative pain [1, 6-9]. Thus, any types of a biologically derived transplant appear to be imperfect solutions, mainly due to a restricted quantity of donor tissues, donor site morbidity, as well as potential risks of an immunological incompatibility and disease transfer $[7,9,10]$. In this light, man-made materials (alloplastic or synthetic bone grafts) stand out as a reasonable option because they are easily available, might be processed and modified to suit the specific needs of a given application [11, 12]. What's more, there are no concerns about potential infections, immunological incompatibility, sterility, and donor site morbidity.
Therefore, investigations on artificial materials for bone tissue repair appear to be one of the key subjects in the field of biomaterials research for clinical applications [13].

Currently, there are several classes of synthetic bone grafting biomaterials for in vivo applications [14-17]. The examples include natural coral, coral-derived materials, bovine porous demineralized bone, human demineralized bone matrix, bioactive glasses, glass-ceramics, and calcium orthophosphates [9]. All of these biomaterials are biocompatible and osteoconductive, guiding bone tissue from the edges toward the center of the defect, and aim to provide a scaffold of interconnected pores with pore dimensions ranging from $200[18,19]$ to $2 \mathrm{~mm} \mathrm{[20],} \mathrm{to}$ facilitate tissue and vessel ingrowths. Among them, porous bioceramics made of calcium orthophosphates appear to be very prominent due to both the excellent biocompatibility and bonding ability to living bone in the body. This is directly related to the fact that the inorganic material of mammalian calcified tissues, i.e., of bone and teeth, consists of calcium orthophosphates [21-23]. Due to this reason, other artificial materials are normally encapsulated by fibrous tissue, when implanted in body defects, while calcium orthophosphates are not [24]. Several types of calcium orthophosphate-based bioceramics with different chemical composition are already on the market $[9,25]$. Unfortunately, as for any ceramic material, calcium orthophosphate bioceramics by itself lack the mechanical and elastic properties of the calcified tissues; namely, scaffolds made of calcium orthophosphates only suffer from a low elasticity, a high brittleness, a poor tensile strength, a low mechanical reliability, and fracture toughness, which leads to the concerns about their mechanical performance after implantation [26-28]. Besides, in many cases, it is difficult to form calcium orthophosphate bioceramics into the desired shapes.

The superior strength and partial elasticity of biological calcified tissues (e.g., bones) are due to the presence of bioorganic polymers (mainly, collagen type I fibers ${ }^{1}$ ) rather than to a natural ceramic (mainly, a poorly crystalline ionsubstituted calcium-deficient hydroxyapatite, often referred to as "biological apatite") phase [30, 31]. The elastic collagen fibers are aligned in bone along the main stress directions. The biochemical composition of bone is given in Table 1 [32]. A decalcified bone becomes very flexible being easily twisted, whereas a bone without collagen is very brittle; thus, the inorganic nanocrystals of biological apatite provide with the hardness and stiffness, whereas the bioorganic fibers are responsible for the elasticity and

\footnotetext{
${ }^{1}$ One molecule of collagen type $\mathrm{I}$ is a triple helix with 338 repetitions of amino acid residues and is about $300 \mathrm{~nm}$ in length [29]. Additionally, bone contains small quantities of other bioorganic materials, such as proteins, polysaccharides, and lipids, as well as bone contains cells and blood vessels.
} 
Table 1 The biochemical composition of bone [32] species to species and from bone to bone

\begin{tabular}{llll}
\hline Inorganic phases & wt\% & Bioorganic phases & wt\% \\
\hline $\begin{array}{l}\text { Calcium orthophosphates } \\
\text { (biological apatite) }\end{array}$ & $\sim 60$ & Collagen type I & $\sim 20$ \\
Water & $\sim 9$ & $\begin{array}{c}\text { Non-collagenous proteins: osteocalcin, osteonectin, } \\
\text { osteopontin, thrombospondin, morphogenetic } \\
\text { proteins, sialoprotein, serum proteins }\end{array}$ & $\sim 3$ \\
& & $\begin{array}{l}\text { Other traces: polysaccharides, lipids, cytokines } \\
\text { Carbonates }\end{array}$ & Balance \\
Citrates & $\sim 4$ & Primary bone cells: osteoblasts, osteocytes, osteoclasts & Balance \\
Sodium & $\sim 0.7$ & & \\
Magnesium & $\sim 0.5$ & & \\
Other traces: $\mathrm{Cl}^{-}, \mathrm{F}^{-}, \mathrm{K}^{+}$ & Balance & & \\
$\mathrm{Sr}^{2+}, \mathrm{Pb}^{2+}, \mathrm{Zn}^{2+}, \mathrm{Cu}^{2+}$, & & & \\
$\mathrm{Fe}^{2+}$ & & & \\
\hline
\end{tabular}

[26]. A good sterilizability, storability, and processability, as well as a relatively low cost are also of a great importance to permit a clinical application. Unfortunately, no artificial biomaterial is yet available, which embodies all these requirements and unlikely it will appear in the nearest future. Until now, most of the available biomaterials appear to be either predominantly osteogenic or osteoinductive or else purely osteoconductive [2].

Careful consideration of the bone type and mechanical properties are needed to design bone substitutes. Indeed, in high load-bearing bones such as the femur, the stiffness of the implant needs to be adequate, not too stiff to result in strain shielding, but rigid enough to present stability. However, in relatively low load-bearing applications such as cranial bone repairs, it is more important to have stability and the correct three-dimensional shapes for esthetic reasons. One of the most promising alternatives is to apply materials with similar composition and nanostructure to that of bone tissue [36]. Mimicking the structure of calcified tissues and addressing the limitations of the individual materials, development of organic-inorganic hybrid biomaterials provides excellent possibilities for improving the conventional bone implants. In this sense, suitable biocomposites of tailored physical, biological, and mechanical properties with the predictable degradation behavior can be prepared by combining biologically relevant calcium orthophosphates with bioresorbable polymers $[45,46]$. As a rule, the general behavior of these bioorganic/calcium orthophosphate composites is dependent on nature, structure, and relative contents of the constitutive components, although other parameters such as the preparation conditions also determine the properties of the final materials. Currently, biocomposites with calcium orthophosphates incorporated as either a filler or a coating (or both) either into or onto a biodegradable polymer matrix, in the form of particles or fibers, are increasingly considered for using as bone tissue engineering scaffolds due to their improved physical, biological, and mechanical properties [47-53]. In addition, such biocomposites could fulfill general sue [44]. Finally, there is an opinion, that in the case of a serious trauma, bone should fracture rather than the implant 
requirements to the next generation of biomaterials, those should combine the bioactive and bioresorbable properties to activate in vivo mechanisms of tissue regeneration, stimulating the body to heal itself and leading to the replacement of the implants by the regenerating tissue [46, 54, 55]. Thus, through the successful combinations of ductile polymer matrixes with hard and bioactive particulate bioceramic fillers, optimal materials can be designed and, ideally, this approach could lead to a superior construction to be used as either implants or posterior dental restorative material [56].

A lint-reinforced plaster was the first composite used in clinical orthopedics as an external immobilizer (bandage) in the treatment of bone fracture by Mathijsen in 1852 [57], followed by Dreesman in 1892 [58]. A great progress in the clinical application of various types of composite materials has been achieved since then. Based on the previous experience and newly gained knowledge, various composite materials with tailored mechanical and biological performance can be manufactured and used to meet various clinical requirements [59]. However, this review presents only a brief history and advances in the field of calcium orthophosphate-based biocomposites and hybrid biomaterials suitable for biomedical application. The majority of the reviewed literature is restricted to the recent publications; a limited number of papers published in the 20th century have been cited. Various aspects of the material constituents, fabrication technologies, structural and bioactive properties, and phase interaction have been considered and discussed in details. Finally, several critical issues and scientific challenges that are needed for further advancement are outlined.

\section{General information on composites and biocomposites}

According to Wikipedia, the free encyclopedia, "composite materials (or composites for short) are engineered materials made from two or more constituent materials with significantly different physical or chemical properties and which remain separate and distinct on a macroscopic level within the finished structure" [60]. Thus, composites are always heterogeneous. Following the point of view of some predecessors, we also consider that "for the purpose of this review, composites are defined as those having a distinct phase distributed through their bulk, as opposed to modular or coated components" [61, p. 1329]. For this reason, with a few important exceptions, the structures obtained by soaking of various materials in supersaturated solutions containing ions of calcium and orthophosphate (e.g., Refs. [62-67]), those obtained by coating of various materials by calcium orthophosphates (e.g., Refs. [68-73]), as well as calcium orthophosphates coated by other compounds [74] have not been considered; however, composite coatings have been considered. Occasionally, porous calcium orthophosphate scaffolds filled by cells inside the pores $[75,76]$, as well as calcium orthophosphates impregnated by biologically active substances [77] are also defined as composites; nevertheless, such structures have not been considered in this review either.

In any composite, there are two major categories of constituent materials: a matrix (or a continuous phase) and (a) dispersed phase(s). In order to create a composite, at least one portion of each type is required. General information on the major fabrication and processing techniques might be found elsewhere [61]. The continuous phase is responsible for filling the volume, as well as it surrounds, and supports the dispersed material(s) by maintaining their relative positions. The dispersed phase(s) is(are) usually responsible for enhancing one or more properties of the matrix. Most of the composites target an enhancement of mechanical properties of the matrix, such as stiffness and strength; however, other properties, such as erosion stability, transport properties (electrical or thermal), radiopacity, density, or biocompatibility, might also be of a great interest. This synergism produces the properties, which are unavailable from the individual constituent materials [78]. What's more, by controlling the volume fractions and local and global arrangement of the dispersed phase, the properties and design of composites can be varied and tailored to suit the necessary conditions. For example, in the case of ceramics, the dispersed phase serves to impede crack growth. In this case, it acts as reinforcement. A number of methods, including deflecting crack tips, forming bridges across crack faces, absorbing energy during pullout and causing a redistribution of stresses in regions adjacent to crack tips, can be used to accomplish this [79]. Other factors to be considered in composites are the volume fraction of (a) dispersed phase(s), its(their) orientation and homogeneity of the overall composite. For example, higher volume fractions of reinforcement phases tend to improve the mechanical properties of the composites, while continuous and aligned fibers best prevent crack propagation with the added property of anisotropic behavior. Furthermore, the uniform distribution of the dispersed phase is also desirable, as it imparts consistent properties to the composite [60, 78].

In general, composites might be simple, complex, graded, and hierarchical. The term "a simple composite" is referred to the composites those result from the homogeneous dispersion of one dispersed phase throughout a matrix. The term "a complex composite" is referred to the composites those result from the homogeneous dispersion of several dispersed phases throughout one matrix. The term "a graded composite" is referred to the composites those result from the intentionally structurally 
inhomogeneous dispersion of one or several dispersed phases throughout one matrix. The term "a hierarchical composite" is referred to the cases, when fine entities of either a simple or a complex composite is somehow aggregated to form coarser ones (e.g., granules or particles) which afterwards are dispersed inside another matrix to produce the second hierarchical scale of the composite structure. Another classification type of the available composites is based on either the matrix materials (metals, ceramics and polymers) or the reinforcement dimensions/ shapes (particulates, whiskers/short fibers, and continuous fibers) [59].

In most cases, three interdependent factors must be considered in designing of any composite: (i) selection of the suitable matrix and dispersed materials, (ii) choice of appropriate fabrication and processing methods, (iii) internal and external designs of the device itself [61]. Besides, any composite must be formed to shape. To do this, the matrix material can be added before or after the dispersed material has been placed into a mold cavity or onto the mold surface. The matrix material experiences a melding event, depending upon the nature of the matrix material, that can occur in various ways such as chemical polymerization, setting, curing, or solidification from a melted state. Due to a general inhomogeneity, the physical properties of many composite materials are not isotropic, but rather orthotropic (i.e., there are different properties or strengths in different orthogonal directions) $[60,78]$.

Biocomposites are defined as the composites able to interact well with the human body in vivo and, ideally, contain one or more component that stimulates the healing process and uptake of the implant. Thus, for biocomposites the biological compatibility appears to be more important than any other type of compatibility [59]. The most common properties from the bioorganic and inorganic domains to be combined in biocomposites have been summarized in Table 2 [36]. In 1990, Williams summarized the major types of biocomposites that were used in orthopedic applications that time [80]. In 2003, Wang published an excellent update [81]. For general advantages of the

Table 2 General respective properties from the bioorganic and inorganic domains, to be combined in various composites and hybrid materials [36]

\begin{tabular}{ll}
\hline Inorganic & Bioorganic \\
\hline Hardness, brittleness & Elasticity, plasticity \\
High density & Low density \\
Thermal stability & Permeability \\
Hydrophilicity & Hydrophobicity \\
High refractive index & Selective complexation \\
Mixed valence slate (red-ox) & Chemical reactivity \\
Strength & Bioactivity \\
\hline
\end{tabular}

modern calcium orthophosphate-based biocomposites over calcium orthophosphate bioceramics and bioresorbable polymers individually, the interested readers are advised to get through "Composite materials strategy" chapter of Ref. [46].

\section{The major constituent materials of biocomposites for biomedical applications}

\section{Calcium orthophosphates}

The main driving force behind the use of calcium orthophosphates as bone substitute materials is their chemical similarity to the mineral component of mammalian bones and teeth [21-23]. As a result, in addition to being nontoxic, they are biocompatible, not recognized as foreign materials in the body and, most importantly, both exhibit bioactive behavior and integrate into living tissue by the same processes active in remodeling healthy bone. This leads to an intimate physicochemical bond between the implants and bone, termed osteointegration [81]. More to the point, calcium orthophosphates are also known to support osteoblast adhesion and proliferation [82, 83]. Even so, the major limitations to use calcium orthophosphates as load-bearing biomaterials are their mechanical properties; namely, they are brittle with poor fatigue resistance [26-28]. The poor mechanical behavior is even more evident for highly porous ceramics and scaffolds because porosity $>100 \mu \mathrm{m}$ is considered as the requirement for proper vascularization and bone cell colonization [8486], i.e., why, in biomedical applications calcium orthophosphates are used primarily as fillers and coatings [23].

The complete list of known calcium orthophosphates, including their standard abbreviations and the major properties, is given in Table 3, while the detailed information on calcium orthophosphates, their synthesis, structure, chemistry, other properties, and biomedical application have been comprehensively reviewed recently [23], where the interested readers are referred to. Even thorough more information might be found in various books and monographs [87-93].

\section{Polymers}

Polymers are a class of materials consisting of large molecules, often containing many thousands of small units, or monomers, joined together chemically to form one giant chain, thus creating very ductile materials. In this respect, polymers are comparable with major functional components of the biological environment: lipids, proteins, and polysaccharides. They differ from each other in chemical composition, molecular weight, polydispersity, 
Table 3 Existing calcium orthophosphates and their major properties

\begin{tabular}{|c|c|c|c|c|c|}
\hline $\begin{array}{l}\mathrm{Ca} / \mathrm{P} \text { ionic } \\
\text { ratio }\end{array}$ & Compound & Chemical formula & $\begin{array}{l}\text { Solubility } \\
\text { at } 25^{\circ} \mathrm{C} \text {, } \\
-\log \left(K_{\mathrm{s}}\right)\end{array}$ & $\begin{array}{l}\text { Solubility at } 37{ }^{\circ} \mathrm{C} \text {, } \\
-\log \left(K_{\mathrm{s}}\right)\end{array}$ & $\begin{array}{l}\mathrm{pH} \text { stability range } \\
\text { in aqueous } \\
\text { solutions at } 25^{\circ} \mathrm{C}\end{array}$ \\
\hline 0.5 & $\begin{array}{l}\text { Monocalcium phosphate } \\
\text { monohydrate (MCPM) }\end{array}$ & $\mathrm{Ca}\left(\mathrm{H}_{2} \mathrm{PO}_{4}\right)_{2} \cdot \mathrm{H}_{2} \mathrm{O}$ & 1.14 & Data not found & $0.0-2.0$ \\
\hline 0.5 & $\begin{array}{l}\text { Monocalcium phosphate } \\
\text { anhydrous (MCPA) }\end{array}$ & $\mathrm{Ca}\left(\mathrm{H}_{2} \mathrm{PO}_{4}\right)_{2}$ & 1.14 & Data not found & $\mathrm{a}$ \\
\hline 1.0 & $\begin{array}{l}\text { Dicalcium phosphate dihydrate } \\
\text { (DCPD), mineral brushite }\end{array}$ & $\mathrm{CaHPO}_{4} \cdot 2 \mathrm{H}_{2} \mathrm{O}$ & 6.59 & 6.63 & $2.0-6.0$ \\
\hline 1.0 & $\begin{array}{l}\text { Dicalcium phosphate anhydrous } \\
\text { (DCPA), mineral monetite }\end{array}$ & $\mathrm{CaHPO}_{4}$ & 6.90 & 7.02 & $\mathrm{a}$ \\
\hline 1.33 & Octacalcium phosphate (OCP) & $\mathrm{Ca}_{8}\left(\mathrm{HPO}_{4}\right)_{2}\left(\mathrm{PO}_{4}\right)_{4} \cdot 5 \mathrm{H}_{2} \mathrm{O}$ & 96.6 & 95.9 & $5.5-7.0$ \\
\hline 1.5 & $\alpha$-Tricalcium phosphate $(\alpha-$ TCP) & $\alpha-\mathrm{Ca}_{3}\left(\mathrm{PO}_{4}\right)_{2}$ & 25.5 & 25.5 & $\mathrm{~b}$ \\
\hline 1.5 & $\beta$-Tricalcium phosphate $(\beta$-TCP) & $\beta-\mathrm{Ca}_{3}\left(\mathrm{PO}_{4}\right)_{2}$ & 28.9 & 29.5 & $\mathrm{~b}$ \\
\hline $1.2-2.2$ & $\begin{array}{l}\text { Amorphous calcium phosphate } \\
\text { (ACP) }\end{array}$ & $\begin{array}{l}\mathrm{Ca}_{x} \mathrm{H}_{y}\left(\mathrm{PO}_{4}\right)_{z} \cdot n \mathrm{H}_{2} \mathrm{O} \\
\quad n=3-4.5 ; 15-20 \% \mathrm{H}_{2} \mathrm{O}\end{array}$ & $\mathrm{c}$ & c & $\sim 5-12^{\mathrm{d}}$ \\
\hline $1.5-1.67$ & $\begin{array}{l}\text { Calcium-deficient hydroxyapatite } \\
(\text { (CDHA })^{\mathrm{e}}\end{array}$ & $\begin{array}{l}\mathrm{Ca}_{10-\mathrm{x}}\left(\mathrm{HPO}_{4}\right)_{\mathrm{x}} \\
\quad\left(\mathrm{PO}_{4}\right)_{6-x}(\mathrm{OH})_{2-x}^{\mathrm{f}}(0<x<1)\end{array}$ & $\sim 85.1$ & $\sim 85.1$ & $6.5-9.5$ \\
\hline 1.67 & Hydroxyapatite (HA) & $\mathrm{Ca}_{10}\left(\mathrm{PO}_{4}\right)_{6}(\mathrm{OH})_{2}$ & 116.8 & 117.2 & $9.5-12$ \\
\hline 1.67 & Fluorapatite (FA) & $\mathrm{Ca}_{10}\left(\mathrm{PO}_{4}\right)_{6} \mathrm{~F}_{2}$ & 120.0 & 119.2 & $7-12$ \\
\hline 2.0 & $\begin{array}{l}\text { Tetracalcium phosphate (TTCP), } \\
\text { mineral hilgenstockite }\end{array}$ & $\mathrm{Ca}_{4}\left(\mathrm{PO}_{4}\right)_{2} \mathrm{O}$ & $38-44$ & $37-42$ & $\mathrm{~b}$ \\
\hline
\end{tabular}

The solubility is given as the logarithm of the ion product of the given formulae (excluding hydrate water) with concentrations in mol/L [23]

${ }^{\text {a }}$ Stable at temperatures above $100{ }^{\circ} \mathrm{C}$

b These compounds cannot be precipitated from aqueous solutions

${ }^{\mathrm{c}}$ Cannot be measured precisely. However, the following values were found: $25.7 \pm 0.1(\mathrm{pH}=7.40), 29.9 \pm 0.1(\mathrm{pH}=6.00), 32.7 \pm 0.1$ $(\mathrm{pH}=5.28)$

d Always metastable

e Occasionally, CDHA is named as precipitated HA

${ }^{\mathrm{f}}$ In the case $x=1$ (the boundary condition with $\mathrm{Ca} / \mathrm{P}=1.5$ ), the chemical formula of $\mathrm{CDHA}$ looks as follows: $\mathrm{Ca}_{9}\left(\mathrm{HPO}_{4}\right)\left(\mathrm{PO}_{4}\right)_{5}(\mathrm{OH})$

crystallinity, hydrophobicity, solubility, and thermal transitions. Besides, their properties can be fine-tuned over a wide range by varying the type of polymer, chain length, as well as by copolymerization or blending of two or more polymers [94, 95]. Opposite to ceramics, polymers exhibit substantial viscoelastic properties and can easily be fabricated into complex structures, such as sponge-like sheets, gels, or complex structures with intricate porous networks and channels [96]. X-ray transparent and non-magnetic polymeric materials are fully compatible with the modern diagnostic methods such as computed tomography and magnetic resonance imaging. Unfortunately, most of them are unable to meet the strict demands of the in vivo physiological environment. Namely, the main requirements to polymers suitable for biomedical applications are that they must be biocompatible, not eliciting an excessive or chronic inflammatory response upon implantation and, for those that degrade, that they breakdown into non-toxic products only. Unfortunately, polymers, for the most part, lack rigidity, ductility, and ultimate mechanical properties required in load-bearing applications. Moreover, the sterilization processes (autoclave, ethylene oxide, and ${ }^{60} \mathrm{Co}$ irradiation) may affect the polymer properties [97].

There is a variety of biocompatible polymers suitable for biomedical applications. For example, polyacrylates, poly(acrylonitrile-co-vinylchloride) and polylysine have been investigated for cell encapsulation and immunoisolation [98, 99]. Polyorthoesters and poly( $\varepsilon$-caprolactone) (PCL) have been investigated as drug-delivery devices, the latter for long-term sustained release because of their slow degradation rates [100]. PCL is a hydrolytic polyester having appropriate resorption period and releases non-toxic byproducts upon degradation [101]. Other polyesters and polytetrafluoroethylene (PTFE) are used for vascular tissue replacement. Polyurethanes are in use as coatings for pacemaker lead insulation and have been investigated for reconstruction of the meniscus [102, 103]. Polymers considered for orthopedic purposes include polyanhydrides, which have also been investigated as delivery devices (due to their rapid and well-defined surface erosion), for bone 
augmentation or replacement since they can be photopolymerized in situ [100, 104, 105]. To overcome their poor mechanical properties, they have been copolymerized with imides or formulated to be crosslinkable in situ [105]. Other polymers, such as polyphosphazenes, can have their properties (e.g., degradation rate) easily modified by varying the nature of their side groups and have been shown to support osteoblast adhesion, which makes them candidate materials for skeletal tissue regeneration [105]. PPF has emerged as a good bone replacement material, exhibiting good mechanical properties (comparable to trabecular bone), possessing the capability to crosslink in vivo through the $\mathrm{C}=\mathrm{C}$ bond and being hydrolytically degradable. It has also been examined as a material for drug-delivery devices [100, 104-107]. Polycarbonates have been suggested as suitable materials to make scaffolds for bone replacement and have been modified with tyrosinederived amino acids to render them biodegradable [100]. Polydioxanone has been also tested for biomedical applications [108]. Polymethylmethacrylate (PMMA) is widely used in orthopedics, as a bone cement for implant fixation, as well as to repair certain fractures and bone defects, for example, osteoporotic vertebral bodies [109]. However, PMMA sets by a polymerization of toxic monomers, which also evolves significant amounts of heat that damages tissues. Moreover, it is neither degradable nor bioactive, it does not bond chemically to bones and might generate particulate debris leading to an inflammatory foreign body response [104, 110]. A number of other non-degradable polymers applied in orthopedic surgery include PE in its different modifications such as low density PE, high-density polyethylene (HDPE), and Ultrahigh molecular weight polyethylene (used as the articular surface of total hip replacement implants [111, 112]), polyethylene terepthalate, polypropylene, and PTFE, which are applied to repair knee ligaments [113]. Polyactive ${ }^{\mathrm{TM}}$, a block copolymer of polyethylene glycol (PEG) and polybutyleneterephthalate
(PBT), was also considered for biomedical application [114-118]. Cellulose [119] and its esters [120] are also popular. Finally yet importantly, polyethylene oxide, polyhydroxybutyrate (PHB), and blends thereof have also been tested for biomedical applications [46].

Nonetheless, the most popular synthetic polymers used in medicine are the linear aliphatic poly( $\alpha$-hydroxyesters) such as PLA, polyglycolic acid (PGA) and their copolymers-poly(lactic-co-glycolic) acid (PLGA) (Table 4). These materials have been extensively studied; they appear to be the only synthetic and biodegradable polymers with an extensive FDA approval history [46, 105, 121-125]. They are biocompatible, mostly non-inflammatory, as well as degrade in vivo through hydrolysis and possible enzymatic action into products that are removed from the body by regular metabolic pathways [45, 100, 105, 125-130]. Besides, they might be used for drug-delivery purposes [131]. Poly( $\alpha$-hydroxyesters) have been investigated as scaffolds for replacement and regeneration of a variety of tissues, cell carriers, controlled delivery devices for drugs or proteins (e.g., growth factors), membranes or films, screws, pins, and plates for orthopedic applications [100, $103,105,122,125,132-134]$. Additionally, the degradation rate of PLGA can be adjusted by varying the amounts of the two component monomers (Table 4), which in orthopedic applications can be exploited to create materials that degrade in concert with bone ingrowth [129, 135]. Furthermore, PLGA is known to support osteoblast migration and proliferation $[55,105,126,136]$, which is a necessity for bone tissue regeneration. Unfortunately, such polymers on their own, though they reduce the effect of stress-shielding, are too weak to be used in load-bearing situations and are only recommended in certain clinical indications, such as ankle and elbow fractures [125, 130]. In addition, they exhibit bulk degradation, leading to both a loss in mechanical properties and lowering of the local solution $\mathrm{pH}$ that accelerates further degradation in an

Table 4 Major properties of several FDA approved biodegradable polymers [121]

\begin{tabular}{llll}
\hline Polymer & Thermal properties ${ }^{\mathrm{a}}\left({ }^{\circ} \mathrm{C}\right)$ & $\begin{array}{l}\text { Tensile } \\
\text { modulus }(\mathrm{GPa})\end{array}$ & $\begin{array}{l}\text { Degradation } \\
\text { time (months) }\end{array}$ \\
\hline Polyglycolic acid (PGA) & $t_{\mathrm{g}}=35-40, t_{\mathrm{m}}=225-230$ & 7.06 & $\begin{array}{r}6-12 \text { (strength loss } \\
\text { within } 3 \text { weeks) }\end{array}$ \\
L-polylactic acid (LPLA) & $t_{\mathrm{g}}=60-65, t_{\mathrm{m}}=173-178$ & 2.7 & $>24$ \\
D,L-polylactic acid (DLPLA) & $t_{\mathrm{g}}=55-60$ amorphous & 1.9 & $12-16$ \\
85/15 D,L-polylactic-co-glycolic acid (85/15 DLPLGA) & $t_{\mathrm{g}}=50-55$ amorphous & 2.0 & $5-6$ \\
75/25 D,L-polylactic-co-glycolic acid (75/25 DLPLGA) & $t_{\mathrm{g}}=50-55$ amorphous & 2.0 & $4-5$ \\
65/35 D,L-polylactic-co-glycolic acid (65/35 DLPLGA) & $t_{\mathrm{g}}=45-50$ amorphous & 2.0 & $3-4$ \\
50/50 D,L-polylactic-co-glycolic acid (50/50 DLPLGA) & $t_{\mathrm{g}}=45-50$ amorphous & 2.0 & $1-2$ \\
PCL & $t_{\mathrm{g}}=(-60)-(-65), t_{\mathrm{m}}=58-63$ & 0.4 & $>24$
\end{tabular}

${ }^{\mathrm{a}} t_{\mathrm{g}}$ glass transition temperature, $t_{\mathrm{m}}$ melting point 
autocatalytic manner. As the body is unable to cope with the vast amounts of implant degradation products, this might lead to an inflammatory foreign body response [105, $125,132]$. Finally, poly $(\alpha$-hydroxyesters $)$ do not possess the bioactive and osteoconductive properties of calcium orthophosphates [122, 137].

Several classifications of the biomedically relevant polymers are possible. For example, some authors distinguish between synthetic polymers like PLA and PGA or their copolymers with PCL, and polymers of biological origin like polysaccharides (starch, alginate, chitin/chito$\operatorname{san}^{2}$ [138-140], gelatin, cellulose, hyaluronic acid derivatives), proteins (soy, collagen, fibrin [9], silk), and a variety of biofibers, such as lignocellulosic natural fibers $[8,141,142]$. Other authors differentiate between resorbable or biodegradable (e.g., poly $\alpha$-hydroxyesters), polysaccharides and proteins) and non-resorbable (e.g., PE, PMMA, and cellulose) polymers [56, 142]. As synthetic polymers can be produced under the controlled conditions, they in general exhibit predictable and reproducible mechanical and physical properties such as tensile strength, elastic modulus, and degradation rate. Control of impurities is a further advantage of synthetic polymers. The list of synthetic biodegradable polymers used for biomedical application as scaffold materials is available as Table 1 in Ref. [142], while further details on polymers suitable for biomedical applications are available in the literatures $[97,134,143-151]$ where the interested readers are referred. Good reviews on the synthesis of different biodegradable polymers [152], as well as on the experimental trends in polymer nanocomposites [153] are available elsewhere.

Inorganic materials and compounds (metals, ceramics, glass, oxides, carbon, etc.)

Titanium (Ti) is one of the best biocompatible metals and used most widely as implant $[13,154]$. Besides, there are other metallic implants made of pure $\mathrm{Zr}, \mathrm{Hf}, \mathrm{V}, \mathrm{Nb}, \mathrm{Ta}$, Re [154], Ni, Fe, Cu [155-157], Ag, stainless steels, and various alloys [157] suitable for biomedical application. Recent studies revealed even a greater biomedical potential of porous metals [158-160]. The metallic implants provide the necessary strength and toughness that are required in load-bearing parts of the body and, due to these advantages, metals will continue to play an important role as orthopedic biomaterials in the future, even though there are concerns with regard to the release of certain ions from and corrosion products of metallic implants. Of course, neither

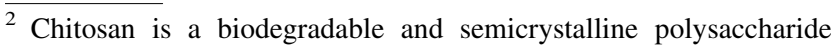
obtained from $\mathrm{N}$-deacetylation of chitin, which is harvested from the exoskeleton of marine crustaceans.
}

metals nor alloys are biomimetic ${ }^{3}$ in terms of chemical composition because there are no elemental metals in the human body. In addition, even biocompatible metals are bioinert: while not rejected by the human body, any metallic implants cannot actively interact with the surrounding tissues. Nevertheless, in some cases (especially when they are coated by calcium orthophosphates; however, that is another story) the metallic implants can show a reasonable biocompatibility [162]. Only permanent implants are made of metals and alloys, in which degradation or corrosion is not desirable. However, during recent years a number of magnesium alloys have been proposed, which are aimed to degrade in the body in order to make room for the ingrowing bone $[160,163]$.

Special types of glasses and glass ceramics are also suitable materials for biomedical applications [164-166] and a special $\mathrm{Na}_{2} \mathrm{O}-\mathrm{CaO}-\mathrm{SiO}_{2}-\mathrm{P}_{2} \mathrm{O}_{5}$ glass named Bioglass $^{\circledR}[11,24,27,28,167,168]$ is the most popular among them. They are produced via standard glass production techniques and require pure raw materials. Bioglass $^{\circledR}$ is a biocompatible and osteoconductive biomaterial. It bonds to bone without an intervening fibrous connective tissue interface and, due to these properties, it has been widely used for filling bone defects [169]. The primary shortcoming of Bioglass ${ }^{\circledR}$ is mechanical weakness and low fracture toughness due to an amorphous two-dimensional glass network. The bending strength of most Bioglass ${ }^{\circledR}$ compositions is in the range of 40 to $60 \mathrm{MPa}$, which is not suitable for major load-bearing applications. Making porosity in Bioglass ${ }^{\circledR}$-based scaffolds is beneficial for even better resorption and bioactivity [170].

By heat treatment, a suitable glass can be converted into glass-crystal composites containing crystalline phase(s) of controlled sizes and contents. The resultant glass ceramics can have superior mechanical properties to the parent glass as well as to sintered crystalline ceramics. The bioactive apatite-wollastonite (A-W) glass ceramics is made from the parent glass in the pseudoternary system $3 \mathrm{CaO} \cdot \mathrm{P}_{2} \mathrm{O}_{5}-$ $\mathrm{CaO} \cdot \mathrm{SiO}_{2}-\mathrm{MgO} \cdot \mathrm{CaO} \cdot 2 \mathrm{SiO}_{2}$, which is produced by a conventional melt-quenching method. The bioactivity of A-W glass ceramics is much higher than that of sintered HA. It possesses excellent mechanical properties and has therefore been used clinically for iliac and vertebrae prostheses and as intervertebral spacers [13, 171, 172].

Metal oxide ceramics, such as alumina $\left(\mathrm{Al}_{2} \mathrm{O}_{3}\right.$, high purity, polycrystalline, fine grained), zirconia $\left(\mathrm{ZrO}_{2}\right)$, and some other oxides (e.g., $\mathrm{TiO}_{2}$ ), have been widely studied due to their bioinertness, excellent tribological properties,

\footnotetext{
3 The term biomimetic can be defined as a processing technique that either mimics or inspires the biological mechanism, in part or whole [161].
} 
high wear resistance, fracture toughness and strength, as well as a relatively low friction [13, 173]. Unfortunately, due to transformation from the tetragonal to the monoclinic phase, a volume change occurs when pure zirconia is cooled down, which causes cracking of the zirconia ceramics. Therefore, additives such as calcia $(\mathrm{CaO})$, magnesia $(\mathrm{MgO})$, and yttria $\left(\mathrm{Y}_{2} \mathrm{O}_{3}\right)$ must be mixed with zirconia to stabilize the material in either the tetragonal or the cubic phase. Such material is called PSZ [174-176]. However, the brittle nature of any ceramics has limited their scope of clinical applications and hence more research needs to be conducted to improve their properties.

\section{Calcium orthophosphate-based biocomposites and hybrid biomaterials}

Generally, the use of calcium orthophosphate-based biocomposites and hybrid biomaterials for clinical applications has included several (partly overlapping) broad areas:

- biocomposites with polymers,

- cement-based biocomposites and concretes,

- nano-calcium orthophosphate-based biocomposites and nanocomposites,

- biocomposites with collagen,

- biocomposites with other bioorganic compounds and biological macromolecules,

- injectable bone substitutes (IBS),

- biocomposites with glasses, inorganic compounds, and metals,

- functionally graded biocomposites,

- biosensors.

The details of each subject are given below.

\section{Biocomposites with polymers}

Typically, the polymeric components of biocomposites and hybrid biomaterials comprise polymers that both have shown a good biocompatibility and are routinely used in surgical applications. In general, since polymers have a low modulus (2-7 GPa, as the maximum) as compared with that of bone (3-30 GPa), calcium orthophosphate bioceramics need to be loaded at a high-weight-percent ratio. Besides, general knowledge on composite mechanics suggests that any high-aspect-ratio particles, such as whiskers or fibers, significantly improve the modulus at a lower loading [147]. Thus, some attempts have been already performed to prepare biocomposites containing whiskerlike [177-180] or needle-like [181-183] calcium orthophosphates, as well as calcium orthophosphate fibers [45, 184].
The history of implantable polymer-calcium orthophosphate biocomposites and hybrid biomaterials started in $1981^{4}$ from the pioneering study by Prof. William Bonfield and colleagues performed on HA/PE composites [186, 187]. That initial study introduced a bone-analogue concept, when proposed biocomposites comprised a polymer ductile matrix of PE and a ceramic stiff phase of HA, and was substantially extended and developed in further investigations by that research group [94, 188-205]. More recent studies included investigations on the influence of surface topography of HA/PE composites on cell proliferation and attachment [206-212]. The material is composed of a particular combination of HA particles at a volume loading of $\sim 40 \%$ uniformly dispensed in a HDPE matrix. The idea was to mimic bone by using a polymeric matrix that can develop a considerable anisotropic character through adequate orientation techniques reinforced with a bone-like ceramics that assures both a mechanical reinforcement and a bioactive character of the composite. Following FDA approval in 1994, in 1995 this material has become commercially available under the trade name HAPEX $^{\mathrm{TM}}$ (Smith and Nephew, Richards, USA), and until now remains the only clinically successful bioactive composite that appeared to be a major step in the implant field $[28,213]$. The major production stages of $\mathrm{HAPEX}^{\mathrm{TM}}$ include blending, compounding, and centrifugal milling. A bulk material or device is then created from this powder by compression and injection molding [59]. Besides, HA/ HDPE biocomposites might be prepared by a hot rolling technique that facilitated uniform dispersion and blending of the reinforcements in the matrix [214].

A mechanical interlock between the two phases of HAPEX $^{\mathrm{TM}}$ is formed by shrinkage of HDPE onto the HA particles during cooling [94, 215]. Both HA particle size and their distribution in the HDPE matrix were recognized as important parameters affecting the mechanical behavior of HAPEX ${ }^{\mathrm{TM}}$ [197]. Namely, smaller HA particles were found to lead to stiffer composites due to general increasing of interfaces between the polymer and the ceramics; furthermore, rigidity of $\mathrm{HAPEX}^{\mathrm{TM}}$ was found to be proportional to HA volume fraction [189]. In this formulation, HA could be replaced by other calcium orthophosphates [216].

Initial clinical applications of $\mathrm{HAPEX}^{\mathrm{TM}}$ came in orbital reconstruction [217] but since 1995, the main uses of this composite have been in the shafts of middle ear implants for the treatment of conductive hearing loss [218, 219]. In both applications, HAPEX ${ }^{\mathrm{TM}}$ offers the advantage of in situ shaping, so a surgeon can make final alterations to optimize the fit of the prosthesis to the bone of a patient

\footnotetext{
${ }^{4}$ However, a more general topic "ceramic-plastic material as a bone substitute" is, at least, 18 years older [185].
} 
and subsequent activity requires only limited mechanical loading with virtually no risk of failure from insufficient tensile strength [94, 167]. As compared with cortical bones, $\mathrm{HA} / \mathrm{PE}$ composites have a superior fracture toughness for HA concentrations below $40 \%$ and similar fracture toughness in the 45-50\% range. Their Young's modulus is in the range of 1 to $8 \mathrm{GPa}$, which is quite close to that of bone. The examination of the fracture surfaces revealed that only mechanical bond occurs between HA and PE. Unfortunately, the HA/PE composites are not biodegradable, the available surface area of HA is low and the presence of bioinert PE decreases the ability to bond to bones. Furthermore, HAPEX $^{\mathrm{TM}}$ has been designed with a maximized density to increase its strength but the resulting lack of porosity limits the ingrowth of osteoblasts when the implant is placed into the body [26, 168]. Further details on HAPEX $^{\mathrm{TM}}$ are available elsewhere [94]. Except of HAP$\mathrm{EX}^{\mathrm{TM}}$, other types of HA/PE biocomposites are also known [220-224].

Both linear and branched PE was used as a matrix and the biocomposites with the former were found to give a higher modulus [221]. The reinforcing mechanisms in calcium orthophosphate/polymer biocomposites have yet to be convincingly disclosed. Generally, if a poor filler choice is made, the polymeric matrix might be affected by the filler through reduction of molecular weight during composite processing, formation of an immobilized shell of polymer around the particles (transcrystallization, surfaceinduced crystallization, or epitaxial growth) and changes in conformation of the polymer due to particle surfaces and inter-particle spacing [94]. On the other hand, the reinforcing effect of calcium orthophosphate particles might depend on the molding technique employed: a higher orientation of the polymeric matrix was found to result in a higher mechanical performance of the composite [225, 226].

Many other blends of calcium orthophosphates with various polymers are possible, including rather unusual formulations with dendrimers [227]. The list of the appropriate calcium orthophosphates is shown in Table 3 (except of MCPM and MCPA - both are too acidic and, therefore, are not biocompatible [23]), while many biomedically suitable polymers have been listed above. The combination of calcium orthophosphates and polymers into biocomposites has a twofold purpose. The desirable mechanical properties of polymers compensate for a poor mechanical behavior of calcium orthophosphate bioceramics, while in turn the desirable bioactive properties of calcium orthophosphates improve those of polymers, expanding the possible uses of each material within the body [127-129, 228-231]. Namely, polymers have been added to calcium orthophosphates in order to improve their mechanical strength $[127,228]$ and calcium orthophosphate fillers have been blended with polymers to improve their compressive strength and modulus, in addition to increase their osteoconductive properties [48, 129, 137, 232-236]. Furthermore, biocompatibility of such biocomposites is enhanced because calcium orthophosphate fillers induce an increased initial flash spread of serum proteins compared with the more hydrophobic polymer surfaces [237]. What's more, experimental results of these biocomposites indicate favorable cell-material interactions with increased cell activities as compared with each polymer alone [230]. As a rule, with increasing of calcium orthophosphate content, both Young's modulus and bioactivity of the biocomposites increase, while the ductility decreases [26, 232]. Furthermore, such formulations can provide a sustained release of calcium and orthophosphate ions into the milieus, which is important for mineralized tissue regeneration [229]. Indeed, a combination of two different materials draws on the advantages of each one to create a superior biocomposite with respect to the materials on their own.

It is logical to assume that the proper biocomposite of a calcium orthophosphate (for instance, CDHA) with a bioorganic polymer (for instance, collagen) would yield the physical, chemical, and mechanical properties similar to those of human bones. Different ways have been already realized to bring these two components together into composites, like mechanical blending, ball milling, dispersion of ceramic fillers into a polymer-solvent solution, a melt extrusion of a ceramic/polymer powder mixture, coprecipitation, and electrochemical codeposition [32, 59, 238-240]. Besides, there is an in situ formation, which involves either synthesizing the reinforcement inside a preformed matrix material or synthesizing the matrix material around the reinforcement [59, 241]. For example, several papers have reported this method to produce various composites of apatites with carbon nanotubes [242247]. Another example comprises using amino acid-capped gold nanoparticles as scaffolds to grow CDHA [248]. In certain cases, a mechano-chemical route [249], emulsions [250-253], freeze-drying [254] and freeze-thawing techniques [255], flame-sprayed technique [256], or geltemplated mineralization [257] might be applied to produce calcium othophosphates-based biocomposites. Various fabrication procedures are available elsewhere [32, 59, 238], where the interested readers are referred.

The interfacial bonding between a calcium orthophosphate and a polymer is an important issue of any biocomposite. If adhesion between the phases is poor, the mechanical properties of a biocomposite suffer. In order to solve the problem, various approaches have been already introduced. For example, a diisocyanate coupling agent was used to bind PEG/PBT (Polyactive ${ }^{\mathrm{TM}}$ ) block copolymers to HA filler particles. Using surface-modified HA 
particles as a filler in a PEG/PBT matrix significantly improved the elastic modulus and strength of the polymer as compared with the polymers filled with ungrafted HA $[234,258]$. Another group used processing conditions to achieve a better adhesion of the filler to the matrix. Ignjatovic et al. [127, 128, 259] prepared poly(L-lactic acid) (PLLA)/HA composites by pressing blends of varying PLLA and HA content at different temperatures and pressures. They found that maximum compressive strength was achieved at $\sim 15 \mathrm{wt} \%$ of PLLA. Using blends with $20 \mathrm{wt} \%$ of PLLA, the authors also established that increasing the pressing temperature and pressure improved the mechanical properties. The former was explained by decrease in viscosity of the PLLA associated with a temperature increase, hence leading to improved wettability of HA particles. The latter was explained by increased compaction and penetration of pores at higher pressure, in conjunction with a greater fluidity of the polymer at higher temperatures. The combination of high pressures and temperatures was found to decrease porosity and guarantee a close apposition of a polymer to the particles, thereby improving the compressive strength [228] and fracture energy [260] of the biocomposites. The PLLA/HA biocomposites scaffolds were found to improve cell survival over plain PLLA scaffolds [261].

It is also possible to introduce porosity into calcium orthophosphate-based biocomposites, which is advantageous for most applications as bone substitution material. The porosity facilitates the migration of osteoblasts from surrounding bones to the implant site [129, 262, 263]. Various material processing strategies to prepare composite scaffolds with interconnected porosity comprise thermally induced phase separation, solvent casting, and particle leaching, solid freeform fabrication techniques, microsphere sintering, and coating [142, 264-266]. A supercritical gas foaming technique might be used as well [238, 267, 268].

\section{Apatite-based biocomposites}

A biological apatite is known to be the major inorganic phase of mammalian calcified tissues [21, 22]. Consequently, CDHA, HA, carbonateapatite (both with and without dopants) and, occasionally, FA have been applied to prepare biocomposites with other compounds, usually with the aim to improve the bioactivity. For example, PS composed with HA can be used as a starting material for long-term implants [269-271]. Retrieved in vivo, HA/PS biocomposite-coated samples from rabbit distal femurs demonstrated direct bone apposition to the coatings, as compared with the fibrous encapsulation that occurred when uncoated samples were used [269]. The resorption time of such biocomposites is a very important factor, which depends on polymer's microstructure and the presence of modifying phases [270].

Various apatite-containing biocomposites with PVA [255, 272-278], polyvinyl alcohol phosphate (PVAP) [280], and several other polymeric components [279, 281292] have already been developed. Namely, PVA/CDHA biocomposite blocks were prepared by precipitation of CDHA in aqueous solutions of PVA [255]. An artificial cornea consisted of a porous nano-HA/PVA hydrogel skirt and a transparent center of PVA hydrogel has been prepared as well. The results displayed a good biocompatibility and interlocking between artificial cornea and host tissues [276, 277]. PVAP has been chosen as a polymer matrix, because its phosphate groups can act as a coupling/anchoring agent, which has a higher affinity toward the HA surface [280]. Greish and Brown [283-285] developed HA/Ca poly(vinyl phosphonate) biocomposites. A template-driven nucleation and mineral growth process for the high-affinity integration of CDHA with polyhydroxyethyl methacrylate (PHEMA) hydrogel scaffold have been developed as well [292].

Polyetheretherketone (PEEK) [177, 179, 293-299] and high-impact polystyrene [300] were applied to create biocomposites with HA having a potential for clinical use in load-bearing applications. The study on reinforcing PEEK with thermally sprayed HA particles revealed that the mechanical properties increased monotonically with the reinforcement concentration, with a maximum value in the study of 40\% volume fraction of HA particles [295-297]. The reported ranges of stiffness within 2.8-16.0 GPa and strength within 45.5-69 MPa exceeded the lower values for human bone (7-30 GPa and 50-150 MPa, respectively) [296]. Modeling of the mechanical behavior of HA/PEEK biocomposites is available elsewhere [298].

Biodegradable poly $(\alpha$-hydroxyesters $)$ are well established in clinical medicine. Currently, they provide with a good choice when a suitable polymeric filler material is sought. For example, HA/PLGA composites were developed, which appeared to possess a cellular-compatibility suitable for bone tissue regeneration [301-308]. Zhang and Ma [48, 233] seeded highly porous PLLA foams with HA particles in order to improve the osteoconductivity of polymer scaffolds for bone tissue engineering. They pointed out that hydration of the foams prior to incubation in simulated body fluid increased the amount of carbonated CDHA material due to an increase in $\mathrm{COOH}$ and $\mathrm{OH}$ groups on the polymer surface, which apparently acted as nucleation sites for apatite. The following values of Young's modulus, compressive, bending, and tensile strengths for PLLA/HA composites have been achieved: 5-12 GPa, 78-137 MPa, 44-280 MPa, and 10-30 MPa, respectively [309]. However, these data do not appear to be in a good agreement with HA/PLLA biocomposite unit cell model predictions [310]. 
On their own, PGA and PLA are known to degrade to acidic products (glycolic and lactic acids, respectively) that both catalyze polymer degradation and cause inflammatory reactions of the surrounding tissues [311]. Thus, in biocomposites of poly( $\alpha$-hydroxyesters) with calcium orthophosphates, the presence of slightly basic compounds (HA, TTCP) to some extent neutralizes the acid molecules, provides with a weak $\mathrm{pH}$-buffering effect at the polymer surface and, therefore, more or less compensates these drawbacks [137, 312-314]. However, additives of even more basic chemicals (e.g., $\mathrm{CaO}, \mathrm{CaCO}_{3}$ ) might be necessary [142, 313, 315, 316]. Extensive cell culture experiments on $\mathrm{pH}$-stabilized composites of PGA and carbonateapatite were reported, which afterwards were supported by extensive in vitro $\mathrm{pH}$-studies [317]. A consequent development of this approach has led to designing of functionally graded composite skull implants consisting of polylactides, carbonateapatite, and $\mathrm{CaCO}_{3}$ [318, 319]. Besides the $\mathrm{pH}$-buffering effect, inclusion of calcium orthophosphates was found to modify both surface and bulk properties of the biodegradable poly( $\alpha$-hydroxyesters) by increasing the hydrophilicity and water absorption of the polymer matrix, thus altering the scaffold degradation kinetics. For example, polymer biocomposites filled with HA particles was found to hydrolyze homogeneously due to water penetrating into interfacial regions [320].

Biocomposites of poly( $\alpha$-hydroxyesters $)$ with calcium orthophosphates are mainly prepared by incorporating the inorganic phase into a polymeric solution, followed by drying under vacuum. The resulting solid composites might be shaped using different processing techniques. One can also prepare these biocomposites by mixing HA particles with L-lactide prior the polymerization [312] or by a combination of slip-casting technique and hot-pressing [321]. A surfactant might be useful to keep the suspension homogeneity [322]. Besides, HA/PLA [251, 252] and HA/ PLGA [253] microspheres might be prepared by a microemulsion technique. More complex carbonated-FA/PLA porous biocomposite scaffolds are also known [323]. An interesting list of references, assigned to the different ways of preparing $\mathrm{HA} / \mathrm{poly}(\alpha$-hydroxyesters) biodegradable composites, might be found in publications by Durucan and Brown [49, 324, 325]. The authors prepared CDHA/PLA and CDHA/PLGA composites by solvent casting technique with a subsequent hydrolysis of $\alpha$-TCP to CDHA in aqueous solutions. The presence of both polymers was found to inhibit $\alpha$-TCP hydrolysis, if compared with that of single-phase $\alpha$-TCP; what is more, the inhibiting effect of PLA exceeded that of PLGA [49, 324, 325]. The physical interactions between calcium orthophosphates and poly $(\alpha-$ hydroxyesters) might be easily seen in Fig. 1 [49]. Nevertheless, it should not be forgotten that typically non-meltbased routes lead to the development of composites with lower mechanical performance and many times require the use of toxic solvents and intensive hand labor [146].

The mechanical properties of poly( $\alpha$-hydroxyesters) could be substantially improved by the addition of calcium orthophosphates [326, 327]. Shikinami and Okuno [137] developed CDHA/PLLA composites of very high mechanical properties; mini-screws and mini-plates made of these composites have been manufactured and tested [320]. They have shown easy handling and shaping according to the implant site geometry, total resorbability, good ability to bond directly to the bone tissue without
Fig. 1 SEM micrographs of a $\alpha$-TCP compact; b $\alpha$-TCP-PLGA biocomposite (bars $=5 \mu \mathrm{m}$ ). Reprinted from Ref. [49] with permission

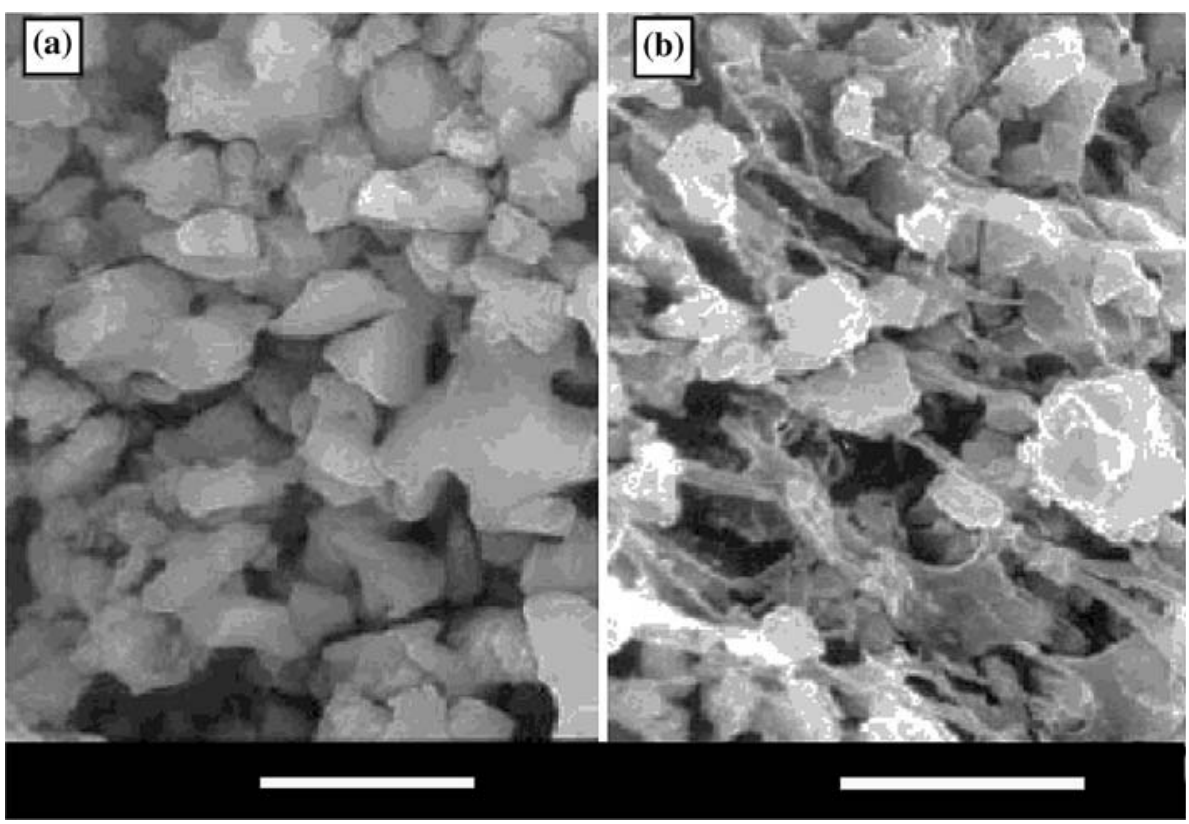


interposed fibrous tissue, osteoconductivity, biocompatibility and high stiffness retainable for the period necessary to achieve bone union [320]. The initial bending strength of $280 \mathrm{MPa}$ exceeded that of cortical bone (120-210 MPa), while the modulus was as high as $12 \mathrm{GPa}$ [137]. The strength could be maintained above $200 \mathrm{MPa}$ up to 25 weeks in phosphate-buffered saline solution. Such biocomposites were obtained from precipitation of a PLLA/ dichloromethane solution, where small granules of uniformly distributed CDHA microparticles (average size of $3 \mu \mathrm{m}$ ) could be prepared [136]. Porous scaffolds of polyDL-lactic acid (PDLLA) and HA have been manufactured as well [268, 328, 329]. Upon implantation into rabbit femora, a newly formed bone was observed and biodegradation was significantly enhanced if compared with single-phase HA bioceramics. This might be due to a local release of lactic acid, which in turn dissolves HA. In other studies, PLA and PGA fibers were combined with porous HA scaffolds. Such reinforcement did not hinder bone ingrowth into the implants, which supported further development of such biocomposites as bone graft substitutes [47, 48, 309, 330, 331].

Recently, blends (named as SEVA-C) of ethylene-vinyl alcohol copolymer (EVOH) with starch filled with 10 $30 \mathrm{wt} \%$ HA have been fabricated to yield biocomposites with modulus up to $\sim 7 \mathrm{GPa}$ with a $30 \%$ HA loading [332337]. The incorporation of bioactive fillers such as HA in SEVA-C aimed to assure the bioactive behavior of the composite and to provide the necessary stiffness within the typical range of human cortical bone properties. These biocomposites exhibited a strong in vitro bioactivity that was supported by the polymer's water-uptake capability [338]. However, the reinforcement of SEVA-C by HA particles was found to affect the rheological behavior of the blend. A degradation model of these biocomposites is available [339].

Higher homologues poly(3-hydroxybutyrate), 3-PHB, and poly(3-hydroxyvalerate), 3-PHV, show almost no biodegradation. Nevertheless, biocomposites of these polymers with calcium orthophosphates showed a good biocompatibility both in vitro and in vivo [94, 340-345]. Both bioactivity and mechanical properties of these biocomposites can be tailored by varying the volume percentage of calcium orthophosphates. Similarly, biocomposites of poly(hydroxybutyrate-co-hydroxyvalerate) (PHBHV) with both HA and amorphous carbonated apatite (almost ACP) appeared to have a promising potential for repair and replacement of damaged bones [346-349].

Along this line, PCL is used as a slowly biodegradable, a but well-biocompatible polymer. PCL/HA composites have been already discussed as suitable materials for substitution, regeneration, and repair of bone tissues [264, 350357]. For example, biocomposites were obtained by infiltration of $\varepsilon$-caprolactone monomer into porous apatite blocks and in situ polymerization [353]. The composites were found to be biodegradable and might be applied as cancellous or trabecular bone replacement material or for cartilage regeneration. Both the mechanical performance and biocompatibility in osteoblast cell culture of PCL were shown to be strongly increased when HA was added [358]. Several preparation techniques of PCL/HA composites are known. For example, to make composite fibers of PCL/ nano-HA, the desired amount of nano-HA powder was dispersed in a solvent using magnetic stirrer followed by ultrasonication for $30 \mathrm{~min}$. Then, PCL was dissolved in this suspension, followed by the solvent evaporation [359]. The opposite preparation order is also possible: PCL was initially dissolved in chloroform at room temperature (7-10\% weight/volume $)$, then HA $(\sim 10 \mu \mathrm{m}$ particle size $)$ was suspended in the solution, sonicated for $60 \mathrm{~s}$, followed by the solvent evaporation [129] or salt-leaching [360]. The mechanical properties obtained by this technique were about one-third that of trabecular bone. In a comparative study, PCL and biological apatite were mixed in the ratio 19:1 in an extruder [361]. At the end of the preparation, the mixture was cooled in an atmosphere of nitrogen. The authors observed that the presence of biological apatite improved the modulus while concurrently increasing the hydrophilicity of the polymeric substrate. Besides, an increase in apatite concentration was found to increase both the modulus and yield stress of the composite, which indicated to good interfacial interactions between the biological apatite and PCL. It was also observed that the presence of biological apatite stimulated osteoblasts attachment to the biomaterial and cell proliferation [361]. In another study, a PCL/HA biocomposite was prepared by blending in melt form at $120{ }^{\circ} \mathrm{C}$ until the torque reached equilibrium in the rheometer that was attached to the blender [362]. Then the sample was compression-molded and cut into specimens of appropriate size for testing. It was observed that the composite containing $20 \mathrm{wt} \% \mathrm{HA}$ had the highest strength [362]. However, a direct grafting of PCL on the surface of HA particles seems to be the most interesting preparation technique [350]. HA porous scaffolds were coated by a PCL/HA composite coating [50]. In this system, PCL, as a coating component, was able to improve the brittleness and low strength of the HA scaffolds, whereas the particles in the coating were to improve the osteoconductivity and bioactivity of the coating layer. More complex PDLLA/PCL/HA biocomposites have been prepared as well [363]. Further details on both PCL/HA biocomposites and processing methodologies thereof might be found elsewhere [264].

The spread of attached human osteoblasts onto PLA and PCL films reinforced with CDHA and sintered HA was shown to be higher than for the polymers alone [152]. 


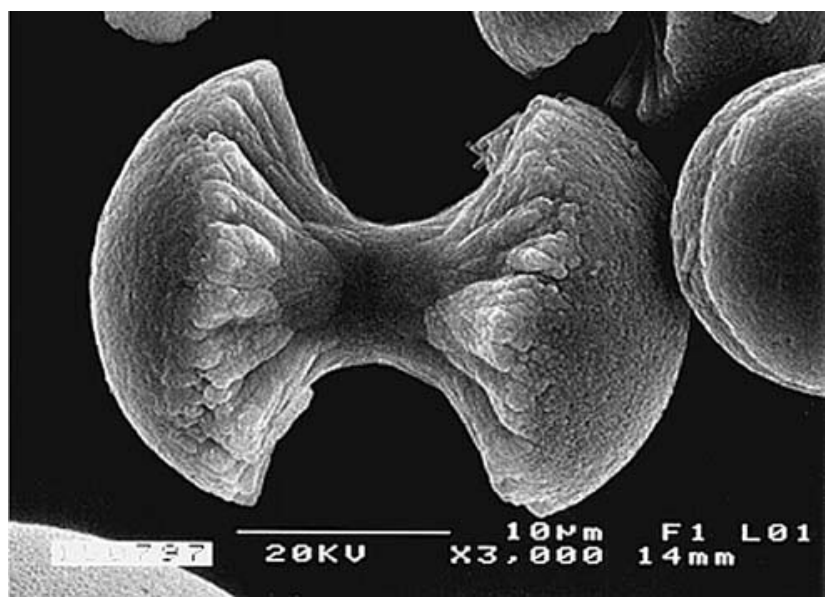

Fig. 2 A biomimetically grown aggregate of FA that was crystallized in a gelatin matrix. Its shape can be explained and simulated by a fractal growth mechanism. Scale bar: $10 \mu \mathrm{m}$. Reprinted from Ref. [366] with permission

Moreover, biochemical assays relating cell activity to DNA content allowed concluding that cell activity was more intense for the composite films [152]. Kim et al. [50] coated porous HA blocks with PCL from dichloromethane solution and performed drug-release studies. The antibiotic tetracycline hydrochloride was added into this layer, yielding a bioactive implant with drug release for longer than a week.

Yoon et al. [364] investigated the highest mechanical and chemical stability of FA by preparing FA/collagen biocomposites and studied their effect in osteoblast-like cell culture. The researchers found an increased cellular activity in FA composites compared with HA composites. This finding was confirmed in another study by means of variations in the fluoride content for FA-HA/PCL composites [365]. An interesting phenomenon of fractal growth of FA/gelatin composite crystals (Fig. 2) was achieved by diffusion of calcium- and orthophosphate + fluoride-solutions from the opposite sides into a tube filled with a gelatin gel [366-374]. The reasons of this phenomenon are not quite clear yet; besides, up to now nothing has yet been reported on a possible biomedical application of such very unusual structural composites.

\section{TCP-based biocomposites}

Both $\alpha$-TCP and $\beta$-TCP have a higher solubility than HA (Table 3). Besides, they are faster resorbed in vivo. ${ }^{5}$ Therefore, these calcium orthophosphates were used instead of HA to prepare completely biodegradable biocomposites [376-394]. For example, a biodegradable and

\footnotetext{
5 However, there are some reports about a lack of TCP biodegradation after implantation in calvarial defects [375].
}

osteoconductive biocomposite made of $\beta$-TCP particles and gelatin was proposed [385]. This material was tested in vivo with good results. It was found to be biocompatible, osteoconductive, and biodegradable with no need for a second surgical operation to remove the device after healing occurred. Herbal extracts might be added to this biocomposite [386]. Another research group prepared biocomposites of crosslinked gelatin with $\beta$-TCP; they found both a good biocompatibility and bone formation upon subcutaneous implantation in rats [387]. Yang et al. [392] extended this to porous (porosity about 75\%) $\beta$-TCP/ gelatin biocomposites those also contained BMP-4. Besides, cell-compatible and possessive some osteoinductive properties porous $\beta$-TCP/alginate-gelatin hybrid scaffolds were prepared and successfully tested in vitro [389]. More to the point, biocomposites of $\beta$-TCP with PLLA [382, 383] and copolyester lactide-co-glycolide-co$\varepsilon$-caprolactone [384] were prepared. Although $\beta$-TCP was able to counter the acidic degradation of the polyester to some extent, it did not prevent a $\mathrm{pH}$ drop down to $\sim 6$. Nevertheless, implantation of this biocomposite in beagles' mandibular bones was successful [384].

Based on the self-reinforcement concept, biocomposites of TCP with polylactides were prepared and studied using conventional mechanical testing [395]. Bioresorbable scaffolds were fabricated from such biocomposites [396]. Chitosan was also used as the matrix for the incorporation of $\beta$-TCP by a solid/liquid phase separation of the polymer solution and subsequent sublimation of the solvent. Due to complexation of the functional groups of chitosan with calcium ions of $\beta$-TCP, these biocomposites had a better compressive modulus and strength [397]. PCL/ $\beta$-TCP biocomposites were developed as well [398-401] and their in vitro degradation behavior was systematically monitored by immersion in simulated body fluid at $37{ }^{\circ} \mathrm{C}$ [400]. To extend this topic further, the PCL/ $\beta$-TCP biocomposites might be loaded by drugs [401].

Cell culture tests on $\beta$-TCP/PLLA biocomposites were reported; the biocomposites showed no cytotoxicity and evidenced good cell attachment to its surface [376]. An in vitro study with primary rat calvarial osteoblasts showed an increased cellular activity in the BMP-loaded samples [392]. Other researchers investigated BMP-2-loaded porous $\beta$-TCP/gelatin biocomposites (porosity $95 \%$, average pore size 180-200 $\mu \mathrm{m}$ ) [402] and confirmed the precious study. Biocomposites of $\beta$-TCP and glutaraldehyde crosslinked gelatin were manufactured and tested in vitro to measure the material cytotoxicity [388]. The experimental results revealed that the amount of glutaraldehyde crosslinking agent should be less than $8 \%$ to decrease the toxicity on the osteoblasts and to avoid inhibition of cellular growth caused by the release of residual or uncrosslinked glutaraldehyde. 
A long-term implantation study of PDLLA/ $\alpha-T C P$ composites in a loaded sheep implant model showed good results after 12 months, but a strong osteolytic reaction after 24 months. This was ascribed to the almost complete dissolution of $\alpha$-TCP to this time and an adverse reaction of the remaining PDLLA [403].

More complex calcium orthophosphate-based biocomposites are known as well. For example, there is a composite consisting of three interpenetrating networks: TCP, CDHA, and PLGA [404]. Firstly, a porous TCP network was produced by coating a polyurethane foam by hydrolysable $\alpha$-TCP slurry. Then, a CDHA network was derived from a calcium orthophosphate cement filled in the porous TCP network. Finally, the remaining open pore network in the CDHA/ $\alpha$-TCP structures was infiltrated with PLGA. This biocomposite consists of three phases with different degradation behavior. It was postulated that bone would grow on the fastest degrading network of PLGA, while the remaining calcium orthophosphate phases would remain intact thus maintaining their geometry and loadbearing capability [404].

\section{Other calcium orthophosphate-based biocomposites}

The number of research papers devoted to biocomposites based on other calcium orthophosphates is substantially lesser than those devoted to apatites and TCP. Biphasic calcium phosphate $(\mathrm{BCP})^{6}$ appears to be the most popular among the remaining calcium orthophosphates. Collagencoated BCP ceramics was studied and the biocompatibility toward osteoblasts was found to increase upon coating with collagen [405]. Another research group created porous PDLLA/BCP scaffolds and coated them with a hydrophilic PEG/vancomycin composite for both drug-delivery purposes and surface modification [406]. More to the point, PLGA/BCP composites were fabricated [407, 408] and their cytotoxicity and fibroblast properties were found to be acceptable for natural bone tissue reparation, filling, and augmentation [409, 410]. PCL/BCP biocomposites are known as well [411].

A choice of DCPD-based biocomposites of DCPD, albumin, and duplex DNA was prepared by water/oil/water interfacial reaction method [250]. Core-shell type DCPD/ chitosan biocomposite fibers were prepared by a wet spinning method in another study [412]. The energy-dispersive X-ray spectroscopy analysis indicated that $\mathrm{Ca}$ and $\mathrm{P}$ atoms were mainly distributed on the outer layer of the composite fibers; however, a little amount of $\mathrm{P}$ atoms remained inside the fibers. This indicated that the composite fibers formed a unique core-shell structure with shell

\footnotetext{
${ }^{6} \mathrm{BCP}$ is a solid composite of HA and $\beta$-TCP; however, similar composites of HA and $\alpha$-TCP are possible as well [23].
}

of calcium orthophosphate and core of chitosan [412]. Although, this is not to the point, it is interesting to mention that some DCPD/polymer composites could be used as proton conductors in battery devices [413, 414]. Nothing has been reported on their biocompatibility but, perhaps, sometime the improved formulations will be used to fabricate biocompatible batteries for implantable electronic devices.

Various ACP-based biocomposites for dental applications were developed [415-418]. Besides, several ACPbased formulations were investigated as potential biocomposites for bone grafting [349, 419-421]. Namely, ACP/PPF biocomposites were prepared by in situ precipitation [420], while PHB/carbonated ACP and PHBHV/ carbonated ACP biocomposites appeared to be well suited as slowly biodegradable bone substitution material [349]. Another example comprises hybrid nano-capsules of $\sim 50$ $70 \mathrm{~nm}$ in diameter which were fabricated by ACP mineralization of shell crosslinked polymer micelles and nanocages [421]. These nano-capsules consisted of a continuous ultrathin inorganic surface layer that infiltrated the outer crosslinked polymeric domains. They might be used as structurally robust, $\mathrm{pH}$-responsive biocompatible hybrid nanostructures for drug delivery, bioimaging, and therapeutic applications [421].

\section{Calcium orthophosphate cement-based biocomposites} and concretes

Inorganic self-setting calcium orthophosphate cements, which harden in the body, were introduced by LeGeros et al. [422] and Brown and Chow [423, 424] in the early 1980s. ${ }^{7}$ Since then, these cements have been broadly studied and many formulations have been proposed [427]. The cements set and harden due to various chemical interactions among calcium orthophosphates that finally lead to formation of a monolithic body consisting of either CHDA or DCPD with possible admixtures of other phases. Unfortunately, having the ceramic nature, calcium orthophosphate cements are brittle after hardening and the setting time is sometimes unsuitable for clinical procedures [427]. Therefore, various attempts have been performed to transform the cements into biocomposites, e.g., by adding hydroxylcarboxylic acids, to control the setting time [428], gelatin to improve both the mechanical properties and the setting time [391, 429-431] or osteocalcin/collagen to increase the bioactivity [432]. More to the point, various reinforcement additives of different shapes and nature are

\footnotetext{
7 There is an opinion [425] that the self-setting calcium orthophosphate cements for orthopedic and dental restorative applications have first been described in the early 1970s by Driskell et al. [426] in US Patent No. 3913229.
} 
widely used to improve the mechanical properties of calcium orthophosphate cements [427]. Even carbon nanotubes were used for this purpose [433]! Although the biomaterials community does not use this term, a substantial amount of the reinforced cement formulations might be defined as calcium orthophosphate-based concretes. ${ }^{8}$ The idea behind the concretes is simple: if a strong filler is present in the matrix, it might stop crack propagation.

Various apatite-containing biocomposite formulations based on PMMA [435-445] and PEMA [94, 446, 447] have been already developed. Such biocomposites might be prepared by dispersion of apatite powder into a PMMA viscous fluid [448] and used for drug-delivery purposes [449]. When the mechanical properties of the biocomposite concretes composed of PMMA matrix and HA particles of various sizes were tested, the tensile results showed that strength was independent on particle sizes. In addition, up to $40 \mathrm{wt} \% \mathrm{HA}$ could be added without impairing the mechanical properties [438, 439]. After immersion into Ringer's solution, the tensile strength was not altered, whereas the fatigue properties were significantly reduced. The biocompatibility of PMMA/HA biocomposites was tested in vivo and enhanced osteogenic properties of the implants compared with single-phase PMMA were observed [436, 440-443]. It was shown that not only the mechanical properties of PMMA were improved but the osteoblast response of PMMA was also enhanced with the addition of HA [440]. Thereby, by adding calcium orthophosphates, a non-biodegradable PMMA was made more bioactive and osteoconductive, yielding a well-processable biocomposite concrete. As a drawback, the PMMA/HA formulations possess a low flexural, compressive, and tensile strength.

A biocomposite made from HA granules and bis-phenol- $\alpha$-glycidylmethacrylate-based resin appeared to possess comparable mechanical and biological properties to typical PMMA cement, leading to potential uses for implant fixation [450]. In order to improve the mechanical properties of calcium orthophosphate cements and stabilize them at the implant site, various researchers have resorted to formulations that set in situ, primarily through crosslinking reactions of the polymeric matrix. For example, TTCP was reacted with polyacrylic acid (PAA), forming a crosslinked CDHA/calcium polyacrylate biocomposite [451]. In aqueous solutions, TTCP hydrolyzes to CDHA [23] and the

\footnotetext{
${ }^{8}$ According to Wikipedia, the free encyclopedia: "Concrete is a construction material that consists of a cement (commonly Portland cement), aggregates (generally gravel and sand) and water. It solidifies and hardens after mixing and placement due to a chemical process known as hydration. The water reacts with the cement, which bonds the other components together, eventually creating a stone-like material" [434].
}

liberated calcium cations react with PAA, forming the crosslinked network [451]. Reed et al. [452] synthesized a dicarboxy polyphosphazene that can be crosslinked by calcium cations and cement-based (TTCP + DCPD) CDHA/polyphosphazene biocomposites with a compressive strength $\sim 10 \mathrm{MPa}$ and of $\sim 65 \%$ porosity were prepared as a result. To mimic PMMA cements, PFF/ $\beta$-TCP biocomposites were prepared with the addition of vinyl monomer to crosslink PPF. As a result, quick setting and degradable biocomposite cements with a low-heat output and compressive strengths in the range of 1 to $12 \mathrm{MPa}$ were prepared by varying the molecular weight of PPF, as well as the contents of the monomer, $\beta$-TCP, initiator, and porogen $(\mathrm{NaCl})[453,454]$. An acrylic cement with Sr-containing HA as a filler [110] and an injectable polydimethylsiloxane/HA cement [455] have been prepared as well.

In order to improve the mechanical properties of calcium orthophosphate cements, numerous researchers blended various polymers with the cements. For example, gelatin might be added to calcium orthophosphate cement formulations, primarily to stabilize the paste in aqueous solution before it develops adequate rigidity and, secondly, to improve the compressive strength [391, 429, 456]. Adding rod-like fillers to the cement formulations also caused an improvement in the mechanical properties [456]. For example, PAA and PVA were successfully used to improve the mechanical properties of a TTCP + DCPD cement but, unfortunately, with an inevitable and unacceptable reduction of both workability and setting time $[457,458]$. Similar findings were reported in the presence of sodium alginate and sodium polyacrylate [459]. Other polymers, such as polyphosphazene, might be used as well [460-462]. Other examples of polymer/calcium orthophosphate cement formulations might be found elsewhere [463, 464].

Porous calcium orthophosphate scaffolds with interconnected macropores $(\sim 1 \mathrm{~mm})$, micropores $(\sim 5 \mu \mathrm{m})$, and of high porosity $(\sim 80 \%)$ were prepared by coating polyurethane foams with a TTCP + DCPA cement, followed by firing at $1200{ }^{\circ} \mathrm{C}$. In order to improve the mechanical properties of the scaffolds, the open micropores of the struts were then infiltrated by a PLGA solution to achieve an interpenetrating bioactive ceramic/biodegradable polymer composite structure. The PLGA-filled struts were further coated with a 58S bioactive glass/PLGA composite coating. The obtained complex porous biocomposites could be used as tissue engineering scaffolds for low-load-bearing applications [465]. A more complicated construction, in which the PLGA macroporous phase has been reinforced with a bioresorbable TTCP + DCPA cement, followed by surface coating of the entire construct by a non-stoichiomentic CDHA layer, has been designed as 
well [466]. The latter approach has culminated in a unique, three-phase biocomposite that is simple to fabricate, osteoconductive, and completely biodegradable.

A porosity level of 42 to $80 \%$ was introduced into calcium orthophosphate cement/chitosan biocomposites by the addition of the water-soluble mannitol [467]. Chitosan significantly improved the mechanical strength of the entire biocomposite [468]. A similar approach was used by other researchers who studied the effect of the addition of PLGA microparticles [469-472] (which can also be loaded with drugs or growth factors [473-475]) to calcium orthophosphate cements. These biocomposites were implanted into cranial defects of rats and a content of $\sim 30 \mathrm{wt} \%$ of the microparticles was found to give the best results [469], while the addition of a growth factor to the biocomposites significantly increased bone contact at 2 weeks and enhanced new bone formation at 8 weeks [475]. The in vivo rabbit femur implant tests showed that PLGA/calcium orthophosphate cement formulations exhibited outstanding biocompatibility and bioactivity, as well as a better osteoconduction and degradability than pure calcium orthophosphate cements [470]. Further details on calcium orthophosphate cement-based biocomposites and concretes might be found in Ref. [427, chapter "Reinforced calcium orthophosphate cements"].

Nano-calcium orthophosphate-based biocomposites and nano-biocomposites

Nanophase materials are the materials that have grain sizes under $\sim 100 \mathrm{~nm}$. They have different mechanical and optical properties if compared with the large-grained materials of the same chemical composition. Namely, nanophase materials have the unique surface properties, such as an increased number of atoms, grain boundaries, and defects at the surface, huge surface area and altered electronic structure, if compared with the conventional micron-sized materials. For example, nano-HA (size $\sim 67 \mathrm{~nm}$ ) has a higher surface roughness of $17 \mathrm{~nm}$ if compared with $10 \mathrm{~nm}$ for the conventional submicron size HA $(\sim 180 \mathrm{~nm})$, while the contact angles (a quantitative measure of the wetting of a solid by a liquid) are significantly lower for nano-HA (6.1) if compared with the conventional HA (11.51). Additionally, the diameter of individual pores in a nano-HA compact is five times smaller (pore diameter $\sim 6.6 \AA$ ) than that in the conventional grain-sized HA compacts (pore diameter within 19.8-31.0 ̊) [476-478]. Besides, nano-HA promotes osteoblast cells adhesion, differentiation, and proliferation, osteointegration and deposition of calcium containing minerals on its surface better than microcrystalline HA; thus enhancing formation of a new bone tissue within a short period [476-478]. More to the point, nano-HA was found to cause apoptosis of the leukemia P388 cells [479].
Composites of two or more materials, in which at least one of the materials is of a nanometer-scale, are defined as nanocomposites [32]. Natural bone mineral is a hierarchical nanocomposite of biological origin, because it consists of nano-sized blade-like crystals of biological apatite grown in intimate contact with an organic matrix rich in collagen fibers and organized in a complicated hierarchical structure [21, 22, 38]. Given the fact that the major organic phase of bone is collagen, i.e., a natural polymer (Table 1), it is obvious that a composite of a nanophase calcium orthophosphate with a biodegradable polymer should be advantageous as bone substitution material. The inorganic nanophase would be responsible for the mechanical strength (hardness) and bioactivity, while the polymer phase would provide the elasticity. In addition, the solubility of calcium orthophosphates depends on their crystallite size (smaller crystals have a higher solubility) and on their carbonate content (higher carbonate content increases the solubility) [480]. To the author's best knowledge, among calcium orthophosphates listed in Table 3, before very recently only apatites (CDHA, HA and, perhaps, FA) have been available in the nanocrystalline state. However, very recently, nanoDCPA [481-483] and nano-MCPM [484] have been synthesized and applied to prepare nano-biocomposites with strong ionic release to combat tooth caries.

A number of investigations have been conducted recently to determine the mineralization, biocompatibility, and mechanical properties of the nano-biocomposites based on various (bio)polymers and nano-HA. ${ }^{9}$ These studies covered nano-HA/PLA [268, 485-492] and its copolymer with PGA [493-495], nano-HA/collagen [496-508], nano-HA/collagen/PLA [508-516], nano-HA/collagen/PVA [517], nanoHA/collagen/alginate [518, 519], nano-HA/gelatin [520525], nano-HA/poly(hexamethylene adipamide) [526], nano-HA/PPF [527], nano-HA/polyamide [528-539], nanoHA/PVA [276, 277, 540-542], nano-HA/PVAP [280], nano-HA/poly(ethylene-co-acrylic) acid [543, 544], nanoHA/chitosan [545-548], nano-HA/konjac glucomannan/ chitosan [549], nano-HA/PHEMA/PCL [550], nano-HA/ PCL [322, 359, 551, 552], nano-HA/Ti [553, 554], PCL semi-interpenetrating nanocomposites [555], and many other biocompatible hybrid formulations [223, 257, 271, 347, 556-574]. Several nano-biocomposites were found to be applicable as carriers for growth factors delivery [34, 575, 576]. Besides, the data are available on the excellent biocompartibility of such nano-biocomposites [507]. The dispersion state of nanoparticles appears to be the critical parameter in controlling the mechanical properties of

\footnotetext{
${ }^{9}$ Unfortunately, in the majority of the already published papers it often remained unclear whether "nano-HA" represented the stoichiometric nano-HA or a non-stoichiometric nano-CDHA.
} 
nano-biocomposites, as nanoparticles always tend to aggregate owing to their high surface energy [347].

Porous (porosity $\sim 85 \%$ ) biocomposites of nano-HA with collagen and PLA have been prepared by precipitation and freeze-drying; the nano-biocomposites did not show a pH drop upon in vitro degradation [509-511]. They were implanted in the radius of rabbits and showed a high biocompatibility and partial resorption after 12 weeks. NanoHA/chitosan biocomposites with improved mechanical stability were prepared from HA/chitosan nanorods [577]. Nano-HA/PLLA biocomposites of high porosity ( $~ 90 \%)$ were prepared using thermally induced phase separation [578]. Besides, nano-HA was used to prepare biocomposites with PAA and the nanostructure of the resulting nanocrystals exhibited a core-shell configuration [579, 580].

Nano-HA crystals appeared to be suitable for intraosseous implantation and offered a potential to formulate enhanced biocomposites for clinical applications [581]. Thus, the biocompatibility of chitosan in osteoblast cell culture was significantly improved by addition of nano-HA [582]. Similar finding is valid for nano-HA/polyamide biocomposites [531]. Further details on nano-HA-based biocomposites might be found in an excellent review [32]. More to the point, a more general review on nanobiomaterial applications in orthopedics is also available [583], where the interested readers are referred.

\section{Biocomposites with collagen}

The main constituent of the bioorganic matrix of bones is type I collagen ${ }^{10}$ (Table 1) with molecules about $300 \mathrm{~nm}$ in length. This protein is conducive to crystal formation in the associated inorganic matrix. It is easily degraded and resorbed by the body and allows good attachment to cells. Collagen alone is not effective as an osteoinductive material, but it becomes osteoconductive in combination with calcium orthophosphates [585]. Both collagen type I and HA were found to enhance osteoblast differentiation [586] but combined together, they were shown to accelerate osteogenesis. However, this tendency is not so straightforward: the data are available that implanted HA/ collagen biocomposites enhanced regeneration of calvaria bone defects in young rats but postponed the regeneration of calvaria bone in aged rats [587]. Finally, the addition of calcium orthophosphates to collagen sheets was found to give a higher stability and an increased resistance to $3 \mathrm{D}$ swelling compared with the collagen reference [588]. Therefore, a bone-analogue based on these two constituents

\footnotetext{
10 The structural and biochemical properties of collagens have been widely investigated and over 25 collagen subtypes have been identified [584].
}

should possess the remarkable properties. Furthermore, the addition of bone marrow constituents gives osteogenic and osteoinductive properties to calcium orthophosphate/collagen biocomposites [1].

The unique characteristics of bones are the spatial orientation between the calcium orthophosphate nanophase and collagen macromolecules at the nanolevel [35], where nanocrystals (about 50-nm-length) of biological apatite are aligned parallel to the collagen fibrils [21, 22, 31, 38], which is believed to be the source of the mechanical strength of bones. The collagen molecules and the nanocrystals of biological apatite assembled into mineralized fibrils are approximately 6-nm-diameter and 300-nm-long $[31,35,38,510,589]$. Although the complete mechanisms involved in the bone building strategy are still unclear, the strengthening effect of apatite nanocrystals in calcified tissues might be explained by the fact that the collagen matrix is a load transfer medium and thus transfers the load to the intrinsically rigid inorganic nanocrystals. Furthermore, nanocrystals of biological apatite located in between tangled fibrils crosslink the fibers either through a mechanical interlocking or by forming calcium ion bridges, thus increasing deformation resistance of the collagenous fiber network [590].

When calcium orthophosphates are combined with collagen in a laboratory, the biocomposites appear to be substantially different from natural bone tissue due to a lack of real interaction between the two components, i.e., interactions that are able to modify the intrinsic characteristics of the singular components themselves. The main characteristics of the route, by which the mineralized hard tissues are formed in vivo, are that the organic matrix is laid down first and the inorganic reinforcing phase grows within this organic matrix [21, 22, 31, 38]. Although to date, neither the elegance of the biomineral assembly mechanisms nor the intricate composite nano-architectures have been duplicated by non-biological methods, the best way to mimic bone is to copy the way it is formed, namely by nucleation and growth of CDHA nanocrystals from a supersaturated solution both onto and within the collagen fibrils [591-593]. Such syntheses were denoted as "biologically inspired" which means they reproduce an ordered pattern and an environment very similar to natural ones [594-596]. The biologically inspired biocomposites of collagen and calcium orthophosphates (mainly, apatites) for bone substitute have a long history [29, 364, 499, 597615] and started from the pioneering study by Mittelmeier and Nizard [616], who mixed calcium orthophosphate granules with a collagen web. Such combinations were found to be bioactive, osteoconductive, osteoinductive [29, 585, 617-619] and, in general, artificial grafts manufactured from this type of the biocomposites are likely to behave similarly to bones and be of more use in surgery 
than those prepared from any other materials. Indeed, some data are available on the superiority of calcium orthophosphate/collagen biocomposite scaffolds over the artificial polymeric and calcium orthophosphate bioceramic scaffolds individually [620].

It has been found that calcium orthophosphates may be successfully precipitated onto a collagen substrate of whatever form or source $[29,36,499,621,622]$. However, adherence of calcium orthophosphate crystals to collagen did depend on how much the collagen had been denatured: the more fibrillar the collagen, the greater attachment. Clarke et al. [602] first reported the production of a biocomposite produced by precipitation of DCPD onto a collagen matrix with the aid of phosphorylated amino acids commonly associated with fracture sites. Apatite cements (DCPD + TTCP) have been mixed with a collagen suspension, hydrated, and allowed to set. CDHA crystals were found to nucleate on the collagen fibril network, giving a material with the mechanical properties weaker than those reported for bone. More to the point, these biocomposites were without the nanostructure similar to that of bone [599, 623]. The oriented growth of OCP crystals on collagen was achieved by an experimental device in which $\mathrm{Ca}^{2+}$ and $\mathrm{PO}_{4}{ }^{3-}$ ions diffused into a collagen disk from the opposite directions [622, 624, 625]. Unfortunately, these experiments were designed to simulate the mechanism of in vivo precipitation of biological apatite only; due to this reason, the mechanical properties of the biocomposites were not tested [626].

Conventionally, collagen/calcium orthophosphate biocomposites can be prepared by blending or mixing of collagen and calcium orthophosphates, as well as by biomimetic methods $[29,32,34,37,496,499,510,576,589$, 594-596, 599, 621, 627-633]. Besides, collagen might be incorporated into calcium orthophosphate cements [599, $623,634]$. Typically, the type I collagen sponge is presoaked in $\mathrm{PO}_{4}{ }^{3-}$-containing a highly basic aqueous solution and then is immersed into a $\mathrm{Ca}^{2+}$-containing solution to allow mineral deposition. Also, collagen I fibers might be dissolved in acetic acid and then this solution is added to phosphoric acid, followed by the neutralization synthesis (performed at $25{ }^{\circ} \mathrm{C}$ and solution $\mathrm{pH}$ within 9-10) between an aqueous suspension of $\mathrm{Ca}(\mathrm{OH})_{2}$ and the $\mathrm{H}_{3} \mathrm{PO}_{4} /$ collagen solution [594, 595]. In order to ensure the quality of the final product, it is necessary to control the $\mathrm{Ca} / \mathrm{P}$ ionic ratio in the reaction solution. One way to do this is to dissolve a commercial calcium orthophosphate in an acid; another is to add $\mathrm{Ca}^{2+}$ and $\mathrm{PO}_{4}{ }^{3-}$ ions in a certain ratio to the solution and after that induce the reaction [35]. Biomimetically, one can achieve an oriented growth of CDHA crystals onto dissolved collagen fibrils in aqueous solutions via a selforganization mechanism [628]. A number of authors produced calcium orthophosphate/collagen biocomposites by mixing preformed ceramic particles with a collagen suspension [635-637]. However, in all blended composites, the crystallite sizes of calcium orthophosphates were not uniform and the crystals were often aggregated and randomly distributed within a fibrous matrix of collagen. Therefore, no structural similarity to natural bone was obtained, and only a compositional similarity to that of natural bone was achieved. Crystallization of CDHA in aqueous solutions might be performed in the presence of a previously dispersed collagen $[29,499]$. More to the point, collagen might be first dispersed in an acidic solution, followed by addition of calcium and orthophosphate ions and then coprecipitation of collagen and CDHA might be induced by either increasing the solution $\mathrm{pH}$ or adding mixing agents [37]. Although it resulted in biocomposites with poor mechanical properties, pressing of the HA/collagen mixtures at $40{ }^{\circ} \mathrm{C}$ under $200 \mathrm{MPa}$ for several days is also known [638]. Attempts have been performed for a computer simulation of apatite/collagen composite formation process [639]. It is interesting to note, that collagen/ HA biocomposites were found to possess some piezoelectric properties [640].

As the majority of the collagen/HA, biocomposites are conventionally processed by anchoring micro-HA particles into collagen matrix, it makes quite difficult to obtain a uniform and homogeneous composite graft. Besides, such biocomposites have inadequate mechanical properties; over and above, the proper pore sizes have not been achieved either. Further, microcrystalline HA, which is in contrast to nanocrystalline natural bone apatite, might take a longer time to be remodeled into a new bone tissue upon the implantation. In addition, some of the biocomposites exhibited very poor mechanical properties, probably due to a lack of strong interfacial bonding between the constituents. The aforementioned data clearly demonstrate that the chemical composition similar to bone is insufficient for manufacturing the proper bone grafts; both the mechanical properties and mimetic of the bone nanostructure are necessary to function as bone in recipient sites. There is a chance for improving osteointegration by reducing the grain size of HA crystals by activating ultrafine apatite growth into the matrix. This may lead to enhance the mechanical properties and osteointegration with improved biological and biochemical affinity to the host bone. Besides, the unidirectional porosity was found to have a positive influence on the ingrowth of the surrounding tissues into the pores of collagen/HA biocomposites [641].

Bovine collagen might be mixed with HA and such biocomposites are marketed commercially as bone-graft substitutes those further can be combined with bone marrow aspirated from the iliac crest of the site of the fracture. Application of these materials was compared with autografts for the management of acute fractures of long bones 
with defects, which had been stabilized by internal or external fixation [642, 643]. These biocomposites are osteogenic, osteoinductive, and osteoconductive; however, they lack the structural strength and require harvest of the patient's bone marrow. Although no transmission of diseases has been recorded yet, the use of bovine collagen might be a source of concern [2].

Collagen sponges with an open porosity $(30-100 \mu \mathrm{m})$ were prepared by a freeze-drying technique and then their surface was coated by a $10-\mu \mathrm{m}$ layer of biomimetic apatite precipitated from simulated body fluid [644]. The researchers found a good in vitro performance with fibroblast cell culture. Collagen/HA microspheres or gel beads have been prepared in the intention of making injectable bone fillers [645, 646]. Liao et al. [647] succeeded in mimicking the bone structure by blending carbonateapatite with collagen. A similar material (mineralized collagen) was implanted into femur of rats and excellent clinical results were observed after 12 weeks [648]. Collagen/HA biocomposites were prepared and their mechanical performance was increased by crosslinking the collagen fibers with glutaraldehyde [500, 502, 503]. These biocomposites were tested in rabbits and showed a good biological performance, osteoconductivity, and biodegradation. A similar approach was selected to prepare HA/collagen microspheres (diameter $\sim 5 \mu \mathrm{m}$ ) by a water-oil emulsion technique in which the surface was also crosslinked by glutaraldehyde [646]. That material showed a good in vitro performance with osteoblast cell culture. A porous bonegraft substitute was formed from a nano-HA/collagen biocomposite combined with PLA by a freeze-drying method; the resulting material was found to mimic natural bone at several hierarchical levels [510]. Subsequent in vitro experiments confirmed a good adhesion, proliferation, and migration of osteoblasts into this composite [509]. A further increase in biocompatibility might be achieved by the addition of silicon; thus, to enhance bone substitution, Si-substituted HA/collagen composites have been developed with silicon located preferentially in the collagen phase [501]. Porous (porosity level $\sim 95 \%$ with interconnected pores of $50-100 \mu \mathrm{m}$ ) biocomposites of collagen (crosslinked with glutaraldehyde) and $\beta$-TCP have been prepared by a freeze-drying technique, followed by sublimation of the solvent; the biocomposites showed a good biocompatibility upon implantation in the rabbit jaw [649].

Biocomposites of calcium orthophosphates with collagen were found to be useful for drug-delivery purposes [519, 607, 650-652]. Namely, an HA/collagen-alginate $(20 \mu \mathrm{L})$ with the rh-BMP2 $(100 \mu \mathrm{g} / \mathrm{mL}, 15 \mu \mathrm{L})$ showed bone formation throughout the implant 5 weeks after implantation without obvious deformation of the material [519]. Gotterbarm et al. [651] developed a two-layered collagen/ $\beta$-TCP implant augmented with chondral inductive growth factors for the repair of osteochondral defects in the trochlear groove of minipigs. This approach might be a new promising option for the treatment of deep osteochondral defects in joint surgery.

To conclude this part, one should note that biocomposites of apatites with collagen are a very hot topic of the research and up to now, just a few papers are devoted to biocomposites of other calcium orthophosphates with collagen [651, 653]. These biomaterials mimic natural bones to some extent, while their subsequent biological evaluation suggests that they are readily incorporated into the bone metabolism in a way similar to bone remodeling, instead of acting as permanent implant [510, 616]. Collagraft $^{\circledR}$, Bio-Oss ${ }^{\circledR}$, and Healos ${ }^{\circledR}$ are the several examples of the commercially available calcium orthophosphate/collagen bone grafts for clinical use [32]. However, the performance of these biocomposites depends on the source of collagen from which it was processed. Several attempts have been made to simulate the collagen-HA interfacial behavior in real bone by means of crosslinking agents such as glutaraldehyde [500, 502, 503, 621, 646, 649] with the purpose to improve the mechanical properties of these biocomposites. Unfortunately, a further progress in this direction is restricted by a high cost, difficulty to control cross-infection, a poor definition of commercial sources of collagens, as well as by a lack of an appropriate technology to fabricate bone-resembling microstructures. Further details on calcium orthophosphate/collagen composites, including the list of the commercially available products, might be found elsewhere [32, 611].

Biocomposites with other bioorganic compounds and biological macromolecules

Besides collagen, both human and mammalian bodies contain dozens types of various bioorganic compounds, proteins, and biological macromolecules. The substantial amounts of them potentially might be used to prepare biocomposites with calcium orthophosphates. For example, a biologically strong adhesion (to prevent invasion of bacteria) between teeth and the surrounding epithelial tissues is attributed to a cell-adhesive protein, laminin [654]. In order to mimic the nature, a laminin/apatite biocomposite layer was successfully created on the surface of both titanium [655] and EVOH [656, 657] using the biomimetic approach.

Calcium orthophosphate/gelatin biocomposites are widely investigated as potential bone replacement biomaterials [254, 272-274, 366-374, 385-392, 402, 429-431, 456, 520-525, 658-669]. For example, gelatin foams were successfully mechanically reinforced by $\mathrm{HA}$ and then crosslinked by a carbodiimide derivative [254]. Such foams were shown to be a good carrier for antibiotic tetracycline 
[662]. Several biocomposites of calcium orthophosphates with alginates ${ }^{11}$ have been prepared [389, 518, 519, 523, 595, 670]. For example, porous HA/alginate composites based on hydrogels were prepared both biomimetically [595] and by using a freeze-drying technique [670]. Another research group succeeded in preparation of biphasic but monolithic scaffolds using a similar preparation route [671]. Their biocompatibility in cell culture experiments and in vitro biodegradability were high; however, a mechanical strength could be better.

Various biocomposites of calcium orthophosphates with chitosan [239, 397, 412, 419, 435, 467, 545-549, 566, 567, 577, 582, 663, 669, 672-683] and chitin [183, 394, 513, 684-688] are also very popular. For example, a solutionbased method was developed to combine HA powders with chitin, in which the ceramic particles were uniformly dispersed [684, 685]. Unfortunately, it was difficult to obtain the uniform dispersions. The mechanical properties of the final biocomposites were not very good; due to a poor adhesion between the filler and the matrix both the tensile strength and modulus were found to decrease with the increase in the HA amount. Microscopic examination revealed that HA particles were intervened between the polymer chains, weakening their interactions, and decreasing the entire strength [684, 685].

Biocomposites of CDHA with water-soluble proteins, such as bovine serum albumin (BSA), might be prepared by a precipitation method [463, 689-692]. In such biocomposites, BSA is not strongly fixed to solid CDHA, which is useful for a sustained release. However, this is not the case if a water/oil/water interfacial reaction route has been used [250]. To extend this subject, inclusion of DNA into CDHA/BSA biocomposites was claimed [250, 693695]. Besides, bionanocomposites of an unspecified calcium orthophosphate with DNA were prepared as well [696].

Akashi and co-workers [697] developed a procedure to prepare calcium orthophosphate-based biocomposites by soaking hydrogels in supersaturated by $\mathrm{Ca}^{2+}$ and $\mathrm{PO}_{4}{ }^{3-}$ ions solutions in order to precipitate CDHA in the hydrogels (up to $70 \mathrm{wt} \%$ of CDHA could be added to these biocomposites). This procedure was applied to chitosan; the 3D shape of the resulting biocomposite was controlled by the shape of the starting chitosan hydrogel [698]. Another research group developed biocomposites based on in situ calcium orthophosphate mineralization of selfassembled supramolecular hydrogels [699].

Various biocomposites of CDHA with glutamic and aspartic amino acids, as well as poly-glutamic and

\footnotetext{
11 Alginates are a family of unbranched binary copolymers with a structure comprising 1-4 glycosidically linked $\beta$-D-mannuronic acid and its C-5 epimer $\alpha$-Lguluronic acid [595].
}

poly-aspartic amino acids have been prepared and investigated by Bigi et al. [279, 281, 700-703]. These (poly)amino acids were quantitatively incorporated into CDHA crystals, provoking a reduction of the coherent length of the crystalline domains and decreasing the crystal sizes. The relative amounts of the (poly)amino acid content in the solid phase, determined through HPLC analysis, increased with their concentration in solution up to a maximum of about $7.8 \mathrm{wt} \%$ for CDHA/aspartic acid and $4.3 \mathrm{wt} \%$ for CDHA/glutamic acid biocomposites. The small crystal dimensions, which implied a great surface area, and the presence of (poly)amino acids were suggested to be relevant for possible application of these biocomposites for hard tissues replacement [279, 281, 700-703].

Recently, $\mathrm{BCP}(\mathrm{HA}+\beta$-TCP)/agarose macroporous scaffolds with controlled and complete interconnection, high porosity, thoroughly open pores, and tailored pore size were prepared for tissue engineering application [704, 705]. Agarose, a biodegradable polymer, was selected as the organic matrix, because it was a biocompatible hydrogel, which acted as gelling agent leading to strong gels and fast room temperature polymerization. Porous scaffolds with the designed architecture were manufactured by combining a low-temperature shaping method with stereo-lithography and two drying techniques. The biocompatibility of this BCP/agarose system was tested with mouse L929 fibroblast and human Saos-2 osteoblast during different colonization times [704].

Fibrin sealants are non-cytotoxic, fully resorbable, biological matrices that simulate the last stages of a natural coagulation cascade, forming a structured fibrin clot similar to a physiological clot [706]. Biocomposites of calcium orthophosphates with fibrin sealants might develop the clinical applications of bone substitutes. The 3D mesh of fibrin sealant interpenetrates the macro- and micro-porous structure of calcium orthophosphate ceramics [9]. The physical, chemical, and biological properties of calcium orthophosphate bioceramics and the fibrin glue might be cumulated in biocomposites, suitable for preparation of advanced bone grafts [707-718].

Furthermore, there are biocomposites of calcium orthophosphates with bisphosphonates [719], silk fibroin (that is a hard protein extracted from silk cocoon) [249, 562-564, 569, 570, 720-725], chitosan + silk fibroin [726], fibronectin [727], and casein phosphopeptides [728]. Besides, the reader's attention is pointed out to an interesting approach to crystallize CDHA inside poly(allylamine)/poly(styrene sulfonate) polyelectrolyte capsules resulting in empty biocomposite spheres of micron size [729]. Depending on the amount of precipitated CDHA, the thickness of the shell of biocomposite spheres can be varied between 25 and $150 \mathrm{~nm}$. These biocomposite 
capsules might find application as medical agents for bone repairing and catalytic microreactors [729].

Injectable bone substitutes

IBS represent ready-to-use suspensions of calcium orthophosphate powder(s) in a liquid carrier phase. They look like viscous pastes with the rheological properties, sufficient to inject them into bone defects by means of surgical syringes and needles. Usually, the necessary level of viscosity is created by the addition of water-soluble polymers $[104,730,731]$. Therefore the majority of calcium orthophosphate-based IBS formulations might be considered as a subgroup of calcium orthophosphate/polymer biocomposites. For example, an IBS was described that involved a silanized hydroxyethylcellulose carrier with $\mathrm{BCP}$, consisting of HA and $\beta$-TCP [732]. The suspension is liquid at $\mathrm{pH}$ within $10-12$, but gels quickly at $\mathrm{pH}<9$. Injectable composites can be formed with $\beta$-TCP to improve mechanical integrity [453]. Similarly, Bennett et al. [733] showed that a polydioxanone-co-glycolide-based biocomposite reinforced with HA or $\beta$-TCP can be used as an injectable or moldable putty. During the crosslinking reaction following injection, carbon dioxide is released allowing the formation of interconnected pores.

Daculsi et al. [84, 731, 734-740] developed viscous IBS biocomposites based on BCP $(60 \% \mathrm{HA}+40 \% \beta$-TCP) and $2 \%$ aqueous solution of hydroxypropylmethylcellulose (HPMC) that was said to be perfectly biocompatible, resorbable, and easily fitted bone defects (due to an initial plasticity). The best ratio BCP/HPMC aqueous solution was found to be at $\sim 65 / 35 \mathrm{w} / \mathrm{w}$. To extend this subject further, this type of IBS might be loaded by cells [741] or by microparticles [742].

The advanced characteristics of IBS come from their good mechanical properties and biocompatibility and the ease of tissue regeneration. Although the fabrication of IBS biocomposites in most cases improved the mechanical properties of the system and provided the material with resistance to fluids penetration, these achievements were limited by the amount of polymer that can be added to the paste. For instance, Mickiewicz et al. [463] reported that after a critical concentration (that depended on the type and molecular weight of the polymer, but was always around $10 \%$ ), the polymer started forming a thick coating on the crystal clusters, preventing them from interlocking, originating plastic flow and, as a consequence, decreasing mechanical properties. More to the point, Fujishiro et al. [456] reported a decrease in mechanical properties with higher amounts of gel, which was attributed to the formation of pores due to leaching of gelatin in solution. Therefore, it seems that mechanical properties, although improved by the addition of polymers, are still a limitation for the application of calcium orthophosphate-based IBS formulations in load-bearing sites [146].

Biocomposites with glasses, inorganic materials, and metals

In order to overcome the problem of poor mechanical properties of calcium orthophosphate bioceramics, suitable biocomposites of calcium orthophosphates reinforced by various inorganic materials, glasses, and metals have been developed. Such biocomposites are mainly prepared by the common ceramic processing techniques such as thermal treatment after kneading [743-745], powder slurry coating [746], and metal-sol mixing [747]. For example, HA was combined with Bioglass ${ }^{\circledR}$ (Novabone Products, Alachua, FL) $[748,749]$ and with other glasses [750] to form glassceramics biocomposites. Other reinforcement materials for calcium orthophosphates are differentiated by either shape of the fillers, namely, particles [751, 752], platelets [753, 754], whiskers [484, 755, 756], fibers [757-759], or their chemical composition: zirconia and/or PSZ [250, 743-746, $755,760-793]$, alumina [250, 751, 754, 793-802], titania [307, 747, 752, 803-817], other oxides [818-821], silica and/or glasses [822-829], wollastonite [171, 830-837], various metals and alloys [759, 794, 817, 838-851], calcium sulfate [852-854], silicon carbide [756], barium titanate [855], zeolite [856], and several other materials [271, 857-859]. All these materials have been added to calcium orthophosphate bioceramics to improve its reliability. Unfortunately, significant amounts of the reinforcing phases are needed to achieve the desired properties and, as these materials are either bioinert, significantly less bioactive than calcium orthophosphates or not bioresorbable, the ability of the biocomposites to form a stable interface with bone is poorer if compared with calcium orthophosphate bioceramics alone. Due to the presence of bioinert compounds, such formulations might be called bioinert/bioactive composites [822]. The ideal reinforcement material would impart mechanical integrity to a biocomposite at low loadings, without diminishing its bioactivity. As clearly seen from the amount of the references, apatite/zirconia biocomposites are most popular ones among the researchers.

There are several types of HA/glass biocomposites. The first one is also called bioactive glass-ceramics. A dense and homogeneous biocomposite was obtained after a heat treatment of the parent glass, which comprised $\sim 38 \mathrm{wt} \%$ oxy-FAP $\left(\mathrm{Ca}_{10}\left(\mathrm{PO}_{4}\right)_{6}(\mathrm{O}, \mathrm{F})_{2}\right)$ and $\sim 34 \mathrm{wt} \% \beta$-wollastonite $\left(\mathrm{CaO} \cdot \mathrm{SiO}_{2}\right)$ crystals, $50-100 \mathrm{~nm}$ in size in a $\mathrm{MgO}-\mathrm{CaO}-$ $\mathrm{SiO}_{2}$ glassy matrix [171, 830-837]. A-W glass-ceramics is an assembly of small apatite particles effectively reinforced by wollastonite. The bending strength, fracture toughness, and Young's modulus of A-W glass-ceramics are the 
highest among bioactive glass and glass ceramics, enabling it to be used in some major compression load-bearing applications, such as vertebral prostheses and iliac crest replacement. It combines a high bioactivity with the suitable mechanical properties [860]. $\beta$-TCP/wollastonite biocomposites are also known [861-863]. More complicated biocomposites have been developed as well. For example, (A-W)/HDPE composite (AWPEX) biomaterials have been designed to match the mechanical strength of human cortical bone and to provide favorable bioactivity, with potential use in many orthopedic applications [864867]. Other examples comprise wollastonite-reinforced HA/Ca polycarboxylate [868] and glass-reinforced HAP/ polyacrylate [869] biocomposites.

HA/glass biocomposites can be prepared by simple sintering of appropriate HA/glass powder mixtures [870873]. If sintering is carried out below $1000{ }^{\circ} \mathrm{C}, \mathrm{HA}$ does not react with the bioactive glass $[871,872]$ or this reaction is limited [873]. Besides, reaction between HA and glasses depends on the glass composition. In another approach, small quantities of bioactive glass have been added to HA bioceramics in order to improve densification and/or mechanical properties [26]. In addition, biocomposites might be sintered from HA and silica [822]. In general, bioactive glass-ceramics maintain a high strength for a longer time than HA bioceramics under both the in vitro and in vivo conditions [829, 834].

Carbon nanotubes with their small dimensions, a highaspect-ratio (length-to-diameter) as well as the exceptional mechanical properties, including extreme flexibility and strength, significant resistance to bending, high resilience and the ability to reverse any buckling of the tube, have the excellent potential to accomplish necessary mechanical properties [874]. Recent studies have even suggested that they may possess some bioactivity [875-878]. However, due to a huge difference in shapes, it is a challenge to prepare homogeneous mixtures of calcium orthophosphates and carbon nanotubes: "one can imagine something similar to achieving a homogeneous mixture of peas and spaghetti" [874, p. 7]. Additionally, non-functionalized carbon nanotubes tend to agglomerate and form bundles; besides, they are soluble in neither water nor organic solvents. Chemical functionalization allows carbon nanotubes to be dispersed more easily, which can improve interfacial bonding with calcium orthophosphates [247, 874].

Different strategies might be employed to prepare calcium orthophosphate/carbon nanotubes biocomposites. For example, apatites might be chemically synthesized using carboxyl-functionalized carbon nanotubes as a matrix [242-247]. Physico-chemical characterization of these biocomposites showed that nucleation of CDHA initiates through the carboxyl group [247]. Hot-pressing [879], plasma spraying [880], and laser surface alloying [881-883] techniques might be applied as well. The research on calcium orthophosphate (up to now, only apatites)/carbon nanotube biocomposites is in its early stages, with the first papers published in 2004 [246, 433]. Due to this reason, the mechanical property data for such biocomposites have been reported only in few papers; however, these results are encouraging. For example, Chen et al. [883] performed nanoindentation tests on biocomposite coatings to give hardness and Young's modulus values. They found that the higher the loading of nanotubes, the better the properties. Namely, at $20 \mathrm{wt} \%$ loading, hardness was increased by $43 \%$ and Young's modulus by $21 \%$ over a single-phase HA coating [883]. Scratching test results indicated that as alloyed HA biocomposite coatings exhibited improved wear resistance and lower friction coefficient with increasing the amount of carbon nanotubes in the precursor material powders [882]. Additionally, measurements of the elastic modulus and hardness of the biocomposite coatings indicated that the mechanical properties were also affected by the amount of carbon nanotubes [881]. Another research group performed compression tests on bulk HA/nanotubes biocomposites and found an increase in strength over single-phase HA [246]. However, the highest compressive strength they achieved for any material was only $102 \mathrm{MPa}$, which is similar to that of cortical bone but much lower than the typical values for dense HA [874]. More complex formulations, such as poly-L-lysine/HA/carbon nanotube hybrid nanocomposites, have also been developed [884]. Unfortunately, carbon nanotubes are very stable substances; they are neither bioresorbable nor biodegradable. Therefore, during the in vivo bioresorption, the nanotubes will get into the human body from the biocomposite matrix and might cause uncertain health problems. Except of carbon nanotubes, carbon fibers of microscopic dimensions are also used to reinforce HA bioceramics [885-887].

The main disadvantage of HA reinforced by PSZ is degradation of zirconia in wet environments [755, 760, 761, 783]. Transformation of the tetragonal $\mathrm{ZrO}_{2}$ to the monoclinic phase on the surface results in formation of microcracks and consequently lowers the strength of the implant [888, 889].

An HA-based biocomposite reinforced with 20 vol.\% of Ti particles was fabricated by hot-pressing [840]. Besides, calcium orthophosphates/Ti biocomposites might be prepared by powder metallurgy processing [842-844]. At high temperatures, the presence of Ti metal phase was found to promote dehydration and decomposition of HA into $\beta$-TCP and TTCP $[840,842]$ or partial formation of $\beta$-TCP and calcium titanate instead of HA [554, 843, 844]. Comparing with pure HA bioceramics manufactured under the same conditions, the HA/Ti biocomposites possessed a higher fracture toughness, bending strength, work of fracture, porosity, and lower elastic modulus, which is more suitable 
for biomedical applications. However, the mechanical properties appeared to be not high enough to use HA/Ti biocomposites in load-bearing applications. Luckily, the histological evaluations revealed that HA/Ti biocomposites could be partially integrated with newborn bone tissues after 3 weeks and fully osteointegrated at 12 weeks in vivo [840]. Similar findings had been earlier made for HA bioceramics reinforced by addition of silver particulates (5-30 vol.\%) and subsequent sintering of the HA/Ag powder compacts $[838,839]$. Other studies on calcium orthophosphate/Ti biocomposites are available elsewhere [845-848].

To conclude this part, biocomposites consisting of calcium orthophosphates only should be briefly described. First of all, BCP itself, consisting of HA and $\alpha$ - or $\beta$-TCP, should be mentioned [23]. In the 1980s, BCP was called as "TCP ceramics complexed with HA" [890]. More to the point, 70\% HA-powder + 30\% HA-whisker biocomposites have been fabricated by pressureless sintering, hot-pressing, and hot-isostatic pressing. These biocomposites were found to exhibit an improved toughness, attaining the lower fracture-toughness limit of bone without a decrease of bioactivity and biocompatibility [891, 892]. Besides, a dual HA biocomposite that combined two HA materials with different porosities: HA with $75 \%$ porosity, for bone ingrowth and HA with $0 \%$ porosity, for load-bearing was manufactured. This dual HA biocomposite appeared to be suitable for use as an implant material for spinal interbody fusion as a substitute for iliac bone grafts, which could eliminate the disadvantages associated with autograft harvesting [893]. A biodegradable nanocomposite porous scaffold comprising a $\beta$-TCP matrix and HA nanofibres was developed and studied for load-bearing bone tissue engineering. HA nanofibres were prepared by a biomimetic precipitation method, the inclusion of which significantly enhanced the mechanical property of the scaffold, attaining a compressive strength of $9.87 \mathrm{MPa}$, comparable to the high-end value (2-10 MPa) of cancellous bone [894].

\section{Functionally graded biocomposites}

Although, in most cases, the homogeneous distribution of filler(s) inside a matrix is required [355], there are composites, where this is not the case. For example, functionally graded materials (commonly referred to as FGM) might be characterized by the intentional variations in composition and/or structure gradually over volume, resulting in corresponding changes in the properties of the composite. The main feature of such materials is the almost continuously graded composition that results in two different properties at the two ends of the structure. Such composites can be designed for specific function and applications. Various approaches based on the bulk (particulate processing), preform processing, layer processing, and melt processing are used to fabricate the functionally graded materials.

Bone is a biologically formed composite with variable density ranging from very dense and stiff (the cortical bone) to a soft and foamed structure (the trabecular bone). Normally the outer part of long bones consists of cortical bone with the density decreasing toward the core, where the trabecular bone is found. The trabecular bone is porous and the porosity is filled with osseous medulla [21, 22]. This brief description clearly indicates that bones are natural functionally graded composites.

The concept of FGM has been increasingly used for biomaterial design and currently it remains to be an important area of the research. For example, powder metallurgy methods have been used to fabricate HA/Ti functionally graded biocomposite dental implants offering the biocompatible HA on the tissue side and titanium on the outer side for mechanical strength [895-897]. The graded structure in the longitudinal direction contains more $\mathrm{Ti}$ in the upper section and more HA in the lower section. Actually, in the upper section the occlusal force is directly applied and Ti offers the required mechanical performance; in the lower part, which is implanted inside the bone, the HA confers the bioactive and osteoconductive properties to the material [895]. Since the optimum conditions of sintering for Ti and HA are very different, HA/Ti functionally graded biocomposites are difficult to fabricate and the sintering conditions for their mixtures are obliged to compromise. The expected properties of this implant are shown in Fig. 3 [896]. Functionally graded HA/Ti biocomposite coatings might be prepared by rf-plasma spraying [898]. A functionally graded HA/PMMA biocomposite was developed based on sedimentary HA distributions in a PMMA viscous fluid, using a centrifuge to avoid stress convergence on the interface. The stressstrain curves of this biocomposite showed sufficient strength for medical application along with the relaxation of brittleness and fragility [448]. A three-layered graded biocomposite membrane, with one face of $8 \%$ nano-carbonated CDHA/collagen/PLGA porous membrane, the opposite face of pure PLGA non-porous membrane, the middle layer of $4 \%$ nano-carbonated CDHA/collagen/ PLGA as the transition, was prepared through the layer-bylayer casting method [512]. HA/glass FGM layers were coated on titanium alloy (Ti-6Al-4V) substrates. The design of these layers and the use of the glass were for achieving a strong bonding between the FGM-layered coatings and the substrates [899, 900]. More to the point, Ti alloy substrate has been combined with HA granules spread over the surface [901].

Functionally graded $\beta$-TCP/FA biocomposites combine the biostability of FA with bioresorbable properties of 

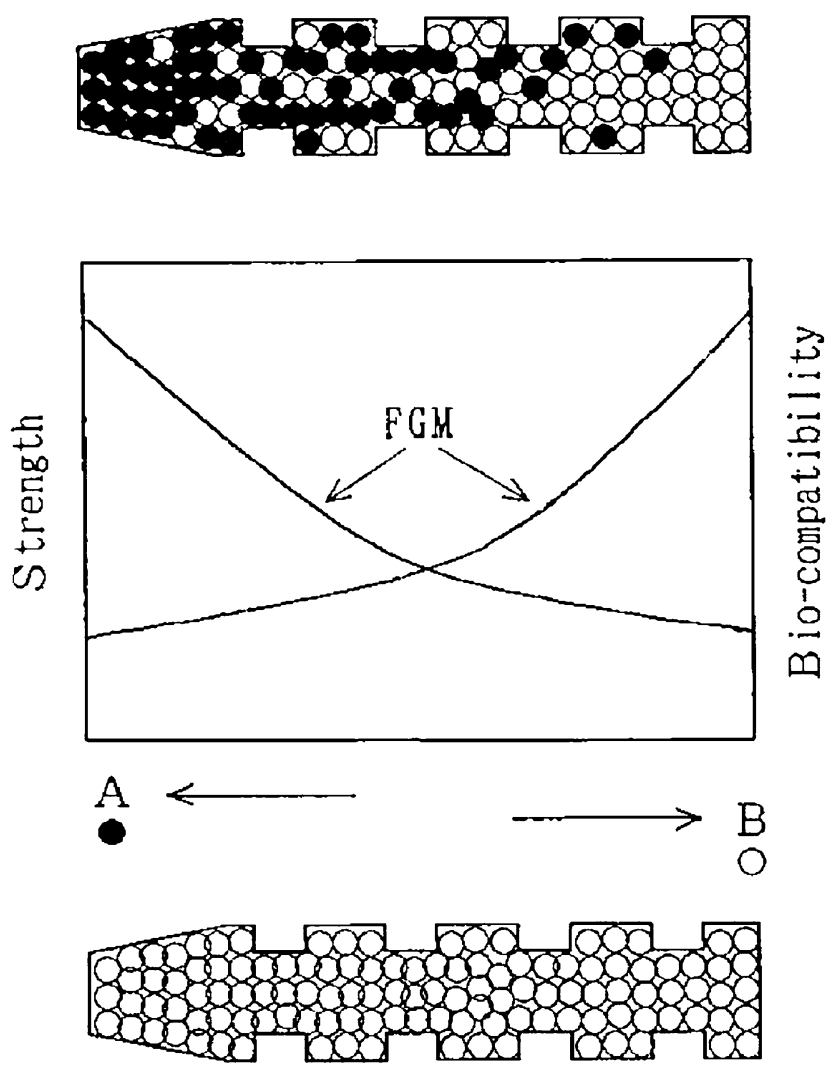

Fig. 3 Expected properties of functionally graded biocomposite dental implant. For comparison, the upper drawing shows a functionally graded implant and the lower one shows a conventional uniform implant. The properties are shown in the middle. The implant with the composition changed from a biocompatible metal (Ti) at one end (left in the figure), increasing the concentration of bioceramics (HA) toward $100 \% \mathrm{HA}$ at the other end (right in the figure), could control both mechanical properties and biocompatibility without an abrupt change due to the formation of discrete boundary. This FGM biocomposite was designed to provide more titanium for the upper part where occlusal force is directly applied and more HA for the lower part, which is implanted inside the jawbone. Reprinted from Ref. [896] with permission

$\beta$-TCP [902]. An interesting multilayered (each layer of 1 -mm-thick) structure consisting of $\beta$-TCP/FA biocomposites with different molar ratios has been prepared, giving rise to formation of an FGM (Fig. 4). After implantation, the preferential dissolution of $\beta$-TCP phase would result in functionally gradient porosity for bone ingrowth [903]. HA/zirconia-graded biocomposites were fabricated to enhance the mechanical properties of HA while retaining its bone bonding property [791]. $\mathrm{TiO}_{2}$ and HA were found to be a good combination for FGM providing both a gradient of bioactivity and a good mechanical strength [903]. Besides, graded $\mathrm{HA} / \mathrm{CaCO}_{3}$ biocomposite structures for bone ingrowth have been developed as well [904]. Functionally graded composite skull implants consisting of polylactides, carbonateapatite, and $\mathrm{CaCO}_{3}$ are

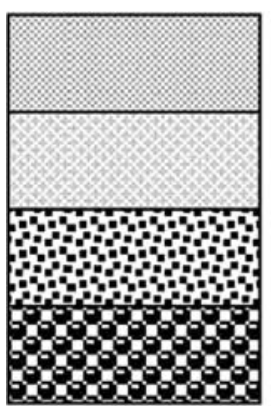

(a)

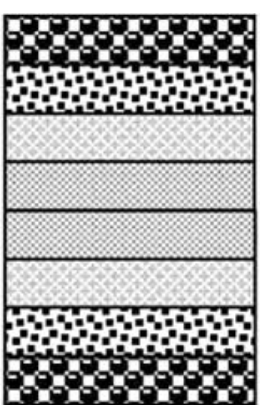

(b)
$\mathrm{BS} \mathrm{FA}+50 \mathrm{TCP}$

ESG FA + 40TCP

$\mathrm{FA}+30 \mathrm{TCP}$

$\mathrm{FA}+20 \mathrm{TCP}$
Fig. 4 A schematic diagram showing the arrangement of the FA/ $\beta$ TCP composite layers: a non-symmetric FGM, b symmetric FGM. Reprinted from Ref. [902] with permission

known as well $[318,319]$. The research in this field is quite promising but currently the mechanical properties of the available biocomposites are clearly in excess of the properties of bone [147].

\section{Biosensors}

A biosensor is a device for detection of an analyte that combines a biological component with a physicochemical detector component. Very briefly, it consists of three parts: a sensitive biological element; a transducer or a detector element that transforms the signal resulting from the interaction of the analyte with the biological element into another signal; and associated electronics that is primarily responsible for the display of the results in a user-friendly way [905].

The surface of biologically relevant calcium orthophosphates (CDHA, HA, $\alpha$-TCP, $\beta$-TCP) has an excellent ability of adsorption for functional biomolecules such as proteins, albumins, DNA, and so on. Therefore, some calcium orthophosphate-based biocomposites and hybrid biomaterials were found to be applicable for biosensor manufacturing [288, 542, 851, 884]. For example, formation of poly-L-lysine/HA/carbon nanotube hybrid nanoparticles was described, and a general design strategy for an immunosensing platform was proposed based on adsorption of antibodies onto this nanocomposite [884]. In another article, a hybrid material formed by assembling of gold nanoparticles onto nano-HA was employed for the interface design of piezoelectric immunosensor, on which the antibodies were bound. The developed sensing interface appeared to possess some advantages, such as activationfree immobilization and high antigen-binding activities of antibodies, over using either nano-HA or gold nanoparticles alone [851]. Until now, just a few papers have been published on biosensor application of calcium orthophosphatebased biocomposites. Presumably, this subject will be 
further developed in the future and, perhaps, sometime implantable biosensors will be designed to perform the continuous concentration monitoring of the important biological macromolecules. Possibly, those biocencors might be able to use an electric power, generated by DCPD/ polymer composite-based battery devices [413, 414].

\section{Interaction between the phases in calcium orthophosphate-based biocomposites}

An important aspect that should be addressed in details is a mutual interaction between calcium orthophosphates and other phases in biocomposites and hybrid biomaterials. In general, an interaction between the phases in any composite can be either mechanical, when it results from radial compression forces exerted by the matrix on the filler particles (e.g., developed during cooling due to thermal contraction), or chemical, when the reactivity of the filler toward the matrix has an important role. In the latter case, it is important to distinguish a physical interaction from chemical bonding [225]. According to Wypych [906], physical interaction is more or less temporary, implicating hydrogen bonding or van der Waals forces, whereas chemical bonding is stronger and more permanent, involving covalent bond formation. Thus, a chemical interfacial bond between the phases is preferred to achieve a higher strength of a composite. The magnitude of the interfacial bond between the phases determines how well a weak matrix transmits stress to the strong fibers. However, while a bond between the matrix and reinforcement must exist for the purpose of stress transfer, it should not be so strong that it prevents toughening mechanisms, such as debonding and fiber pullout [874].
There is still doubt as to the exact bonding mechanism between bone minerals (biological apatite) and collagen, which undoubtedly plays a critical role in determining the mechanical properties of bones. Namely, bone minerals are not directly bonded to collagen, but through non-collagenous proteins that make up $\sim 3 \%$ of bones (Table 1 ) and provide with active sites for biomineralization and for cellular attachment [32]. In bones, the interfacial bonding forces are mainly ionic bonds, hydrogen bonds, and hydrophobic interactions, which give the bones the unique composite behavior [49]. There is an opinion that, opposite to bones, there is no sign of chemical bonding between phases in conventional calcium orthophosphate/collagen biocomposites, probably due to a lack of suitable interfacial bonding during mixing [35]. However, this is not the case for phosphorylated collagens [633]. Anyway, Fouriertransformed infrared (FTIR) spectra of some calcium orthophosphate-based composites and collagen films were measured and transformed into absorption spectra using the Kramers-Kronig equation to demonstrate energy shifts of residues on the $\mathrm{HA} /$ collagen interface. After comparing FTIR spectra of biocomposites and collagen films in detail, red shifts of the absorption bands for $\mathrm{C}-\mathrm{O}$ bonds were observed in the spectra of the biocomposites. These red shifts were described as a decrease in bonding energies of $\mathrm{C}-\mathrm{O}$ bonds and assumed to be caused by an interaction to $\mathrm{Ca}^{2+}$ ions located on the surfaces of apatite nanocrystals, as shown in Fig. 5 [628]. Another proof of a chemical interaction between CDHA and collagen fibers was also evaluated in FTIR spectra of CDHA/collagen biocomposites, in which a shift of the band corresponding to $-\mathrm{COO}^{-}$ stretching from 1340 to $1337 \mathrm{~cm}^{-1}$ was observed [594, 595]. More to the point, nucleation of CDHA crystals onto collagen through a chemical interaction with carboxylate
Fig. 5 A schematic diagram of the relation between selforganization (directional deposition of HA on collagen) and interfacial interaction in biocomposites. Direction of interaction between HA and collagen is restricted by covalent bond between $\mathrm{COO}$ and $\mathrm{Ca}(2)$ to maintain regular coordination number of 7 . Reprinted from Ref. [628] with permission

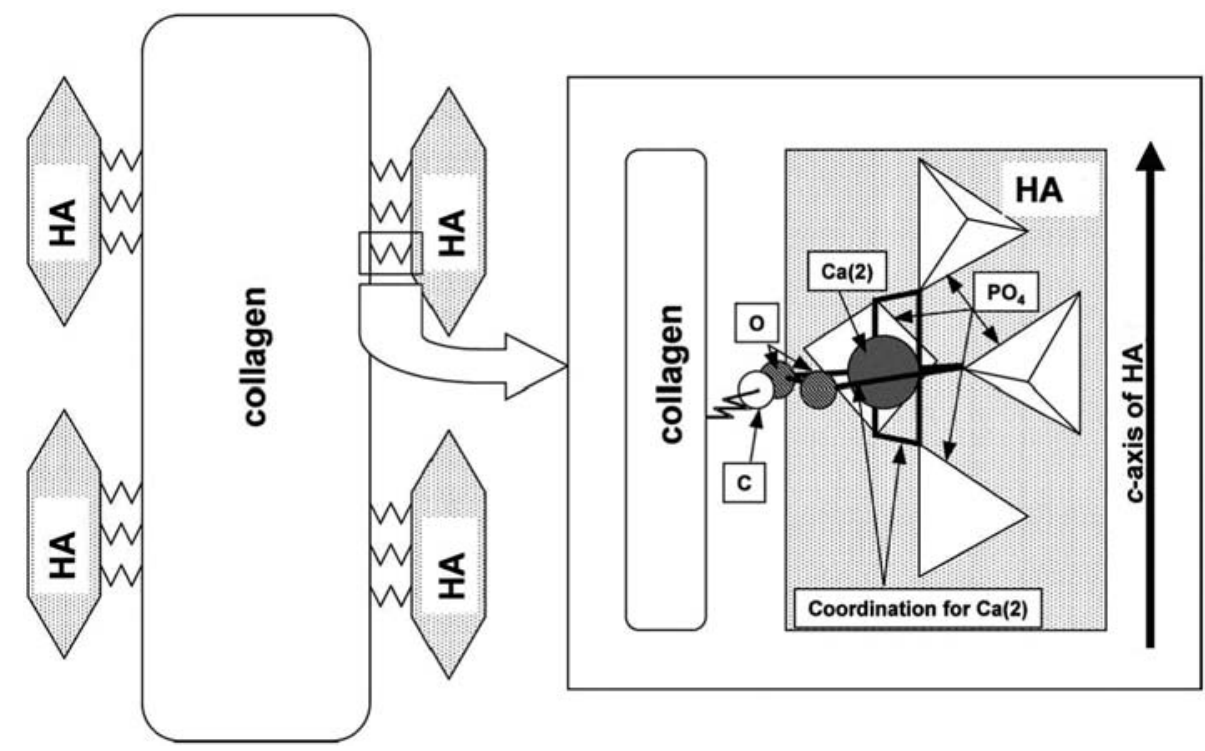


groups of collagen macromolecules has been reported [907-909].

FTIR spectroscopy seems to be the major investigation tool of a possible chemical bonding among the phases in calcium orthophosphate-based biocomposites and hybrid biomaterials [220, 280, 287, 289, 382, 420, 502, 517, 526, 529, 536, 539, 541, 544, 549, 556, 565, 570, 595, 633, 666, $667,726,910,911]$. For example, the characteristic bands at 2918,2850 , and $1472 \mathrm{~cm}^{-1}$ for the hydrocarbon backbone of PE appeared to have zero shift in an HA/PE biocomposite. However, in the case of polyamide, some of the FTIR-bands indicated that the polar groups shifted apparently: the bands at 3304, 1273, and $692 \mathrm{~cm}^{-1}$ derived from stretching of $\mathrm{N}-\mathrm{H}$, stretching of $\mathrm{C}-\mathrm{N}-\mathrm{H}$, and vibrating of $\mathrm{N}-\mathrm{H}$ moved to 3306,1275 , and $690 \mathrm{~cm}^{-1}$ in an HA/polyamide biocomposite, respectively. Both stretching (3568 $\left.\mathrm{cm}^{-1}\right)$ and vibrating $\left(692 \mathrm{~cm}^{-1}\right)$ modes of hydroxyl in HA moved to 3570 and $690 \mathrm{~cm}^{-1}$ in the HA/ polyamide buicomposite, respectively, indicating the formation of hydrogen bonds. Besides, the bands at 1094 and $1031 \mathrm{~cm}^{-1}$ of $\mathrm{PO}_{4}$ modes also shifted to 1093 and $1033 \mathrm{~cm}^{-1}$ in the HA/polyamide biocomposite. The bands shift in a fingerprint area indicated that the hydroxyl and orthophosphate on the surface of HA might interact with plentiful carboxyl and amino groups of polyamide through nucleophilic addition [220]. Comparable conclusions were made for nano-HA/PVA [541], CDHA/alginate [595], ACP/PPF [420], HA/maleic anhydride [289], and $\beta$-TCP/ PLLA [382] biocomposites, where a weak chemical bond was considered to form between $\mathrm{Ca}^{2+}$ ions located on the nano-HA, CDHA, ACP, HA, or $\beta$-TCP surface, respectively, and slightly polarized $\mathrm{O}$ atoms of $\mathrm{C}=\mathrm{O}$ bonds in the surrounding bioorganic compounds. Schematically, this chemical interaction is shown in Fig. 6 [595].

Except of FTIR spectroscopy, other measurement techniques are also able to show some evidences of a chemical interaction between calcium orthophosphates and other compounds in biocomposites [280, 382, 536, 539, 541, 911913]. For example, for CDHA/alendronate nanocrystals

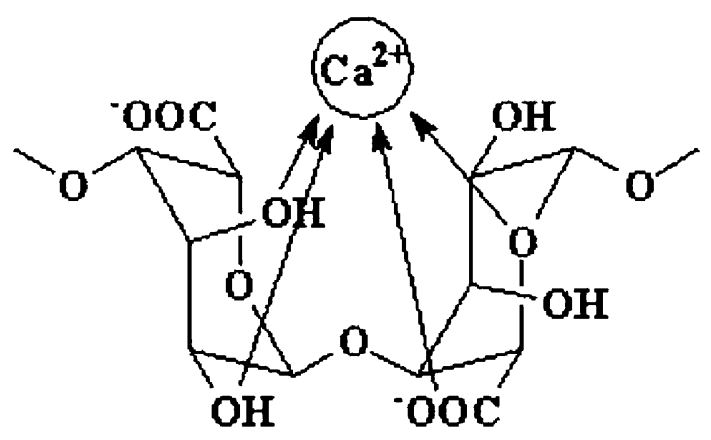

Fig. 6 A schematic diagram of $\mathrm{Ca}^{2+}$ ion binding with alginate chains. Reprinted from Ref. [595] with permission such evidences were observed by thermogravimetric analysis: DTG plots of the nanocrystals appeared to be quite different from those obtained from mechanical mixtures of CDHA and calcium alendronate with similar compositions [912]. Analogous DTG results were obtained for nano-HA/ PVA [541]. In the case of nano-HA/polyamide biocomposites, a hydrogen bonding between the phases was detected by differential scanning calorimetry technique [536]. Another example comprises application of the dynamic mechanical analysis to investigate softening mechanism of $\beta$-TCP/PLLA biocomposites [382]. In the case of nano-HA/PVAP composites, the indirect evidences of chemical bonding between the phases were found by $\mathrm{X}$-ray diffraction and thermogravimetric analysis [280]. A strong structural correlation between the orientation of FA crystallites and the gelatin within the FA/gelatin composite spheres was discovered that indicated to a substantial reorganization of the macromolecular matrix within the area of a growing aggregate [366].

By means of the X-ray photo-electronic spectroscopy (XPS) technique, binding energies of $\mathrm{Ca}, \mathrm{P}$, and $\mathrm{O}$ atoms were found to have some differences between nano-HA (Ca, 350.5 and 345.5; O, 530.2; P, $132.5 \mathrm{eV}$ ) and nano-HA/ konjac glucomannan/chitosan biocomposite $(\mathrm{Ca}, 352.1$ and 347.4; O, 531.2; P, 133.4 eV), respectively [549]. Further measurements by FTIR and X-ray diffraction revealed that nano-HA was mainly linked with konjac glucomannan and chitosan by hydrogen bonding among $\mathrm{OH}^{-}$and $\mathrm{PO}_{4}{ }^{3-}$ of nano-HA and $-\mathrm{C}=\mathrm{O}$ and $-\mathrm{NH}$ of konjac glucomannan and chitosan copolymer and there was a stable interface formed between the three phases in the biocomposite. Meanwhile, coordinate bonding might be formed between $\mathrm{Ca}^{2+}$ and - NH. Stable interfaces have been formed among the three phases in a biocomposite [549]. In HA/collagen biocomposites, a covalent bond formation between $\mathrm{Ca}^{2+}$ of HA and $\mathrm{RCOO}^{-}$of collagen molecules was found by XPS [503]. Similar XPS observations were also made for several other calcium orthophosphate-based biocomposites [529, 556, 565].

The interaction and adhesion between calcium orthophosphate fillers and respective matrixes have a significant effect on the properties of particulate-filled reinforced materials, being essential to transfer the load between the phases and thus improve the mechanical performance of the composites [287]. However, for the substantial amount of the biocomposites discussed in this review, the interaction between the phases is mechanical in nature. This is because the matrix often consists of compounds with no functional groups or unsaturated bonds, which can form ionic complexes with the constituents of calcium orthophosphates. Obviously, less coupling exists between nonpolar polymers and calcium orthophosphate ceramic particles. Therefore, polymers with functional groups pendant 
to the polymer backbone, which can act as sites for bridging to calcium orthophosphates, are more promising in this respect [49]. Besides, the surface of calcium orthophosphates might be modified as well [116, 416, 417, $552,914,915]$. In order to improve the situation, various supplementary reagents are applied. Namely, if the primary effect of a processing additive is to increase the interaction between the phases, such an additive can be regarded as a coupling agent [916]. Coupling agents establish chemical bridges between the matrix and the fillers, promoting the adhesion between the phases. In many cases, their effect is not unique, influencing also the rheology of composites [225].

Optimization of biocomposite properties with coupling agents is currently an important area of the research. The control and development of molecular-level associations of polymer with calcium orthophosphates is suggested to be significant for the resulting mechanical responses in the composites. It appears that a fundamental molecular understanding of interfacial behavior in biocomposite systems is an area not sufficiently addressed in the literature. Various experimental characterization techniques using electron microscopy, vibrational spectroscopy, X-ray diffraction, scanning probe microscopy, and others are used routinely to characterize these materials besides mechanical property characterization. In addition, atomic scale models for simulating the phase interaction and predicting responses in the novel material systems, where nanostructure and nanointerfaces are included, are important to understand and predict the load deformation behavior [147].

A hexamethylene diisocyanate coupling agent was used to bind PEG/PBT (Polyactive ${ }^{\mathrm{TM}}$ ) block copolymers [234] and other polymers [910] to HA filler particles. Thermogravimetric and infrared analysis demonstrated that the polymers were chemically bonded to the HA particles through the isocyanate groups, making it a suitable approach to improve the adhesion [910]. Other researchers used glutaraldehyde as a crosslinked reagent in various calcium orthophosphate-based biocomposites [388, 392, $500,502,503,520,525,585,621,646,649,917]$. The interfacial bonding between calcium orthophosphates and other components might be induced by using various coupling agents and surface modifiers, such as silanes [192, 234, 337, 540, 918-923], zirconates [225, 337, 339, 914, 924], titanates [225, 337, 924], phosphoric acid [543], alkaline pretreatment [722, 725], polyacids [115, 116, 234], and other chemicals. Besides, some polymers might be grafted onto the surface of calcium orthophosphates [552]. Structural modifications of the polymeric matrices, for instance, with the introduction of acrylic acid [195, 234, $919,920]$, have also proved to be effective methods. For example, application of polyacids as a bonding agent for
HA/Polyactive ${ }^{\text {TM }}$ composites caused the surface-modified HA particles to maintain better contact with the polymer at fracture and improved mechanical properties [115, 116, 234]. The use of titanate and zirconate coupling agents appeared to be very dependent on the molding technique employed [225]. Silane-coupled HA powders were tested before applying them as fillers in biodegradable composites [921-923]. This treatment allowed HA withstanding the attack of water without impairing overall bioactivity. Besides, chemically modified reinforcement phase-matrix interface was found to improve the mechanical properties of the biocomposites. Examples of such interface-modified biocomposites include chemically coupled HA/PE [919, 920], chemically formed $\mathrm{HA} / \mathrm{Ca}$ poly(vinylphosphonate) [283], and PLA/HA fibers [184]. These biocomposites are able to consume a large amount of energy in the fracture.

The action of some coupling agents was found to combine two distinct mechanisms: (i) crosslinking of the polymeric matrix (valid for zirconate and titanate coupling agents) and (ii) improvement of the interfacial interactions between the major phases of the composites. This interfacial adhesion improvement appeared to be much dependent on the chemical nature ( $\mathrm{pH}$ and type of metallic center) of the coupling agents [337]. Several studies claimed that silanes do interact with HA [192, 919-923]. It was shown that a silicon-containing inter-phase existed between HA and PE, which promoted the chemical adhesion between the HA particles and the polymer. A silane-coupling agent also facilitated penetration of $\mathrm{PE}$ into cavities of individual HA particles, which resulted in enhanced mechanical interlocking at the matrix-reinforcement interface [919, 920].

Addition of adhesion promoting agents might be an alternative to improve the interaction between the fillers and the matrix. For example, Morita et al. [925] used incorporation of 4-methacryloyloxyethyl trimellitate anhydride to promote adhesion of the polymer to HA. In another study, phosphoric ester was added to the liquid component of the formulation [926]. Both the strength and the affinity index of biocomposites were found to increase, probably due to the effects of copolymerization.

Possible interactions between BCP and HPMC have been investigated in IBS composites [736, 737, 927]. After mixing, there was a decrease in the mean diameter of $\mathrm{BCP}$ granules and this influenced the viscosity of the paste. Dissolution of grain boundaries of $\beta$-TCP crystals and precipitation of CDHA on HA crystal surface was found during the interaction between BCP and HPMC in aqueous solutions. Both phenomena were responsible for the observed granulometric changes [736, 737]; however, within the sensitivity of the employed measurement techniques, no chemical bonding between BCP and HPMC was detected [927]. 
A coprecipitation method was used to prepare CDHA/ chitosan biocomposites [672]. Growth of CDHA crystals was inhibited by organic acids with more than two carboxyl groups, which strongly bind to CDHA surfaces via a COO-Ca bond. Transmission electron microscopy images revealed that CDHA-formed elliptic aggregates with chemical interactions (probably coordination bond) between $\mathrm{Ca}$ on its surface and amino groups of chitosan; the CDHA nanocrystals were found to align along the chitosan molecules, with the amino groups working as the nucleation sites [672]. Formation of calcium crosslinked polymer carboxylate salts was suggested during the setting of calcium orthophosphate cement (TTCP + DCPA)/ polyphosphazane biocomposites; the chemical involvement of the polymer in the cement setting was concluded based on the results of $\mathrm{pH}$ monitoring [460-462].

A chemical bond between the phases was presumed in PCL/HA composites, prepared by the grafting technique [350]; unfortunately, no strong experimental evidences were provided. In another study, CDHA/poly( $\alpha$-hydroxyester) composites were prepared by a low-temperature chemical route [324]. In that study, pre-composite structures were prepared by combining $\alpha$-TCP with PLA, PLGA and copolymers thereof. The final biocomposite structure was achieved by in situ hydrolysis of $\alpha$-TCP to CDHA performed at $56{ }^{\circ} \mathrm{C}$ either in solvent cast or pressed precomposites. That transformation occurred without any chemical reaction between the polymer and calcium orthophosphates, as it was determined by FTIR spectroscopy [324].

In nearly every study on HA/carbon nanotubes biocomposites, the nanotubes have been functionalized before combining them with HA. Most researchers have done this by oxidation [242-246], although non-covalent functionalizing with sodium dodecylsulfate [246] and coating the nanotubes by a polymer [928] before combining them with HA have also been reported. Several studies by transmission electron microscopy have shown evidences that the functionalization has enhanced interaction between carbon nanotubes and HA [245, 246, 929].

If calcium orthophosphate-based biocomposites are able to sustain a high-temperature sintering (valid for the formulations consisting of inorganic components only), an inter-diffusion of chemical elements will take place between the phases. Such effect has been detected by energy-dispersive X-ray spectroscopy in $\mathrm{HA} / \mathrm{TiO}_{2}$ biocomposite particles with partial formation of calcium titanates; this process was found to be favorable to enhancing the cohesive strength of particles in the composite coating [817]. A similar high-temperature interaction between HA and zirconia [743, 768], as well as between HA and Ti [554, 840, 842-844], was also detected. Besides, partial decomposition of HA and formation of different calcium aluminates were detected in $\mathrm{HA} / \mathrm{Al}_{2} \mathrm{O}_{3}$ biocomposites after sintering at $1200-1300{ }^{\circ} \mathrm{C}[795,801$, 802].

\section{Bioactivity and biodegradation of calcium orthophosphate-based biocomposites}

The continuous degradation of an implant causes a gradual load transfer to the healing tissue, preventing stressshielding atrophy and stimulates the healing and remodeling of bones. Some requirements must be fulfilled by the ideal prosthetic biodegradable materials, such as biocompatibility, adequate initial strength and stiffness, retention of mechanical properties throughout sufficient time to assure its biofunctionality and non-toxicity of the degradation by-products [146]. Generally speaking, bioactivity (i.e., ability of bonding to bones) of biologically relevant calcium orthophosphates reinforced by other materials is usually lower than that of pure calcium orthophosphates $[27,28,930]$.

In general, both bioactivity and biodegradability of any biocomposite are determined by the same properties of the constituents. Both processes are very multi-factorial because, after implantation, the surface of any graft is rapidly colonized by cells. Much more biology, than chemistry and material science altogether, is involved into these very complex processes and many specific details still remain unknown. In order to simplify the task, the biodegradability of the biologically relevant calcium orthophosphates might be described by a chemical dissolution in slightly acidic media (calcium orthophosphates are almost insoluble in alkaline solutions [87-93]), which, in the case of CDHA, might be described as a sequence of four successive chemical equations [427, 931, 932]:

$$
\begin{aligned}
& \mathrm{Ca}_{10-x}\left(\mathrm{HPO}_{4}\right)_{x}\left(\mathrm{PO}_{4}\right)_{6-x}(\mathrm{OH})_{2-x}+(2-x) \mathrm{H}^{+} \\
& \quad \rightarrow \mathrm{Ca}_{10-x}\left(\mathrm{HPO}_{4}\right)_{x}\left(\mathrm{PO}_{4}\right)_{6-x}\left(\mathrm{H}_{2} \mathrm{O}\right)_{2-x}(2-x)+ \\
& \mathrm{Ca}_{10-x}\left(\mathrm{HPO}_{4}\right)_{x}\left(\mathrm{PO}_{4}\right)_{6-x}\left(\mathrm{H}_{2} \mathrm{O}\right)_{2-x}(2-x)+ \\
& \quad \rightarrow 3 \mathrm{Ca}_{3}\left(\mathrm{PO}_{4}\right)_{2}+(1-x) \mathrm{Ca}^{2+}+(2-x) \mathrm{H}_{2} \mathrm{O} \\
& \mathrm{Ca}_{3}\left(\mathrm{PO}_{4}\right)_{2}+2 \mathrm{H}^{+} \rightarrow \mathrm{Ca}^{2+}+2 \mathrm{CaHPO}_{4} \\
& \mathrm{CaHPO}_{4}+\mathrm{H}^{+} \rightarrow \mathrm{Ca}^{2+}+\mathrm{H}_{2} \mathrm{PO}_{4}^{-}
\end{aligned}
$$

Strange enough, but the bioactivity mechanism of calcium orthophosphates is not well described in literature; therefore, biomaterials researchers [72] are forced to use a modified scheme for the bioactivity mechanism of bioactive glasses-the concept introduced by Prof. Hench [27, 28]. The mechanism of bonding of bioactive glasses to living tissue involves a sequence of 11 successive reaction steps. The initial five steps occurred on the surface of bioactive glasses are "chemistry" only, 
Fig. 7 The sequence of interfacial reactions involved in forming a bond between tissue and bioactive glasses. The border between "dead" and "alive" occurs approximately at stage 6 . For want of anything better, the bioactivity mechanism of calcium orthophosphates should also be described by this scheme with omitting of several initial stages, as it was made for HA in Ref. [72], where three initial chemical stages of the Hench's mechanism were replaced by partial dissolution of HA. Reprinted from Ref. [28] with permission

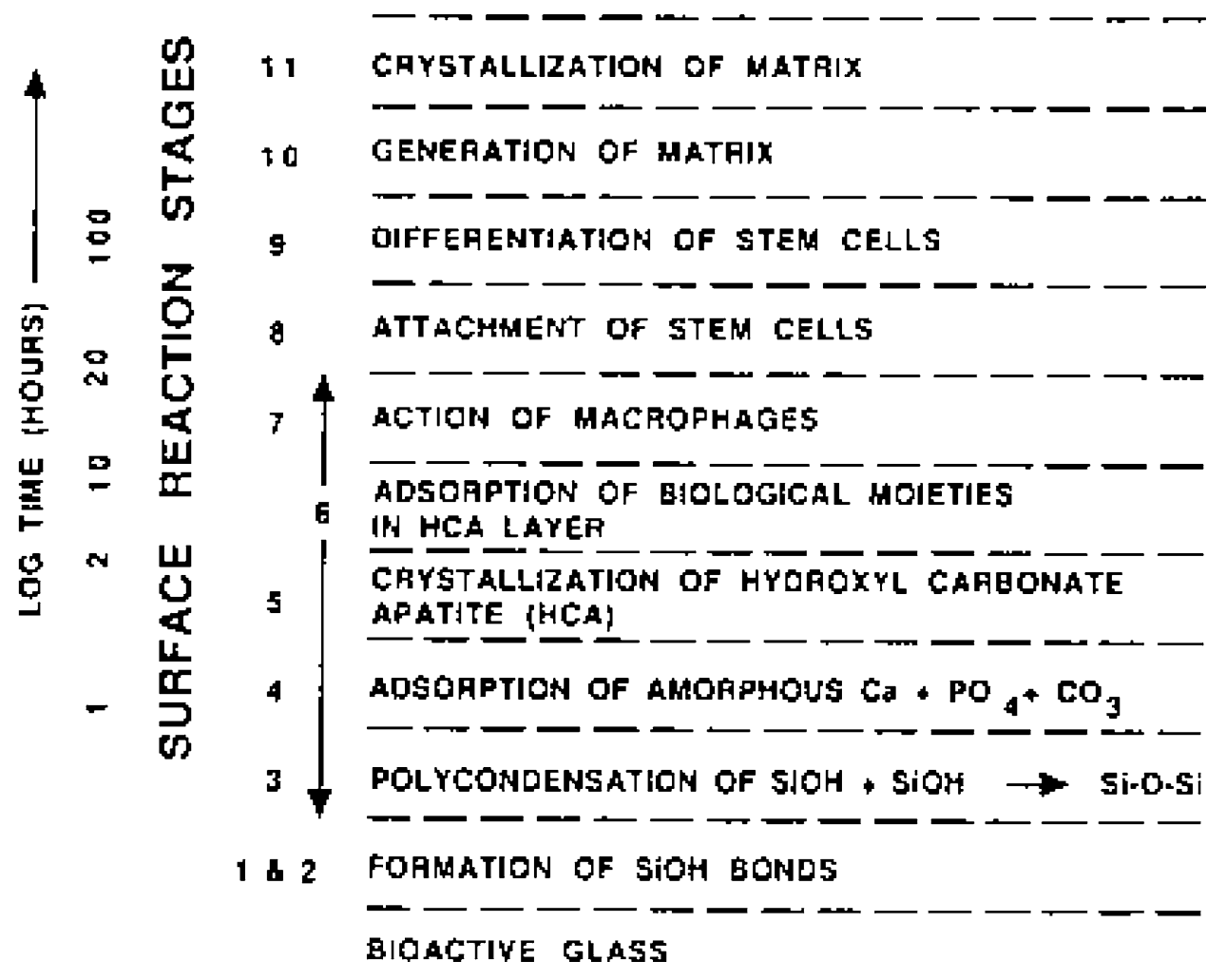

whereas the remaining six steps belong to "biology" because the latter include colonization by osteoblasts, followed by proliferation and differentiation of the cells to form a new bone that had a mechanically strong bond to the implant surface (Fig. 7).

Biodegradability of polymers generally depends on the following factors: (1) chemical stability of the polymer backbone, (2) hydrophobicity of the monomer, (3) morphology of the polymer, (4) initial molecular weight, (5) fabrication processes, (6) geometry of the implant, (7) properties of the scaffold such as porosity and pore diameter [264]. A summary on degradation of PLA and PGA, as well as that of starch/ethylene vinyl alcohol copolymer (SEVA) is available in literature [146, p. 798 and p. 803, respectively], where the interested readers are referred to. Biodegradation of HA/PLLA and CDHA/PLLA composite rods in subcutis and medullary cavities of rabbits were investigated mechanically and histologically; the degradation was found to be faster for the case of using uncalcinated CDHA instead of calcinated HA [933]. In a more detailed study, new bone formation was detected at 2 weeks after implantation, especially for formulations with a high HA content [934]. More to the point, a direct contact between bones and these composites without intervening fibrous tissue was detected in this case [934, 935]. SEVA-C and SEVA-C/HA biocomposites were found to exhibit a non-cytotoxic behavior [936, 937], inducing a satisfactory tissue response when implanted as shown by in vivo studies [937]. Furthermore, SEVA-C/HA biocomposites induce a positive response on osteoblast-like cells to what concerns cell adhesion and proliferation [936].

Both in vitro (the samples were immersed into $1 \%$ trypsin/phosphate-buffered saline solution at $37^{\circ} \mathrm{C}$ ) and in vivo (implantation of samples into the posterolateral lumbar spine of rabbits) biodegradation have been investigated for nano-HA/collagen/PLA biocomposites [511]. The results demonstrated that weight loss increased continuously in vitro with a reduction in mass of $19.6 \%$ after 4 weeks. During the experimental period in vitro, the relative rate of reduction of the three components in this material was shown to differ greatly: collagen decreased the fastest, from $40 \%$ by weight to $20 \%$ in the composite; HA content increased from 45 to $60 \%$, whereas PLA changed little. In vivo, the collagen/HA ratio appeared to be slightly higher near the transverse process than in the central part of the intertransverse process [511]. These data clearly demonstrate a biodegradation independence of various components of biocomposites.

\section{Some challenges and critical issues}

The scientific information summarized in this review represents the recent developments of calcium orthophosphate-based biocomposites and hybrid biomaterials 
from a variety of approaches, starting from conventional ones to tissue engineering. Such formulations combined with osteoconductive, osteoinductive factors, and/or osteogenic cells have gained much interest as a new and versatile class of biomaterials, and are perceived to be beneficial in many aspects as bone grafts [32]. However, current applications of these biomaterials in medicine and surgery are still remarkably less than might be expected. In many biomedical applications, research and testing of such formulations have been introduced and highly developed but only in a very few cases an industrial production and commercial distribution of medical devices partially or entirely made of biocomposites have started. The medical application of biocomposites and hybrid biomaterials requires a better understanding of the objectives and limitations involved. Recently, the main critical issues have been summarized as follows [213]:

- There are not enough reliable experimental and clinical data supporting the long-term performance of biocomposites with respect to monolithic traditional materials.

- The design of biocomposites and hybrid biomaterials is far more complex than that of conventional monolithic materials because of the large number of additional design variables that must be considered.

- The available fabrication methods may limit the possible reinforcement configurations, may be time consuming, expensive, highly skilled and may require special cleaning and sterilization processes.

- There are no satisfactory standards yet for biocompatibility testing of the biocomposite implants because the ways in which the different components of any biocomposite interact to living tissues are not completely understood.

- There are no adequate standards for the assessment of biocomposite fatigue performance because the fatigue behavior of such materials is far more complex and difficult to predict than that of traditional materials [213].

On the other hand, in spite of an enormous progress in biocomposite processing, to achieve the desired characteristics researchers still need to develop more advanced technologies to fabricate a bone-resembling hierarchical organization over several length scales. Development of novel bone repair materials depends on the progress in research into the structure of natural bones. The key issues are not only to understand the fundamentals of biomineralization, but also to translate such knowledge into practical synthetic pathways to produce better bone grafts. Unfortunately, when it comes to the fabrication of composites mimicking natural bone from the nanometer to the micrometer dimensions, there are many key issues, including the control of morphology, incorporation of foreign ions, interaction with biomolecules, and assembly of the organic and inorganic phases, which are still not well understood. A processing gap between the lower-level building units and the higher-order architecture could severely limit the practical application of current calcium orthophosphate-based biocomposites and hybrid biomaterials. Therefore, further substantial research efforts have been outlined to address the following key challenges [32, 37]:

- Optimizing biocomposite processing conditions.

- Optimization of interfacial bonding and strength equivalent to natural bone.

- Optimization of the surface properties and pore size to maximize bone growth.

- Maintaining the adequate volume of the construct in vivo to allow bone formation to take place.

- Withstanding the load-bearing conditions.

- Matching the bioresorbability of the grafts and their biomechanical properties while forming new bone.

- Understanding the molecular mechanisms by which the cells and the biocomposite matrix interact with each other in vivo to promote bone regeneration.

- Supporting angiogenesis and vascularization for the growth of healthy bone cells and subsequent tissue formation and remodeling [32, 37].

The aforementioned critical issues have to be solved before a widespread commercial use of calcium orthophosphate-based biocomposites and hybrid biomaterials can be made in surgery and medicine.

\section{Conclusions}

All types of calcified tissues of humans and mammals appear to possess a complex hierarchical composite structure. Their mechanical properties are outstanding (considering weak constituents from which they are assembled) and far beyond those, that can be achieved using the same synthetic materials with present technologies. This is because biological organisms produce biocomposites that are organized in terms of both composition and structure, containing both brittle calcium orthophosphates and ductile bioorganic components in very complex structures, hierarchically organized at the nano-, micro-, and meso-levels. Additionally, the calcified tissues are always multifunctional, e.g., bone provides structural support for the body plus blood cell formation. The third defining characteristic of biological systems, in contrast with current synthetic systems, is their self-healing ability, which is nearly universal in nature. These complex structures, which have risen from millions of years of evolution, 
inspire materials scientists in the design of novel biomaterials [938].

Until now, still no reasonable alternative exists to autogenous bone grafts in surgery. However, the studies summarized in this review have shown that the proper combination of a ductile matrix with a brittle, hard, and bioactive calcium orthophosphate filler offers many advantages for biomedical applications. Namely, the desirable properties of some components can compensate for a poor mechanical behavior of calcium orthophosphate bioceramics, while in turn the desirable bioactive properties of calcium orthophosphates improve those of other phases, thus expanding the possible application of each material within the body [94]. However, the reviewed literature clearly indicates that among possible types of calcium orthophosphate-based biocomposites and hybrid biomaterials only simple, complex, and graded ones (see classification of the composites in the section "General information on composites and biocomposites") have been investigated. Presumably, a future progress in this subject will require concentrating efforts on elaboration and development of hierarchical biocomposites. Furthermore, following the modern tendency of tissue engineering, a novel generation of calcium orthophosphate-based biocomposites and hybrid biomaterials should also contain a biological living part.

Much study remains to be done on a long way from a laboratory to clinics, and the success in this field depends on the effective cooperation of clinicians, chemists, biologists, bioengineers, and materials scientists.

Acknowledgement I would like to express the profound gratitude to Dr. Sergey Yakovlev and Dr. Besim Ben-Nissan for their generous assistance in getting pdf-versions and/or hard copies of many unavailable for me scientific papers.

\section{References}

1. Keating JF, McQueen MM (2001) J Bone Joint Surg Br 82B:3

2. Meyer U, Joos U, Wiesmann HP (2004) Int J Oral Maxillofac Surg 33:635

3. Lane JM, Tomin E, Bostrom MPG (1999) Clin Orthop Rel Res 367S:107

4. Murugan R, Ramakrishna S (2005) In: Nalwa HS (ed) Handbook of nanostructured biomaterials and their applications in nanobiotechnology, vol 2. American Scientific Publishers, Stevenson Ranch, p 141

5. Keller EE, Triplett WW (1987) J Oral Maxillofac Surg 45:11

6. Laurie SW, Kaban LB, Mulliken JB, Murray JE (1984) Plast Reconstr Surg 73:933

7. Younger EM, Chapman MW (1989) J Orthop Trauma 3:192

8. Neumann M, Epple M (2006) Eur J Trauma 32:125

9. Le Guéhennec L, Layrolle P, Daculsi G (2004) Eur Cells Mater $8: 1$

10. Fuchs JR, Nasseri BA, Vacanti JP (2001) Ann Thorac Surg $72: 557$
11. Hench LL, Wilson J (1984) Science 226:630

12. Rose FRAJ, Oreffo ROC (2002) Biochem Biophys Res 292:1

13. Kokubo T, Kim HM, Kawashita M (2003) Biomaterials 24:2161

14. Rueger JM (1998) Orthopäde 27:72

15. Greenwald AS, Boden SD, Goldberg VM, Khan Y, Laurencin CT, Rosier RN (2001) J Bone Joint Surg Am 83:98

16. Finkemeier CG (2002) J Bone Joint Surg Am 84:454

17. Giannoudis PV, Dinopoulos H, Tsiridis E (2005) Injury 36(Suppl 3):S20

18. Yang S, Leong KF, Du Z, Chua CK (2001) Tissue Eng 7:679

19. Burg KJL, Porter S, Kellam JF (2000) Biomaterials 21:2347

20. Holy CE, Shoichet MS, Davies JE (2000) J Biomed Mater Res 51:376

21. Lowenstam HA, Weiner S (1989) On biomineralization. Oxford University Press, New York

22. Weiner S, Wagner HD (1998) Ann Rev Mater Sci 28:271

23. Dorozhkin SV (2007) J Mater Sci 42:1061. doi:10.1007/ s10853-006-1467-8

24. Hench LL, Wilson J (1993) In: Hench LL, Wilson J (eds) Advanced series in ceramics, vol 1. World Scientific, Singapore, p 1

25. Tadic D, Epple M (2004) Biomaterials 25:987

26. Suchanek W, Yoshimura M (1998) J Mater Res 13:94

27. Hench LL (1991) J Am Ceram Soc 74:1487

28. Hench LL (1998) J Am Ceram Soc 81:1705

29. Itoh S, Kikuchi M, Koyama Y, Takakuda K, Shinomiya K, Tanaka J (2002) Biomaterials 23:3919

30. Thompson JB, Kindt JH, Drake B, Hansma HG, Morse DE, Hansma PK (2001) Nature 414:773

31. Fratzl P, Gupta HS, Paschalis EP, Roschger P (2004) J Mater Chem 14:2115

32. Murugan R, Ramakrishna S (2005) Compos Sci Technol $65: 2385$

33. Burr DB (2002) Bone 31:8

34. Itoh S, Kikuchi M, Koyama Y, Matumoto HN, Takakuda K, Shinomiya K, Tanaka J (2005) Biomed Mater Eng 15:29

35. Cui FZ, Li Y, Ge J (2007) Mater Sci Eng R 57:1

36. Vallet-Regi M, Arcos D (2006) Curr Nanosci 2:179

37. Chan CK, Kumar TSS, Liao S, Murugan R, Ngiam M, Ramakrishna S (2006) Nanomedicine 1:177

38. Olszta MJ, Cheng XG, Jee SS, Kumar BR, Kim YY, Kaufman MJ, Douglas EP, Gower LB (2007) Mater Sci Eng R 58:77

39. Bauer T, Muschler G (2000) Clin Orthop Relat Res 371:10

40. Athanasiou KA, Zhu CF, Lanctot DR, Agrawal CM, Wang X (2000) Tissue Eng 6:361

41. Zioupos P (1998) Mater Sci Eng C 6:33

42. Doblaré M, Garcia JM, Gómez MJ (2004) Eng Fract Mech 71:1809

43. Vallet-Regi M (2006) Dalton Trans 5211

44. Huiskes R, Ruimerman R, Harry van Lenthe G, Janssen JD (2000) Nature 405:704

45. Thomson RC, Yaszemski MJ, Powers JM, Mikos AG (1998) Biomaterials 19:1935

46. Boccaccini AR, Blaker JJ (2005) Expert Rev Med Devices 2:303

47. Verheyen CCPM, de Wijn JR, van Blitterswijk CA, de Groot K, Rozing PM (1993) J Biomed Mater Res 27:433

48. Zhang RY, Ma PX (1999) J Biomed Mater Res 44:446

49. Durucan C, Brown PW (2001) Adv Eng Mater 3:227

50. Kim HW, Knowles JC, Kim HE (2004) Biomaterials 25:1279

51. Hutmacher DW, Schantz JT, Lam CXF, Tan KC, Lim TC (2007) J Tissue Eng Regen Med 1:245

52. Guarino V, Causa F, Ambrosio L (2007) Expert Rev Med Devices 4:405

53. Yunos DM, Bretcanu O, Boccaccini AR (2008) J Mater Sci 43:4433. doi:10.1007/s10853-008-2552-y 
54. Hench LL, Polak JM (2002) Science 295:1014

55. Crane GM, Ishaug SL, Mikos AG (1995) Nat Med 1:1322

56. LeGeros RZ (1988) Adv Dent Res 2:164

57. Mathijsen A (1852) Nieuwe Wijze van Aanwending van het Gips-Verband bij Beenbreuken. J.B. van Loghem, Haarlem

58. Dreesman H (1892) Beitr Klin Chir 9:804

59. Wang M (2003) Biomaterials 24:2133

60. http://en.wikipedia.org/wiki/Composite_material. Assessed June 2008

61. Evans SL, Gregson PJ (1998) Biomaterials 19:1329

62. Habibovic $P$, Barrère $F$, van Blitterswijk $C A$, de Groot $K$, Layrolle P (2002) J Am Ceram Soc 85:517

63. Zhang RY, Ma PX (2004) Macromol Biosci 4:100

64. Oliveira AL, Mano JF, Reis RL (2003) Curr Opin Solid State Mater Sci 7:309

65. Wan YZ, Hong L, Jia SR, Huang Y, Zhu Y, Wang YL, Jiang HJ (2006) Compos Sci Technol 66:1825

66. Wan YZ, Huang Y, Yuan CD, Raman S, Zhu Y, Jiang HJ, He F, Gao C (2007) Mater Sci Eng C 27:855

67. Ohtsuki C, Kamitakahara M, Miyazaki T (2007) J Tissue Eng Regen Med 1:33

68. de Groot K, Geesink RGT, Klein CPAT, Serekian P (1987) J Biomed Mater Res 21:1375

69. de Groot K, Wolke JGC, Jansen JA (1998) Proc Inst Mech Eng H 212:137

70. Ignjatovic NL, Liu CZ, Czernuszka JT, Uskokovic DP (2007) Acta Biomater 3:927

71. Manso M, Langlet M, Fernandez M, Vasquez L, Martinez-Duart JM (2003) Mater Sci Eng C 23:451

72. Sun L, Berndt CC, Gross KA, Kucuk A (2001) J Biomed Mater Res Appl Biomater 58:570

73. Yoshida K, Hashimoto K, Toda Y, Udagawa S, Kanazawa T (2006) J Eur Ceram Soc 26:515

74. Planeix JM, Jaunky W, Duhoo T, Czernuszka JT, Hosseini MW, Brès EF (2003) J Mater Chem 13:2521

75. Dong J, Uemura T, Kojima H, Kikuchi M, Tanaka J, Tateishi T (2001) Mater Sci Eng C 17:37

76. Zerbo IR, Bronckers ALJJ, de Lange G, Burger EH (2005) Biomaterials 26:1445

77. Krout A, Wen HB, Hippensteel E, Li P (2005) J Biomed Mater Res A 73A:377

78. Matthews FL, Rawlings RD (2000) Composite materials: engineering and science. CRC Press LLC, Boca Raton, FL, p 480

79. Xia Z, Riester L, Curtin WA, Li H, Sheldon BW, Liang J, Chang B, Xu JM (2004) Acta Mater 52:931

80. Williams DF (1990) Encyclopedia of biomaterials. Pergamon, Oxford

81. Ong JL, Chan DCN (1999) Crit Rev Biomed Eng 28:667

82. Davies JE (1996) Anat Rec 245:426

83. Anselme K (2000) Biomaterials 21:667

84. Gauthier O, Bouler JM, Weiss P, Bosco J, Daculsi G, Aguado E (1999) J Biomed Mater Res 47:28

85. Hing KA, Best SM, Bonfield W (1999) J Mater Sci Mater Med 10:135

86. Carotenuto G, Spagnuolo G, Ambrosio L, Nicolais L (1999) J Mater Sci Mater Med 10:671

87. LeGeros RZ (1991) In: Myers HM (ed) Monographs in oral science, vol 15. Karger, Basel, p 201

88. Elliot JC (1994) Structure and chemistry of the apatites and other calcium orthophosphates. Studies in inorganic chemistry, vol 18. Elsevier, Amsterdam, p 389

89. Brown PW, Constantz B (eds) (1994) Hydroxyapatite and related materials. CRC Press, Boca Raton, p 343

90. Amjad Z (ed) (1997) Calcium phosphates in biological and industrial systems. Kluwer Academic Publishers, Boston, MA, p 529
91. Hughes JM, Kohn M, Rakovan J (eds) (2002) Phosphates: geochemical, geobiological and materials importance. Reviews in mineralogy and geochemistry, vol 48. Mineralogical Society of America, Washington, DC

92. Chow LC, Eanes ED (eds) (2001) Octacalcium phosphate. Monographs in oral science, vol 18. S. Karger AG, Basel, 168 pp

93. Brès E, Hardouin P (eds) (1998) Les matériaux en phosphate de calcium. Aspects fondamentaux/calcium phosphate materials. Fundamentals. Sauramps Medical, Montpellier, p 176

94. Rea SM, Bonfield W (2004) J Aust Ceram Soc 40:43

95. Langer R (2000) Acc Chem Res 33:94

96. Thomson RC, Ak S, Yaszemski MJ, Mikos AG (2000) Principles of tissue engineering. Academic Press, NY, p 251

97. Ramakrishna S, Mayer J, Wintermantel E, Leong KW (2001) Compos Sci Technol 61:1189

98. Langer R, Vacanti JP (1993) Science 260:920

99. Lanza RP, Hayes JL, Chick WL (1996) Nat Biotechnol 14:1107

100. Agrawal CM, Ray RB (2001) J Biomed Mater Res 55:141

101. Kweon H, Yoo M, Park I, Kim T, Lee H, Lee S, Oh J, Akaike T, Cho C (2003) Biomaterials 24:801

102. de Groot JH, de Vrijer R, Pennings AJ, Klompmaker J, Veth RPH, Jansen HWB (1996) Biomaterials 17:163

103. Resiak I, Rokicki G (2000) Polimery 45:592

104. Temenoff JS, Mikos AG (2000) Biomaterials 21:2405

105. Behravesh E, Yasko AW, Engel PS, Mikos AG (1999) Clin Orthop Relat Res 367S:S118

106. Lewandrowski KU, Gresser JD, Wise DL, White RL, Trantolo DJ (2000) Biomaterials 21:293

107. Peter SJ, Miller MJ, Yaszemski MJ, Mikos AG (1997) In: Domb AJ, Kost J, Wiseman DM (eds) Handbook of biodegradable polymers. Harwood Academic, Amsterdam, p 87

108. Boland ED, Coleman BD, Barnes CP, Simpson DG, Wnek GE, Bowlin GL (2005) Acta Biomater 1:115

109. Gilbert JL (2001) Encyclopedia of materials: science and technology. Elsevier, Amsterdam, p 11

110. Li YW, Leong JCY, Lu WW, Luk KDK, Cheung KMC, Chiu KY, Chow SP (2000) J Biomed Mater Res 52:164

111. Mckellop H, Shen F, Lu B, Campbell P, Salovey R (1999) J Orthop Res 17:157

112. Kurtz SM, Muratoglu OK, Evans M, Edidin AA (1999) Biomaterials 20:1659

113. Laurencin CT, Ambrosio MA, Borden MD, Cooper JA Jr (1999) Ann Rev Biomed Eng 1:19

114. Jansen JA, de Ruijter JE, Janssen PT, Paquay YG (1995) Biomaterials $16: 819$

115. Liu Q, de Wijn JR, Bakker D, van Blitterswijk CA (1996) J Mater Sci Mater Med 7:551

116. Liu Q, de Wijn JR, Bakker D, van Toledo M, van Blitterswijk CA (1998) J Mater Sci Mater Med 9:23

117. Meijer GJ, Cune MS, van Dooren M, de Putter C, van Blitterswijk CA (1997) J Oral Rehabil 24:85

118. Meijer GJ, Dalmeijer RA, de Putter C, van Blitterswijk CA (1997) J Oral Rehabil 24:93

119. Svensson A, Nicklasson E, Harrah T, Panilaitis B, Kaplan DL, Brittberg M, Gatenholm P (2005) Biomaterials 26:419

120. Granja PL, Barbosa MA, Pouysége L, de Jéso B, Rouais F, Baquuey C (2001) J Mater Sci 36:2163. doi:10.1023/A:101 7587815583

121. Thomas V, Dean DR, Vohra YK (2006) Curr Nanosci 2:155

122. Li SM, Garreau H, Vert M (1990) J Mater Sci Mater Med 1:123

123. Daniels AU, Adriano KP, Smuts WP, Chang MKO, Keller J (1994) J Appl Biomater 5:51

124. Adriano KP, Pohjonen T, Törmällä P (1994) J Appl Biomater $5: 133$

125. Athanasiou KA, Niederauer GG, Agrawal CM (1996) Biomaterials 17:93 
126. Dee KC, Bizios R (1996) Biotechnol Bioeng 50:438

127. Ignjatovic N, Tomic S, Dakic M, Miljkovic M, Plavsic M, Uskokovic D (1999) Biomaterials 20:809

128. Ignjatovic N, Savic V, Najman S, Plavsic M, Uskokovic D (2001) Biomaterials 22:571

129. Marra KG, Szem JW, Kumta PN, DiMilla PA, Weiss LE (1999) J Biomed Mater Res 47:324

130. Ashammakhi N, Rokkanen P (1997) Biomaterials 18:3

131. Boyan B, Lohmann C, Somers A, Neiderauer G, Wozney J, Dean D, Carnes D, Schwartz Z (1999) J Biomed Mater Res 46:51

132. Hofmann GO (1995) Arch Orthop Trauma Surg 114:123

133. Hollinger JO, Leong K (1996) Biomaterials 17:187

134. Griffith LG (2000) Acta Mater 48:263

135. Peter SJ, Miller MJ, Yasko AW, Yaszemski MJ, Mikos AG (1998) J Biomed Mater Res 43:422

136. Ishuang SL, Payne RG, Yaszemski MJ, Aufdemorte TB, Bizios R, Mikos AG (1996) Biotechnol Bioeng 50:443

137. Shikinami Y, Okuno M (1999) Biomaterials 20:859

138. Khor E, Lim LY (2003) Biomaterials 24:2339

139. Ishihara M, Nakanishi K, Ono K, Sato M, Kikuchi M (2002) Biomaterials 23:833

140. Di Martino A, Sittinger M, Risbud MV (2005) Biomaterials 26:5983

141. Piskin E, Bölgen N, Egri S, Isoglu IA (2007) Nanomedicine $2: 441$

142. Rezwana K, Chena QZ, Blakera JJ, Boccaccini AR (2006) Biomaterials 27:3413

143. Mohanty AK, Misra M, Hinrichsen G (2000) Macromol Mater Eng 276(277): 1

144. Seal BL, Otero TC, Panitch A (2001) Mater Sci Eng R 34:147

145. An YH, Woolf SK, Friedman RJ (2000) Biomaterials 21:2635

146. Mano JF, Sousa RA, Boesel LF, Neves NM, Reis RL (2004) Compos Sci Technol 64:789

147. Katti KS (2004) Colloids Surf B Biointerfaces 39:133

148. Hayashi T (1994) Prog Polym Sci 19:663

149. Middleton J, Tipton A (2000) Biomaterials 21:2335

150. Ma PX (2008) Adv Drug Deliv Rev 60:184

151. Coombes AG, Meikle MC (2004) Clin Mater 17:35

152. Okada M (2002) Prog Polym Sci 27:87

153. Jordan J, Jacob KI, Tannenbaum R, Sharaf MA, Jasiuk I (2005) Mater Sci Eng A 393:1

154. Matsuno H, Yokoyama A, Watari F, Uo M, Kawasaki T (2001) Biomaterials 22:1253

155. Uo M, Watari F, Yokoyama A, Matsuno H, Kawasaki T (1999) Biomaterials 20:747

156. Uo M, Watari F, Yokoyama A, Matsuno H, Kawasaki T (2001) Biomaterials 22:1787

157. Uo M, Watari F, Yokoyama A, Matsuno H, Kawasaki T (2001) Biomaterials 21:677

158. Ryan G, Pandit A, Apatsidis DP (2006) Biomaterials 27:2651

159. Shimko DA, Shimko VF, Sander EA, Dickson KF, Nauman EA (2005) J Biomed Mater Res B Appl Biomater 73B:315

160. Wen CE, Yamada Y, Shimojima K, Chino Y, Hosokawa H, Mabuchi M (2004) Mater Lett 58:357

161. Green D, Walsh D, Mann S, Oreffo ROC (2002) Bone 30:810

162. Kokubo T (1998) Acta Mater 46:2519

163. Witte F, Reifenrath J, Müller PP, Crostack HA, Nellesen J, Bach FW, Bormann D, Rudert M (2006) Matwiss u Werkstofflech 37:504

164. Uo M, Mizuno M, Kuboki Y, Makishima A, Watari F (1998) Biomaterials 19:2277

165. Imai T, Watari F, Yamagata S, Kobayashi M, Nagayama K, Nakamura S (1998) Biomaterial 19:2195

166. Watari F, Yamagata S, Imai T, Nakamura S, Kobayashi M (1998) J Mater Sci 33:5661. doi:10.1023/A:1004484703341

167. Hench LL (2006) J Mater Sci Mater Med 17:967
168. Cao W, Hench LL (1996) Ceram Int 22:493

169. Vogel M, Voigt C, Gross U, Müller-Mai C (2001) Biomaterials 22:357

170. de Aza P, Luklinska Z, Santos C, Guitian F, de Aza S (2003) Biomaterials 24:1437

171. Ikeda N, Kawanabe K, Nakamura T (1999) Biomaterials 20:1087

172. Weizhong Y, Dali Z, Guangfu Y (2003) J Biomed Eng 20:541

173. Piconi C, Maccauro G (1999) Biomaterials 20:1

174. Christel P, Meunier A, Heller M, Torre JP, Peille CN (1989) J Biomed Mater Res 23:45

175. Garvie RC, Urban D, Kennedy DR, McMeuer JC (1984) J Mater Sci 19:3224. doi:10.1007/BF00549808

176. Burger W, Richter HG, Piconi C, Vatteroni R, Cittadini A, Bocccalari M (1997) J Mater Sci Mater Med 8:113

177. Converse GL, Yue W, Roeder RK (2007) Biomaterials 28:927

178. Yue W, Roeder RK (2006) J Mater Res 21:2136

179. Converse GL, Roeder RK (2005) Mater Res Soc Symp Proc 898:44

180. Mizutani Y, Hattori M, Okuyama M, Kasuga T, Nogami M (2006) Key Eng Mater 309-311:1079

181. Watanabe T, Ban S, Ito T, Tsuruta S, Kawai T, Nakamura H (2004) Dent Mater J 23:609

182. Li H, Chen Y, Xie Y (2003) Mater Lett 57:2848

183. Peng Q, Weng J, Li X, Gu Z (2005) Key Eng Mater 288289:199

184. Kasuga T, Ota Y, Nogami M, Abe Y (2000) Biomaterials 22:19

185. Smith L (1963) Arch Surg 87:653

186. Bonfield W, Grynpas MD, Tully AE, Bowman J, Abram J (1981) Biomaterials 2:185

187. Bonfield W, Bowman J, Grynpas MD (1981) UK patent 8032647

188. Bonfield W (1988) J Biomed Eng 10:522

189. Wang M, Porter D, Bonfield W (1994) Br Ceram Trans 93:91

190. Guild FJ, Bonfield W (1993) Biomaterials 14:985

191. Huang J, Di Silvio L, Wang M, Tanner KE, Bonfield W (1997) J Mater Sci Mater Med 8:775

192. Deb S, Wang M, Tanner KE, Bonfield W (1996) J Mater Sci Mater Med 7:191

193. Wang M, Joseph R, Bonfield W (1998) Biomaterials 19:2357

194. Suwanprateeb J, Tanner KE, Turner S, Bonfield W (1997) J Mater Sci Mater Med 8:469

195. Ladizesky NH, Ward IM, Bonfield W (1997) J Appl Polym Sci 65:1865

196. Ladizesky NH, Pirhonen EM, Appleyard DB, Ward IM, Bonfield W (1998) Compos Sci Technol 58:419

197. Nazhat SN, Joseph R, Wang M, Smith R, Tanner KE, Bonfield W (2000) J Mater Sci Mater Med 11:621

198. Ladizesky NH, Ward IM, Bonfield W (1996) Polym Adv Technol 8:496

199. Guild FJ, Bonfield W (1998) J Mater Sci Mater Med 9:497

200. Di Silvio L, Dalby M, Bonfield W (1998) J Mater Sci Mater Med 9:845

201. Wang M, Ladizesky NH, Tanner KE, Ward IM, Bonfield W (2000) J Mater Sci 35:1023. doi:10.1023/A:1004731315328

202. That PT, Tanner KE, Bonfield W (2000) J Biomed Mater Res $51: 453$

203. That PT, Tanner KE, Bonfield W (2000) J Biomed Mater Res $51: 461$

204. Bonner M, Ward IM, McGregor W, Tanner KE, Bonfield W (2001) J Mater Sci Lett 20:2049

205. Bonner M, Saunders LS, Ward IM, Davies GW, Wang M, Tanner KE, Bonfield W (2002) J Mater Sci 37:325. doi: 10.1023/A:1013652312670

206. Dalby MJ, Di Silvio L, Davies GW, Bonfield W (2000) J Mater Sci Mater Med 12:805 
207. Di Silvio L, Dalby MJ, Bonfield W (2002) Biomaterials 23:101

208. Dalby MJ, Kayser MV, Bonfield W, Di Silvio L (2002) Biomaterials 23:681

209. Dalby MJ, Di Silvio L, Gurav N, Annaz B, Kayser MV, Bonfield W (2002) Tissue Eng 8:453

210. Zhang Y, Tanner KE, Gurav N, Di Silvio L (2007) J Biomed Mater Res A 81A:409

211. Rea SM, Best SM, Bonfield W (2004) J Mater Sci Mater Med 15:997

212. Rea SM, Brooks RA, Schneider A, Best SM, Bonfield W (2004) J Biomed Mater Res B Appl Biomater 70:250

213. Salernitano E, Migliaresi C (2003) J Appl Biomater Biomech $1: 3$

214. Pandey A, Jan E, Aswath PB (2006) J Mater Sci 41:3369. doi: 10.1007/s10853-005-5350-9

215. Sousa RA, Reis RL, Cunha AM, Bevis MJ (2003) Compos Sci Technol 63:389

216. Homaeigohar SS, Shokrgozar MA, Khavandi A, Sadi AY (2008) J Biomed Mater Res A 84A:491

217. Downes RN, Vardy S, Tanner KE, Bonfield W (1991) Bioceramics 4:239

218. Dornhoffer HL (1998) Laryngoscope 108:531

219. Swain RE, Wang M, Beale B, Bonfield W (1999) Biomed Eng Appl Basis Commun 11:315

220. Yi Z, Li Y, Jidong L, Xiang Z, Hongbing L, Yuanyuan W, Weihu Y (2007) Mater Sci Eng A 452-453:512

221. Unwin AP, Ward IM, Ukleja P, Weng J (2001) J Mater Sci 36:3165. doi:10.1023/A:1017926100999

222. Fang LM, Leng Y, Gao P (2006) Biomaterials 27:3701

223. Fang LM, Gao P, Leng Y (2007) Composites B 38:345

224. Fang LM, Leng Y, Gao P (2005) Biomaterials 26:3471

225. Sousa RA, Reis RL, Cunha AM, Bevis MJ (2002) J Appl Polym Sci $86: 2873$

226. Reis RL, Cunha AM, Oliveira MJ, Campos AR, Bevis MJ (2001) Mat Res Innovat 4:263

227. Donners JJJM, Nolte RJM, Sommerdijk NAJM (2003) Adv Mater 15:313

228. Ignjatovic NL, Plavsic M, Miljkovic MS, Zivkovic LM, Uskokovic DP (1999) J Microsc (Oxford) 196:243

229. Skrtic D, Antonucci JM, Eanes ED (2003) J Res Natl Inst Stand Technol 108:167

230. Rizzi SC, Heath DJ, Coombes AGA, Bock N, Textor M, Downes S (2001) J Biomed Mater Res 55:475

231. Kato K, Eika Y, Ikada Y (1997) J Mater Sci 32:5533. doi: 10.1023/A:1018616306104

232. Damien CJ, Parsons JR (1991) J Appl Biomater 2:187

233. Zhang RY, Ma PX (1999) J Biomed Mater Res 45:285

234. Liu Q, de Wijn JR, van Blitterswijk CA (1998) J Biomed Mater Res 40:490

235. Cerrai P, Guerra GD, Tricoli M, Krajewski A, Ravaglioli A, Martinetti R, Dolcini L, Fini M, Scarano A, Piattelli A (1999) J Mater Sci Mater Med 10:677

236. Roeder RK, Sproul MM, Turner CH (2003) J Biomed Mater Res A $67 \mathrm{~A}: 801$

237. Hutmacher DW (2000) Biomaterials 21:2529

238. Mathieu LM, Bourban PE, Manson JAE (2006) Compos Sci Technol 66:1606

239. Redepenning J, Venkataraman G, Chen J, Stafford N (2003) J Biomed Mater Res A 66A:411

240. Rhee SH, Tanaka J (2001) J Am Ceram Soc 84:459

241. Pezzotti G, Asmus SMF (2001) Mater Sci Eng A 316:231

242. Kealley C, Ben-Nissan B, van Riessen A, Elcombe M (2006) Key Eng Mater 309-311:597

243. Kealley C, Elcombe M, van Riessen A, Ben-Nissan B (2006) Physica B 385-386:496
244. Aryal S, Bahadur KCR, Dharmaraj N, Kim KW, Kim HY (2006) Scr Mater 54:131

245. Wei Q, Yang XP, Chen GQ, Tang JT, Deng XL (2005) N Carbon Mater 20:164

246. Zhao LP, Gao L (2004) Carbon 42:423

247. Aryal S, Bhattarai SR, Bahadur KCR, Khil MS, Lee DR, Kim HY (2006) Mater Sci Eng A 426:202

248. Rautaray D, Mandal S, Sastry M (2005) Langmuir 21:5185

249. Memoto R, Nakamura S, Isobe T, Senna M (2001) J Sol Gel Sci Technol 21:7

250. Fujiwara M, Shiokawa K, Morigaki K, Tatsu Y, Nakahara Y (2008) Mater Sci Eng C 28:280

251. Nagata F, Miyajima T, Yokogawa Y (2006) J Eur Ceram Soc 26:533

252. Russias J, Saiz E, Nalla RK, Tomsia AP (2006) J Mater Sci 41:5127. doi:10.1007/s10853-006-0449-1

253. Khan YM, Cushnie EK, Kelleher JK, Laurencin CT (2007) J Mater Sci 42:4183. doi:10.1007/s10853-006-0636-0

254. Kim HW, Knowles JC, Kim HE (2005) J Biomed Mater Res A 72A:136

255. Sinha A, Das G, Sharma BK, Roy RP, Pramanick AK, Nayar S (2007) Mater Sci Eng C 27:70

256. Sun L, Berndt CC, Gross KA (2002) J Biomater Sci Polym Edn 13:977

257. Sugawara A, Yamane S, Akiyoshi K (2006) Macromol Rapid Commun 27:441

258. Liu Q, de Wijn JR, van Blitterswijk CA (1997) Biomaterials $18: 1263$

259. Uskokovic PS, Tang CY, Tsui CP, Ignjatovic N, Uskokovic DP (2007) J Eur Ceram Soc 27:1559

260. Todo M, Kagawa T (2008) J Mater Sci 43:799. doi: 10.1007/s10853-007-2308-0

261. Woo KM, Seo J, Zhang RY, Ma PX (2007) Biomaterials 28:2622

262. Ma PX, Zhang R, Xiao G, Franceschi R (2001) J Biomed Mater Res $54: 284$

263. Wang M, Chen LJ, Ni J, Weng J, Yue CY (2001) J Mater Sci Mater Med 12:855

264. Baji A, Wong SC, Srivatsan TS, Njus GO, Mathur G (2006) Mater Manuf Process 21:211

265. Wei G, Ma PX (2006) J Biomed Mater Res A 78A:306

266. Guan L, Davies JE (2004) J Biomed Mater Res A 71A:480

267. Teng XR, Ren J, Gu SY (2007) J Biomed Mater Res B Appl Biomater 81B: 185

268. Ren J, Zhao P, Ren T, Gu S, Pan K (2008) J Mater Sci Mater Med 19:1075

269. Wang M, Yue CY, Chua B (2001) J Mater Sci Mater Med 12:821

270. Chlopek J, Rosol P, Morawska-Chochol A (2006) Compos Sci Technol 66:1615

271. Szaraniec B, Rosol P, Chlopek J (2005) e-Polymers 030:1

272. Nayar S, Sinha A (2004) Colloids Surf B Biointerfaces 35:29

273. Chang MC, Ko CC, Douglas WH (2005) J Mater Sci 40:505. doi:10.1007/s10853-005-6115-1

274. Chang MC, Ko CC, Douglas WH (2005) J Mater Sci 40:2723. doi:10.1007/s10853-005-2116-3

275. You C, Miyazaki T, Ishida E, Ashizuka M, Ohtsuki C, Tanihara M (2007) J Eur Ceram Soc 27:1585

276. Xu F, Li Y, Yao X, Liao H, Zhang L (2007) J Mater Sci Mater Med 18:635

277. Xu F, Li Y, Deng Y, Xiong G (2008) J Biomater Sci Polym Edn 19:431

278. Nayar S, Pramanick AK, Sharma BK, Das G, Kumar BR, Sinha A (2008) J Mater Sci Mater Med 19:301

279. Bigi A, Boanini E, Gazzano M, Rubini K (2005) Cryst Res Technol 40:1094 
280. Pramanik N, Biswas SK, Pramanik P (2008) Int J Appl Ceram Technol 5:20

281. Bertoni E, Bigi A, Falini G, Panzavolta S, Roveri N (1999) J Mater Chem 9:779

282. Qiu HJ, Yang J, Kodali P, Koh J, Ameer GA (2006) Biomaterials 27:5845

283. Greish YE, Brown PW (2001) Biomaterials 22:807

284. Greish YE, Brown PW (2001) J Mater Sci Mater Med 12:407

285. Greish YE, Brown PW (2002) J Am Ceram Soc 85:1738

286. Nakahira A, Tamai M, Miki S, Pezotti G (2002) J Mater Sci 37:4425. doi:10.1023/A:1020681309572

287. Sailaja GS, Velayudhan S, Sunny MC, Sreenivasan K, Varma HK, Ramesh P (2003) J Mater Sci 38:3653. doi:10.1023/ A: 1025689701309

288. Zhang H, Xu JJ, Chen HY (2007) J Phys Chem C 111:16564

289. Piticescu RM, Chitanu GC, Albulescu M, Giurginca M, Popescu ML, Łojkowski W (2005) Solid State Phenom 106:47

290. Enlow D, Rawal A, Kanapathipillai M, Schmidt-Rohr K, Mallapragada S, Lo CT, Thiyagarajan P, Akin M (2007) J Mater Chem 17:1570

291. Kaito T, Myoui A, Takaoka K, Saito N, Nishikawa M, Tamai N, Ohgushi H, Yoshikawa H (2005) Biomaterials 26:73

292. Song J, Saiz E, Bertozzi CR (2003) J Am Chem Soc 125:1236

293. Meenan BJ, McClorey C, Akay M (2000) J Mater Sci Mater Med 11:481

294. Fan JP, Tsui CP, Tang CY, Chow CL (2004) Biomaterials 25:5363

295. Abu Bakar MS, Cheng MHW, Tang SM, Yu SC, Liao K, Tan CT, Khor KA, Cheang P (2003) Biomaterials 24:2245

296. Abu Bakar MS, Cheang P, Khor KA (2003) Compos Sci Technol 63:421

297. Abu Bakar MS, Cheang P, Khor KA (2003) Mater Sci Eng A 345:55

298. Fan JP, Tsui CP, Tang CY (2004) Mater Sci Eng A 382:341

299. Yu S, Hariram KP, Kumar R, Cheang P, Aik KK (2005) Biomaterials 26:2343

300. Gong XH, Tang CY, Hu HC, Zhou XP (2004) J Mater Sci Mater Med 15:1141

301. Laurencin CT, Attawia MA, Elgendy HE, Herbert KM (1996) Bone 91:S93

302. Laurencin CT, Attawia MA, Lu LQ, Borden MD, Lu HH, Gorum WJ, Lieberman JR (2001) Biomaterials 22:1271

303. Kim SS, Ahn KM, Park MS, Lee JH, Choi CY, Kim BS (2007) J Biomed Mater Res A 80A:206

304. Oliveira J, Miyazaki T, Lopes M, Ohtsuki C, Santos J (2005) J Mater Sci Mater Med 16:253

305. Kim S, Kim SS, Lee SH, Ahn SE, Gwak SJ, Song JH, Kim BS, Chung HM (2008) Biomaterials 29:1043

306. Petricca SE, Marra KG, Kumta PN (2006) Acta Biomater 2:277

307. Sato M, Slamovich EB, Webster TJ (2005) Biomaterials 26:1349

308. Gu SY, Zhan H, Ren J, Zhou XY (2007) Polym Polym Compos 15:137

309. Verheyen CCPM, de Wijin JR, van Blitterwijk CA, de Groot K (1992) J Biomed Mater Res 26:1277

310. Balac I, Uskokovic PS, Aleksic R, Uskokovic D (2002) J Biomed Mater Res 63:793

311. Dawes E, Rushton N (1994) Clin Mater 17:157

312. Verheyen CCPM, Klein CPAT, de Blieck-Hogervorst JMA, Wolke JGC, de Wijn JR, van Blitterswijk CA, de Groot K (1993) J Mater Sci Mater Med 4:58

313. Li H, Chang J (2005) Compos Sci Technol 65:2226

314. Agrawal CM, Athanasiou KA (1997) J Biomed Mater Res Appl Mater 38:105

315. Peter SJ, Miller ST, Zhu G, Yasko AW, Mikos AG (1998) J Biomed Mater Res 41:1
316. Ara M, Watanabe M, Imai Y (2002) Biomaterials 23:2479

317. Linhart W, Peters F, Lehmann W, Schwarz K, Schilling A, Amling M, Rueger JM, Epple M (2001) J Biomed Mater Res 54:162

318. Schiller C, Epple M (2003) Biomaterials 24:2037

319. Schiller C, Rasche C, Wehmöller M, Beckmann F, Eufinger H, Epple M, Weihe S (2004) Biomaterials 25:1239

320. Shikinami Y, Okuno M (2001) Biomaterials 22:3197

321. Russias J, Saiz E, Nalla RK, Gryn K, Ritchie RO, Tomsia AP (2006) Mater Sci Eng C 26:1289

322. Kim HW, Lee HH, Knowles JC (2006) J Biomed Mater Res A 79A:643

323. Gross KA, Rodríguez-Lorenzo LM (2004) Biomaterials 25:4955

324. Durucan C, Brown PW (2000) J Biomed Mater Res 51:717

325. Durucan C, Brown PW (2000) J Biomed Mater Res 51:726

326. Ignjatovic N, Suljovrujic E, Biudinski-Simendic J, Krakovsky I, Uskokovic D (2004) J Biomed Mater Res B Appl Biomater 71B:284

327. Nazhat SN, Kellomäki M, Törmälä $\mathrm{P}$, Tanner KE, Bonfield W (2001) J Biomed Mater Res 58:335

328. Hasegawa S, Tamura J, Neo M, Goto K, Shikinami Y, Saito M, Kita M, Nakamura T (2005) J Biomed Mater Res A 75A:567

329. Hasegawa S, Neo M, Tamura J, Fujibayashi S, Takemoto M, Shikinami Y, Okazaki K, Nakamura T (2007) J Biomed Mater Res A 81A:930

330. Higashi S, Yamamuro T, Nakamura T, Ikada Y, Hyon SH, Jamshidi K (1986) Biomaterials 7:183

331. Ylinen P (1994) J Mater Sci Mater Med 5:522

332. Reis RL, Cunha AM, Bevis MJ (1998) J Appl Med Polym 2:49

333. Reis RL, Cunha AM (2000) J Appl Med Polym 4:1

334. Sousa RA, Mano JF, Reis RL, Cunha AM, Bevis MJ (2002) Polym Eng Sci 42:1032

335. Marques AP, Reis RL (2005) Mater Sci Eng C 25:215

336. Reis RL, Cunha AM, Allan PS, Bevis MJ (1997) J Polym Adv Tech 16:263

337. Vaz CM, Reis RL, Cunha AM (2002) Biomaterials 23:629

338. Leonor IB, Ito A, Onuma K, Kanzaki N, Reis RL (2003) Biomaterials 24:579

339. Vaz CM, Reis RL, Cunha AM (2001) Mater Res Innovat 4:375

340. Boeree N, Dove J, Cooper JJ, Knowles JC, Hastings GW (1993) Biomaterials 14:793

341. Doyle C, Tanner ET, Bonfield W (1991) Biomaterials 12:841

342. Chen LJ, Wang M (2002) Biomaterials 23:2631

343. Ni J, Wang M (2002) Mater Sci Eng C 20:101

344. Knowles JC, Hastings GW, Ohta H, Niwa S, Boeree N (1992) Biomaterials 13:491

345. Luklinska ZB, Bonfield W (1997) J Mater Sci Mater Med 8:379

346. Chen DZ, Tang CY, Chan KC, Tsui CP, Yu PHF, Leung MCP, Uskokovic PS (2007) Compos Sci Technol 67:1617

347. Rai B, Noohom W, Kithva PH, Grøndahl L, Trau M (2008) Chem Mater 20:2802

348. Wang YW, Wu Q, Chen J, Chen GQ (2005) Biomaterials 26:899

349. Linhart W, Lehmann W, Siedler M, Peters F, Schilling AF, Schwarz K, Amling M, Rueger JM, Epple M (2006) J Mater Sci 41:4806. doi:10.1007/s10853-006-0023-x

350. Azevedo M, Reis RL, Claase M, Grijpma D, Feijen J (2003) J Mater Sci Mater Med 14:103

351. Choi D, Marra KG, Kumta PN (2004) Mater Res Bull 39:417

352. Hao J, Yuan M, Deng X (2003) J Appl Polym Sci 86:676

353. Walsh D, Furuzono T, Tanaka J (2001) Biomaterials 22:1205

354. Cerrai P, Guerra GD, Tricoli M, Krajewski A, Guicciardi S, Ravaglioli A, Maltinti S, Masetti G (1999) J Mater Sci Mater Med 10:283

355. Kim HW (2007) J Biomed Mater Res A 83A:169 
356. Kim HW, Knowles JC, Kim HE (2004) J Biomed Mater Res A 70A: 240

357. Guerra GD, Cerrai P, Tricoli M, Krajewski A, Ravaglioli A, Mazzocchi M, Barbani N (2006) J Mater Sci Mater Med 17:69

358. Causa F, Netti PA, Ambrosio L, Ciapetti G, Baldini N, Pagani S, Martini D, Giunti A (2006) J Biomed Mater Res A 76A:151

359. Thomas V, Jagani S, Johnson K, Jose MV, Dean DR, Vohra YK, Nyairo E (2006) J Nanosci Nanotechol 6:487

360. Dunn A, Campbell P, Marra KG (2001) J Mater Sci Mater Med 12:673

361. Calandrelli L, Immirzi B, Malinconico M, Volpe M, Oliva A, Ragione F (2000) Polymer 41:8027

362. Chen B, Sun K (2005) Polym Test 24:64

363. Ural E, Kesenci K, Fambri L, Migliaresi C, Piskin E (2000) Biomaterials 21:2147

364. Yoon BH, Kim HW, Lee SH, Bae CJ, Koh YH, Kong YM, Kim HE (2005) Biomaterials 26:2957

365. Kim HW, Lee EJ, Kim HE, Salih V, Knowles JC (2005) Biomaterials 26:4395

366. Busch S, Dolhaine H, DuChesne A, Heinz S, Hochrein O, Laeri F, Podebrad O, Vietze U, Weiland T, Kniep R (1999) Eur J Inorg Chem 1643

367. Busch S, Schwarz U, Kniep R (2003) Adv Funct Mater 13:189

368. Simon P, Carrillo-Cabrera W, Formanek P, Göbel C, Geiger D, Ramlau R, Tlatlik H, Buder J, Kniep R (2004) J Mater Chem $14: 2218$

369. Göbel C, Simon P, Buder J, Tlatlik H, Kniep R (2004) J Mater Chem 14:2225

370. Simon P, Schwarz U, Kniep R (2005) J Mater Chem 15:4992

371. Tlatlik H, Simon P, Kawska A, Zahn D, Kniep R (2006) Angew Chem Int Ed Engl 45:1905

372. Simon P, Zahn D, Lichte H, Kniep R (2006) Chem Int Ed Engl 45:1911

373. Kniep R, Simon P (2007) In: Naka K (ed) Crystallization and self-organization process. Topics in current chemistry, vol 270. Springer, Berlin, p 73

374. Kniep R, Simon P (2008) Angew Chem Int Ed Engl 47:1405

375. Handschel J, Wiesmann HP, Stratmann U, Kleinheinz J, Meyer U, Joos U (2002) Biomaterials 23:1689

376. Kikuchi M, Tanaka J, Koyama Y, Takakuda K (1999) J Biomed Mater Res 48:108

377. Yaszemski MJ, Payne RG, Hayes WC, Langer R, Mikos AG (1996) Biomaterials 17:2117

378. Wang M, Wang J, Ni J (2000) Biomechanics 192:741

379. Kikuchi M, Koyama Y, Takakuda K, Miyairi H, Shirahama N, Tanaka J (2002) J Biomed Mater Res 62:265

380. Ignatius AA, Augat P, Claes LE (2001) J Biomater Sci Polym Edn 12:185

381. Ignatius AA, Wolf S, Augat P, Claes LE (2001) J Biomed Mater Res 57:126

382. Kikuchi M, Tanaka J (2000) J Ceram Soc Jpn 108:642

383. Aunoble S, Clement D, Frayssinet P, Harmand MF, le Huec JC (2006) J Biomed Mater Res A 78A:416

384. Kikuchi M, Koyama Y, Yamada T, Imamura Y, Okada T, Shirahama N, Akita K, Takakuda K, Tanaka J (2004) Biomaterials 25:5979

385. Chen TM, Yao CH, Wang HJ, Chou GH, Lee TW, Lin FH (1998) Mater Chem Phys 55:44

386. Dong GC, Chen HM, Yao CH (2008) J Biomed Mater Res A 84A: 167

387. Yao CH, Liu BS, Hsu SH, Chen YS, Tsai CC (2004) J Biomed Mater Res A 69A:709

388. Lin FH, Yao CH, Sun JS, Liu HC, Huang CW (1998) Biomaterials $19: 905$

389. Eslaminejad MB, Mirzadeh H, Mohamadi Y, Nickmahzar A (2007) J Tissue Eng Regen Med 1:417
390. Takahashi Y, Yamamoto M, Tabata Y (2005) Biomaterials 26:3587

391. Bigi A, Cantelli I, Panzavolta S, Rubini K (2004) J Appl Biomat Biomech 2:81

392. Yang SH, Hsu CK, Wang KC, Hou SM, Lin FH (2005) J Biomed Mater Res B Appl Biomater 74B:468

393. Kato M, Namikawa T, Terai H, Hoshino M, Miyamoto S, Takaoka K (2006) Biomaterials 27:3927

394. Muramatsu K, Oba K, Mukai D, Hasegawa K, Masuda S, Yoshihara Y (2007) J Mater Sci Mater Med 18:513

395. Bleach NC, Tanner KE, Kellomäki M, Törmälä P (2001) J Mater Sci Mater Med 12:911

396. Liu L, Xiong Z, Yan YN, Hu YY, Zhang RJ, Wang SG (2007) J Biomed Mater Res A 82A:618

397. Zhang Y, Zhang MQ (2001) J Biomed Mater Res 55:304

398. Rai B, Teoh SH, Hutmacher DW, Cao T, Ho KH (2005) Biomaterials 26:3739

399. Rai B, Teoh SH, Ho KH, Hutmacher DW, Cao T, Chen F, Yacob K (2004) Biomaterials 25:5499

400. Lei Y, Rai B, Ho KH, Teoh SH (2007) Mater Sci Eng C 27:293

401. Miyai T, Ito A, Tamazawa G, Matsuno T, Sogo Y, Nakamura C, Yamazaki A, Satoh T (2008) Biomaterials 29:350

402. Takahashi Y, Yamamoto M, Tabata Y (2005) Biomaterials $26: 4856$

403. Ignatius AA, Betz O, Augat P, Claes LE (2001) J Biomed Mater Res Appl Biomater 58:701

404. Miao X, Lim WK, Huang X, Chen Y (2005) Mater Lett 59:4000

405. Brodie JC, Goldie E, Connel G, Merry J, Grant MH (2005) J Biomed Mater Res A 73A:409

406. Zhang LF, Sun R, Xu L, Du J, Xiong ZC, Chen HC, Xiong CD (2008) Mater Sci Eng C 28:141

407. Ignjatovic $\mathrm{N}$, Ninkov $\mathrm{P}$, Ajdukovic $\mathrm{Z}$, Konstantinovic $\mathrm{V}$, Uskokovic D (2005) Mater Sci Forum 494:519

408. Ignjatovic N, Ninkov P, Ajdukovic Z, Vasiljevic-Radovic D, Uskokovic D (2007) J Eur Ceram Soc 27:1589

409. Ignjatovic N, Ninkov P, Kojic V, Bokurov M, Srdic V, Krnojelac D, Selakovic S, Uskokovic D (2006) Microsc Res Tech 69:976

410. Ajdukovic Z, Ignjatovic N, Petrovic D, Uskokovic D (2007) J Biomater Appl 21:317

411. Kim HW, Knowles JC, Kim HE (2004) J Biomed Mater Res A 70A:467

412. Matsuda A, Ikoma T, Kobayashi H, Tanaka J (2004) Mater Sci Eng C 24:723

413. Tortet L, Gavarri JR, Nihoul G, Dianoux AJ (1997) Solid State Ionics 97:253

414. Tortet L, Gavarri JR, Musso J, Nihoul G, Sarychev AK (1998) J Solid State Chem 141:392

415. Park MS, Eanes ED, Antonucci JM, Skrtic D (1998) Dent Mater $14: 137$

416. Skrtic D, Antonucci JM, Eanes ED, Eichmiller FC, Schumacher GE (2000) J Biomed Mater Res 53:381

417. Skrtic D, Antonucci JM, Eanes ED, Eidelman N (2004) Biomaterials 25:1141

418. Skrtic D, Antonucci JM (2003) Biomaterials 24:2881

419. Gutierrez MC, Jobbágy M, Ferrer ML, del Monte F (2008) Chem Mater 20:11

420. Hakimimehr D, Liu DM, Troczynski T (2005) Biomaterials 26:7297

421. Perkin KK, Turner JL, Wooley KL, Mann S (2005) Nano Lett 5:1457

422. LeGeros RZ, Chohayeb A, Shulman A (1982) J Dent Res 61(Special issue):343

423. Brown WE, Chow LC (1983) J Dent Res 62(Special issue):672

424. Brown WE, Chow LC (1985) US Patent 4518430, 21 May

425. Tas AC (2007) Int J Appl Ceram Technol 4:152 
426. Driskell TD, Heller AL, Koenigs JF (1975) US Patent 3913229 , 21 October

427. Dorozhkin SV (2008) J Mater Sci 43:3028. doi:10.1007/ s10853-008-2527-z

428. Barrelet JA, Hofmann M, Grover LM, Gbureck U (2003) Adv Mater 15:2091

429. Bigi A, Bracci B, Panzavolta S (2004) Biomaterials 25:2893

430. Bigi A, Panzavolta S, Sturba L, Torricelli P, Fini M, Giardino R (2006) J Biomed Mater Res A 78A:739

431. Panzavolta S, Torricelli P, Sturba L, Bracci B, Giardino R, Bigi A (2008) J Biomed Mater Res A 84A:965

432. Rammelt S, Neumann M, Hanisch U, Reinstorf A, Pompe W, Zwipp H, Biewener A (2005) J Biomed Mater Res A 73A:284

433. Wang X, Ye J, Wang Y, Chen L (2007) J Am Ceram Soc 90:962

434. http://en.wikipedia.org/wiki/Concrete. Accessed June 2008

435. Kim SB, Kim YJ, Yoon TL, Park SA, Cho IH, Kim EJ, Kim IA, Shin JW (2004) Biomaterials 25:5715

436. Vallo CI, Montemartini PE, Fanovich MA, Lópes JMP, Cuadrado TR (1999) J Biomed Mater Res Appl Biomater 48:150

437. Sogal A, Hulbert SF (1992) Bioceramics 5:213

438. Harper EJ, Behiri JC, Bonfield W (1995) J Mater Sci Mater Med 6:799

439. Harper EJ, Braden M, Bonfield W (2001) J Mater Sci Mater Med 11:491

440. Moursi AM, Winnard AV, Winnard PL, Lannutti JJ, Seghi RR (2002) Biomaterials 23:133

441. Dalby MJ, Di Silvio L, Harper EJ, Bonfield W (2001) Biomaterials 22:1739

442. Dalby MJ, Di Silvio L, Harper EJ, Bonfield W (2002) Biomaterials 23:569

443. Itokawa $\mathrm{H}$, Hiraide T, Moriya M, Fujimoto M, Nagashima G, Suzuki R, Fujimoto T (2007) Biomaterials 28:4922

444. Cheang P, Khor KA (2003) Mater Sci Eng A 345:47

445. Dalby MJ, Di Silvio L, Harper EJ, Bonfield W (1999) J Mater Sci Mater Med 10:793

446. Deb S, Braden M, Bonfield W (1995) Biomaterials 16:1095

447. Borzacchiello A, Ambrosio L, Nicolais L, Harper EJ, Tanner KE, Bonfield W (1998) J Mater Sci Mater Med 9:835

448. Ohgaki M, Yamashita K (2003) J Am Ceram Soc 86:1440

449. del Real RP, Padilla S, Vallet-Regi M (2000) J Biomed Mater Res 52:1

450. Saito M, Maruoka A, Mori T, Sugano N, Hino K (1994) Biomaterials 15:156

451. Watson KE, Ten Huisen KS, Brown PW (1999) J Mater Sci Mater Med 10:205

452. Reed CS, Ten Huisen KS, Brown PW, Allcock HR (1996) Chem Mater 8:440

453. Peter SJ, Kim P, Yasko AW, Yaszemski MJ, Mikos AG (1999) J Biomed Mater Res 44:314

454. He S, Yaszemski MJ, Yasko AW, Engel PS, Mikos AG (2000) Biomaterials 21:2389

455. Ignjatovic N, Jovanovic J, Suljovrujic E, Uskokovic D (2003) Biomed Mater Eng 13:401

456. Fujishiro Y, Takahashi K, Sato T (2001) J Biomed Mater Res $54: 230$

457. Miyazaki K, Horibe T, Antonucci JM, Takagi S, Chow LC (1993) Dent Mater 9:41

458. Miyazaki K, Horibe T, Antonucci JM, Takagi S, Chow LC (1993) Dent Mater 9:46

459. Dos Santos LA, De Oliveira LC, Rigo ECS, Carrodeguas RG, Boschi AO, De Arruda ACF (1999) Bone 25:99S

460. Greish YE, Brown PW, Bender JD, Allcock HR, Lakshmi S, Laurencin CT (2007) J Am Ceram Soc 90:2728

461. Greish YE, Bender JD, Lakshmi S, Brown PW, Allcock HR, Laurencin CT (2006) J Biomed Mater Res A 77A:416
462. Greish YE, Bender JD, Lakshmi S, Brown PW, Allcock HR, Laurencin CT (2005) Biomaterials 26:1

463. Mickiewicz RA, Mayes AM, Knaack D (2002) J Biomed Mater Res 61:581

464. Carey LE, Xu HHK, Simon CG, Takagi S, Chow LC (2005) Biomaterials 26:5002

465. Miao X, Tan LP, Tan LS, Huang X (2007) Mater Sci Eng C 27:274

466. Lickorish D, Guan L, Davies JE (2007) Biomaterials 28:1495

467. Xu HHK, Simon CG (2005) Biomaterials 26:1337

468. Zhang L, Li Y, Zhou G, Lu GY, Zuo Y (2006) J Inorg Mater 21:1197

469. Ruhe PQ, Hedberg EL, Padron NT, Spauwen PHM, Jansen JA, Mikos AG (2005) J Biomed Mater Res A 74A:533

470. Guo DG, Sun HL, Xu KW, Han Y (2007) J Biomed Mater Res B Appl Biomater 82B:533

471. Habraken WJEM, Wolke JGC, Mikos AG, Jansen JA (2006) J Biomater Sci Polym Edn 17:1057

472. Ruhe PQ, Hedberg-Dirk EL, Padron NT, Spauwen PHM, Jansen JA, Mikos AG (2006) Tissue Eng 12:789

473. Ruhe PQ, Hedberg EL, Padron NT, Spauwen PHM, Jansen JA, Mikos AG (2003) J Bone Joint Surg (Am) 85A(Suppl 3):75

474. Ruhe PQ, Boerman OC, Russel FGM, Spauwen PHM, Mikos AG, Jansen JA (2005) J Control Release 106:162

475. Plachokova A, Link D, van den Dolder J, van den Beucken J, Jansen JA (2007) J Tissue Eng Regen Med 1:457

476. Webster TJ, Siegel RW, Bizios R (1999) Biomaterials 20:1221

477. Webster TJ, Ergun C, Doremus RH, Siegel RW, Bizios R (2000) J Biomat Med Res 51:475

478. Webster TJ, Ergun C, Doremus RH, Siegel RW, Bizios R (2000) Biomaterials 21:1803

479. Li G, Huang J, Li Y, Zhang R, Deng B, Zhang J, Aoki H (2007) Biomed Mater Eng 17:321

480. Tadic D, Peters F, Epple M (2002) Biomaterials 23:2553

481. Xu HHK, Sun L, Weir MD, Antonucci JM, Takagi S, Chow LC, Peltz M (2006) J Dent Res 85:722

482. Xu HHK, Weir MD, Sun L, Takagi S, Chow LC (2007) J Dent Res $86: 378$

483. Xu HHK, Weir MD, Sun L (2007) Dent Mater 23:1482

484. Xu HHK, Sun L, Weir MD, Takagi S, Chow LC, Hockey B (2007) J Biomed Mater Res B Appl Biomater 81B:116

485. Deng XM, Hao JY, Wang CS (2001) Biomaterials 22:2867

486. Hong ZK, Zhang PB, He CL, Qiu XY, Liu AX, Chen L, Chen X, Jing X (2005) Biomaterials 26:6296

487. Deng C, Weng J, Cheng QY, Zhou SB, Lu X, Wan JX, Qu SX, Feng B, Li XH (2007) Curr Appl Phys 7:679

488. Deng C, Weng J, Lu X, Zhou SB, Wan JX, Qu SX, Feng B, Li XH, Cheng QY (2008) Mater Lett 62:607

489. Kothapalli CR, Shaw MT, Wei M (2005) Acta Biomater 1:653

490. Hong Z, Qiu X, Sun J, Deng M, Chen X, Jing X (2004) Polymer 45:6699

491. Xiao Y, Li D, Fan H, Li X, Gu Z, Zhang X (2007) Mater Lett 61:59

492. Qiu X, Han Y, Zhuang X, Chen X, Li Y, Jing X (2007) J Nanoparticle Res 9:901

493. Kim SS, Park MS, Jeon Q, Choi CY, Kim BS (2006) Biomaterials $27: 1399$

494. Hong Z, Zhang P, Liu A, Chen L, Chen X, Jing X (2007) J Biomed Mater Res A 81A:515

495. Huang YX, Ren J, Chen C, Ren TB, Zhou XY (2008) J Biomater Appl 22:409

496. Du C, Cui FZ, Zhu XD, de Groot K (1999) J Biomed Mater Res 44:407

497. Wang RZ, Cui FZ, Lu HB, Wen HB, Ma CL, Li HD (1995) J Mater Sci Lett 14:490 
498. Du C, Cui FZ, Feng QL, Zhu XD, de Groot K (1998) J Biomed Mater Res 42:540

499. Kikuchi M, Itoh S, Ichinose S, Shinomiya K, Tanaka J (2001) Biomaterials 22:1705

500. Kikuchi M, Matsumoto HN, Yamada T, Koyama Y, Takakuda K, Tanaka J (2004) Biomaterials 25:63

501. Lynn AK, Nakamura T, Patel N, Porter AE, Renouf AC, Laity PR, Best SM, Cameron RE, Shimizu Y, Bonfield W (2005) J Biomed Mater Res A 74A:447

502. Chang MC, Tanaka J (2002) Biomaterials 23:4811

503. Chang MC, Tanaka J (2002) Biomaterials 23:3879

504. Murugan R, Ramakrishna S (2006) Appl Phys Lett 88:193124

505. Wang Y, Yang C, Chen X, Zhao N (2006) Adv Eng Mater 8:97

506. Thomas V, Dean DR, Jose MV, Mathew B, Chowdhury S, Vohra YK (2007) Biomacromolecules 8:631

507. Fukui N, Sato T, Kuboki Y, Aoki H (2008) Biomed Mater Eng 18:25

508. Liao SS, Tamura K, Zhu Y, Wang W, Uo M, Akasaka T, Cui FZ, Watari F (2006) J Biomed Mater Res A 76A:820

509. Liao SS, Cui FZ, Zhu Y (2004) J Bioact Compat Polym 19:117

510. Liao SS, Cui FZ, Zhang W, Feng QL (2004) J Biomed Mater Res B Appl Biomater 69B:158

511. Liao SS, Cui FZ (2004) Tissue Eng 10:73

512. Liao SS, Wang W, Uo M, Ohkawa S, Akasaka T, Tamura K, Cui FZ, Watari F (2005) Biomaterials 26:7564-7571

513. Li X, Feng Q, Cui FZ (2006) Mater Sci Eng C 26:716

514. Zhou DS, Zhao KB, Li Y, Cui FZ, Lee IS (2006) J Bioact Compat Polym 21:373

515. Zhang C, Hu YY, Cui FZ, Zhang SM, Ruan DK (2006) Biomed Mater 1:56

516. Liao S, Watari F, Zhu Y, Uo M, Akasaka T, Wang W, Xu G, Cui F (2007) Dent Mater 23:1120

517. Degirmenbasi N, Kalyon DM, Birinci E (2006) Colloids Surf B Biointerfaces 48:42

518. Zhang SM, Cui FZ, Liao SS, Zhu Y, Han L (2003) J Mater Sci Mater Med 14:641

519. Sotome S, Uemura T, Kikuchi M, Chen J, Itoh S, Tanaka J, Tateishi T, Shinomiya K (2004) Mater Sci Eng C 24:341

520. Chang MC, Ko CC, Douglas WH (2003) Biomaterials 24:3087

521. Kim HW, Kim HE, Vehid S (2005) Biomaterials 26:5221

522. Chang MC, Ikoma T, Tanaka J (2004) J Mater Sci 39:5547. doi: 10.1023/B:JMSC.0000039284.70028.fa

523. Teng S, Shi J, Peng B, Chen L (2006) Compos Sci Technol 66:1532

524. Chang MC, Ko CC, Douglas WH (2003) Biomaterials 24:2853

525. Mobini S, Javadpour J, Hosseinalipour M, Ghazi-Khansari M, Khavandi A, Rezaie HR (2008) Adv Appl Ceram 107:4

526. Wang XJ, Li Y, Wei J, de Groot K (2002) Biomaterials 23:4787

527. Lewandrowski KU, Bondre SP, Wise DL, Trantolo DJ (2003) Biomed Mater Eng 13:115

528. Wei J, Li Y, He Y (2005) J Mater Sci 40:793. doi: 10.1007/s10853-005-6326-5

529. Wei J, Li Y, Chen W, Zuo Y (2003) J Mater Sci 38:3303. doi: 10.1023/A:1025194122977

530. Wei J, Li Y (2004) Eur Polym J 40:509

531. Wang H, Li Y, Zuo Y, Li J, Ma S, Cheng L (2007) Biomaterials 28:3338

532. Sender C, Dantras E, Dantras-Laffont L, Lacoste MH, Dandurand J, Mauzac M, Lacout JL, Lavergne C, Demont P, Bernes A, Lacabanne C (2007) J Biomed Mater Res B Appl Biomater 83B:628

533. Yang K, Wei J, Wang CY, Li Y (2007) Chin Sci Bull 52:267

534. Zhang X, Li Y, Lv GY, Zuo Y, Mu YH (2006) Polym Degrad Stab 91:1202

535. Huang M, Feng J, Wang J, Zhang X, Li Y, Yan Y (2003) J Mater Sci Mater Med 14:655
536. Zhang X, Li Y, Zuo Y, Lv GY, Mu YH, Li H (2007) Composites A 38:843

537. Lan W, Li Y, Yi Z, Li Z, Mu YH, Jimei H (2006) Mater Sci Forum 510-511:938

538. Zhang L, Li Y, Wang X, Wei J, Peng X (2005) J Mater Sci 40:107. doi:10.1007/s10853-005-5693-2

539. Zhang X, Li Y, Lv GY, Zuo Y, Mu YH, Lan W (2005) Funct Mater 36:896

540. Yusong P, Dangsheng X, Xiaolin C (2007) J Mater Sci 42:5129. doi:10.1007/s10853-006-1264-4

541. Xu F, Li Y, Wang X, Wei J, Yang A (2004) J Mater Sci 39:5669. doi:10.1023/B:JMSC.0000040074.64787.b3

542. Wang HS, Wang GX, Pan QX (2005) Electroanalysis 17:1854

543. Pramanik N, Mohapatra S, Pramanik P, Bhargava P (2007) J Am Ceram Soc 90:369

544. Pramanik N, Bhargava P, Alam S, Pramanik P (2006) Polym Compos 27:633

545. Zhang L, Li Y, Yang A, Peng X, Wang X, Zhang X (2005) J Mater Sci Mater Med 16:213

546. Zhang YF, Cheng XR, Chen Y, Shi B, Chen XH, Xu DX, Ke J (2007) J Biomater Appl 21:333

547. Kong L, Gao Y, Lu G, Gong Y, Zhao N, Zhang X (2006) Eur Polym J 42:3171

548. Lu XY, Wang XH, Qu SX, Weng J (2008) J Inorg Mater 23:332

549. Zhou G, Li Y, Zhang L, Li H, Wang M, Cheng L, Wang Y, Wang H, Shi P (2007) J Mater Sci 42:2591. doi: 10.1007/s10853-006-1337-4

550. Huang J, Lin YW, Fu XW, Best SM, Brooks RA, Rushton N, Bonfield W (2007) J Mater Sci Mater Med 18:2151

551. Lee HJ, Choi HW, Kim KJ, Lee SC (2006) Chem Mater 18:5111

552. Lee HJ, Kim SE, Choi HW, Kim CW, Kim KJ, Lee SC (2007) Eur Polym J 43:1602

553. Pang P, Li W, Liu Y (2007) Rare Met 26:118

554. Li W, Pang P, Liu Y (2007) Trans Nonferrous Met Soc China 17(Special Issue):S1148

555. Hao JY, Liu Y, Zhou S, Li Z, Deng X (2003) Biomaterials 24:1531

556. Yan Y, Li Y, Zheng Y, Yi Z, Wei J, Xia C, Chen Y (2003) Eur Polym J 39:411

557. Bhattacharyya S, Nair LS, Singh A, Krogman NR, Bender J, Greish YE, Brown PW, Allcock HR, Laurencin CT (2005) MRS Symp Proc 845:91

558. Sinha A, Nayar S, Agrawal A, Bhattacharyya D, Ramachandrarao P (2003) J Am Ceram Soc 86:357

559. Zuo Y, Li Y, Wei J, Han J, Xu F (2004) Funct Mater 35:513

560. Zhou G, Li Y, Zhang L, Zuo Y, Jansen JA (2007) J Biomed Mater Res A 83A:931

561. Daniel-da-Silva AL, Lopes AB, Gil AM, Correia RN (2007) J Mater Sci 42:8581. doi:10.1007/s10853-007-1851-z

562. Furuzono T, Kishida A, Tanaka J (2004) J Mater Sci Mater Med $15: 19$

563. Korematsu A, Furuzono T, Yasuda S, Tanaka J, Kishida A (2004) J Mater Sci 39:3221. doi:10.1023/B:JMSC.00000 25865.44900.74

564. Korematsu A, Furuzono T, Yasuda S, Tanaka J, Kishida A (2005) J Mater Sci Mater Med 16:67

565. Yang K, Wang C, Wei J (2007) Composites B 38:306

566. Jiang L, Li Y, Zhang L, Wang XJ (2008) J Inorg Mater 23:135

567. Jiang L, Li Y, Zhang L, Liao J (2008) J Mater Sci Mater Med 19:981

568. Liou SC, Chen SY, Liu DM (2004) J Mater Sci Mater Med 15:1261

569. Liu L, Liu J, Wang M, Min S, Cai Y, Zhu L, Yao J (2008) J Biomater Sci Polym Edn 19:325

570. Ren YJ, Sun XD, Cui FZ, Wei YT, Cheng ZJ, Kong XD (2007) J Bioact Compat Polym 22:465 
571. Mikołajczyk T, Rabiej S, Bogun M (2006) J Appl Polym Sci 101:760

572. Wei J, Li Y, Lau KT (2007) Composites B 38:301

573. Sundaraseelan J, Sastry TP (2007) J Biomed Nanotechnol 3:401

574. Leeuwenburgh SCG, Jansen JA, Mikos AG (2007) J Biomater Sci Polym Ed 18:1547

575. Sun TS, Guan K, Shi SS, Zhu B, Zheng YJ, Cui FZ, Zhang W, Liao SS (2004) Chin J Traumatol 7:18

576. Itoh S, Kikuehi M, Koyama Y, Takakuda K, Shinomiya K, Tanaka J (2004) Cell Transplant 13:451

577. Hu Q, Li BQ, Wang M, Shen JC (2004) Biomaterials 25:779

578. Wei G, Ma PX (2004) Biomaterials 25:4749

579. Liou SC, Chen SY, Liu DM (2003) Biomaterials 24:3981

580. Liou SC, Chen SY, Liu DM (2005) J Biomed Mater Res B Appl Biomater 73B:117

581. Huang J, Best SM, Bonfield W, Brooks RA, Rushton N, Jayasinghe SN, Edirisinghe MJ (2004) J Mater Sci Mater Med $15: 441$

582. Kong L, Gao Y, Cao W, Gong Y, Zhao N, Zhang X (2005) J Biomed Mater Res A 75A:275

583. Christenson EM, Anseth KS, van den Beucken JJJP, Chan CK, Ercan B, Jansen JA, Laurencin CT, Li WJ, Murugan R, Nair LS, Ramakrishna S, Tuan RS, Webster TJ, Mikos AG (2007) J Orthop Res 25:11

584. Nimni ME (ed) (1988) Collagen. CRC Press, Boca Raton, FL

585. Olmo N, Turnay J, Herrera JI, Gavilanes JG, Lizarbe MA (1996) J Biomed Mater Res 30:77

586. Xie J, Baumann MJ, McCabe LR (2004) J Biomed Mater Res A 71A: 108

587. Tcacencu I, Wendel M (2008) J Mater Sci Mater Med 19:2015

588. Yamauchi K, Goda T, Takeuchi N, Einaga H, Tanabe T (2004) Biomaterials 25:5481

589. Du C, Cui FZ, Zhang W, Feng QL, Zhu XD, de Groot K (2000) J Biomed Mater Res 50:518

590. Hellmich C, Ulm FJ (2002) J Biomech 35:1199

591. Boskey AL (1989) J Phys Chem 93:1628

592. Mathers NJ, Czernuszka JT (1991) J Mater Sci Lett 10:992

593. Sukhodub LF, Moseke C, Sukhodub LB, Sulkio-Cleff B, Maleev VYa, Semenov MA, Bereznyak EG, Bolbukh TV (2004) J Mol Struct 704:53

594. Roveri N, Falini G, Sidoti MC, Tampieri A, Landi E, Sandri M, Parma B (2003) Mater Sci Eng C 23:441

595. Tampieri A, Celotti G, Landi E (2005) Anal Bioanal Chem 381:568

596. Tampieri A, Celotti G, Landi E, Sandri M, Roveri N, Falini G (2003) J Biomed Mater Res A 67A:618

597. Mehlisch DR, Taylor TD, Leibold DG, Hiatt R, Waite DE, Waite PD, Laskin DM, Smith ST, Koretz MM (1987) J Oral Maxillofac Surg 45:408

598. Okazaki M, Ohmae H, Takahashi J, Kimura H, Sakuda M (1990) Biomaterials 11:568

599. Ten Huisen KS, Martin RI, Klimkiewicz M, Brown PW (1995) J Biomed Mater Res 29:803

600. Marouf HA, Quayle AA, Sloan P (1990) Int J Oral Maxillofac Implants 5:148

601. Zerwekh JE, Kourosh S, Scheinberg R, Kitano T, Edwards ML, Shin D, Selby DK (1992) J Orthop Res 10:565

602. Clarke KI, Graves SE, Wong ATC, Triffit JT, Francis MJO, Czernuszka JT (1993) J Mater Sci Mater Med 4:107

603. Rovira A, Bareille R, Lopez L, Rouasis F, Bordenave L, Rey C, Rabaud M (1993) J Mater Sci Mater Med 4:372

604. Zhang QQ, Ren L, Wang C, Liu LR, Wen XJ, Liu YH, Zhang XD (1996) Artif Cells Blood Substit Immobil Biotechnol 24:693

605. Bakoš D, Soldán M, Hernández-Fuentes I (1999) Biomaterials 20:191
606. John A, Hong L, Ikada Y, Tabata Y (2001) J Biomater Sci Polym Ed 12:689

607. 1toh S, Kikuchi M, Takakuda K, Koyama Y, Matsumoto HN, Ichinose S, Tanaka J, Kawauchi T, Shinomiya K (2001) J Biomed Mater Res 54:445

608. Shinomiya K, Itoh S, Kawauchi T, Kikuchi M, Tanaka J (2001) Tissue Eng Therap Use 5:165

609. Uskokovic V, Ignjatovic N, Petranovic N (2002) Mater Sci Forum 413:269

610. Wahl DA, Czernuszka JT (2006) Eur Cells Mater 11:43

611. Ishikawa H, Koshino T, Takeuchi R, Saito T (2001) Biomaterials 22:1689

612. Sachlos E, Gotora D, Czernuszka JT (2006) Tissue Eng 12:2479

613. Venugopal J, Ramakrishna S, Low S, Choon AT, Kumar TSS (2008) J Mater Sci Mater Med 19:2039

614. Teng SH, Lee EJ, Park CS, Choi WY, Shin DS, Kim HE (2008) J Mater Sci Mater Med 19:2453

615. Song JH, Kim HE, Kim HW (2007) J Biomed Mater Res B Appl Biomater 83B:248

616. Mittelmeier H, Nizzard M (1982) In: Hackenbroch MH, Refior HJ, Jäger MG (eds) Osteogenese und Knochenwachstum. Thieme, Stuttgart, Germany

617. Serre CM, Papillard M, Chavassieux P, Boivin G (1993) Biomaterials 14:97

618. Scabbia A, Trombelli L (2004) J Clin Periodontol 31:348

619. Yamasaki Y, Yoshida Y, Okazaki M, Shimazu A, Kubo T, Akagawa Y, Uchida T (2003) Biomaterials 24:4913

620. Wang X, Grogan SP, Rieser F, Winkelmann V, Maquet V, Berge ML, Mainil-Varlet P (2004) Biomaterials 25:3681

621. Chang MC, Ikonama T, Kikuchi M, Tanaka J (2002) J Mater Sci Mater Med 13:993

622. Iijima M, Moriwaki Y, Kuboki Y (1996) Connect Tissue Res 32:519

623. Miyamoto $\mathrm{Y}$, Ishikawa $\mathrm{K}$, Takechi $\mathrm{M}$, Toh $\mathrm{T}$, Yuasa $\mathrm{T}$, Nagayama M, Suzuki K (1998) Biomaterials 19:707

624. Iijima M, Moriwaki Y, Kuboki Y (1994) J Cryst Growth 137:553

625. Iijima M, Iijima K, Moriwaki Y, Kuboki Y (1994) J Cryst Growth 140:91

626. Lawson AC, Czernuszka JT (1998) Proc Inst Mech Eng H 212:413

627. Itoh S, Kikuchi M, Takakuda K, Nagaoka K, Koyama Y, Tanaka J, Shinomiya K (2002) J Biomed Mater Res 63:507

628. Kikuchi M, Ikoma T, Itoh S, Matsumoto HN, Koyama Y, Takakuda K, Shinomiya K, Tanaka J (2004) Compos Sci Technol 64:819

629. Yang XB, Bhataagar RS, Li S, Oreffo RO (2004) Tissue Eng 14:1148

630. Doi Y, Horiguchi T, Moriwaki Y, Kitago H, Kajimoto T, Iwayama Y (1996) J Biomed Mater Res 31:43

631. Bradt JH, Mertig M, Teresiak A, Pompe W (1999) Chem Mater 11:2694

632. Scharnweber D, Born R, Flade K, Roessler S, Stoelzel M, Worch H (2004) Biomaterials 25:2371

633. Li X, Chang J (2008) J Biomed Mater Res A 85A:293

634. Mai R, Reinstorf A, Pilling E, Hlawitschka M, Jung R, Gelinsky M, Schneider M, Loukota R, Pompe W, Eckelt U, Stadlinger B (2008) Oral Surg Oral Med Oral Pathol Oral Radiol Endod 105:e9

635. Young SW, Andrews WA, Muller H, Constantz B (1991) Invest Radiol 2:470

636. Rovira A, Amedee J, Bareille R, Radaud M (1996) Biomaterials $17: 1535$

637. Kazim M, Katowitz JA, Fallon M, Piest KL (1992) Ophthal Plast Reconstr Surg 8:94

638. Hirota K, Nishihara K, Tanaka H (1993) Biomed Mater Eng $3: 147$ 
639. Zahn D, Hochrein O, Kawska A, Brickmann J, Kniep R (2007) J Mater Sci 42:8966. doi:10.1007/s10853-007-1586-x

640. Silva CC, Pinheiro AG, Figueiro SD, Goes JC, Sasaki JM, Miranda MAR, Sombra ASB (2002) J Mater Sci 37:2061. doi: 10.1023/A: 1015219800490

641. Yunoki S, Ikoma T, Tsuchiya A, Monkawa A, Ohta K, Sotome S, Shinomiya K, Tanaka J (2007) J Biomed Mater Res B Appl Biomater 80B:166

642. Chapman MW, Bucholz R, Cornell C (1997) J Bone Joint Surg Am 79A:495

643. Rodrigues CVM, Serricella P, Linhares ABR, Guerdes RM, Borojevic R, Rossi MA, Duarte MEL, Farina M (2003) Biomaterials $24: 4987$

644. Lickorish D, Ramshaw JAM, Werkmeister JA, Glattauer V, Howlett CR (2004) J Biomed Mater Res A 68A:19

645. Hsu FY, Chueh SC, Wang JY (1999) Biomaterials 20:1931

646. Wu TJ, Huang HH, Lan CW, Lin CH, Hsu FY, Wang YJ (2004) Biomaterials 25:651

647. Liao SS, Watari F, Uo M, Ohkawa S, Tamura K, Wang W, Cui FZ (2005) J Biomed Mater Res B Appl Biomater 74B:817

648. Yokoyama A, Gelinsky M, Kawasaki T et al (2005) J Biomed Mater Res B Appl Biomater 75B:464

649. Zou C, Weng W, Deng XJ, Cheng K, Liu X, Du P, Shen G, Han G (2005) Biomaterials 26:5276

650. Martins VCA, Goissis G (2000) Artif Organs 24:224

651. Gotterbarm T, Richter W, Jung M, Berardi Vilei S, MainilVarlet P, Yamashita T, Breusch SJ (2006) Biomaterials 27:3387

652. Martins VC, Goissis G, Ribeiro AC, Marcantonio E Jr, Bet MR (1998) Artif Organs 22:215

653. Jayaraman M, Subramanian MV (2008) Med Sci Monit 8:BR481

654. Ikeda H, Yamaza T, Yoshinari M, Ohsaki Y, Ayukawa Y, Kido MA, Inoue T, Shimono M, Koyano K, Tanaka T (2000) J Periodontol 71:961

655. Uchida M, Oyane A, Kim HM, Kokubo T, Ito A (2004) Adv Mater 16:1071

656. Oyane A, Uchida M, Ito A (2005) J Biomed Mater Res A $72 \mathrm{~A}: 168$

657. Oyane A, Uchida M, Onuma K, Ito A (2006) Biomaterials 27:167

658. Liu WB, Qu SX, Shen R, Jiang CX, Li XH, Feng B, Weng J (2006) J Mater Sci 41:1851. doi:10.1007/s10853-005-3184-0

659. Yaylaoglu MB, Korkusuz P, Ors U, Korkusuz F, Hasirci V (1999) Biomaterials 20:711

660. Kim HW, Song JH, Kim HE (2005) Adv Funct Mater 15:1988

661. Sivakumar M, Panduranga Rao K (2002) Biomaterials 23:3175

662. Kim HW, Knowles JC, Kim HE (2005) J Biomed Mater Res B Appl Biomater 74B:686

663. Yin YJ, Zhao F, Song XF, Yao KD, Lu WW, Leong JC (2000) J Appl Polym Sci 77:2929

664. Kim HW, Yoon BH, Kim HE (2005) J Mater Sci Mater Med 16:1105

665. Hillig WB, Choi Y, Murtha S, Natravali N, Ajayan P (2008) J Mater Sci Mater Med 19:11

666. Chang MC, Douglas WH, Tanaka J (2006) J Mater Sci Mater Med 17:387

667. Chang MC, Douglas WH (2007) J Mater Sci Mater Med 18:2045

668. Teng S, Chen L, Guo Y, Shi J (2007) J Inorg Biochem 101:686

669. Zhao F, Grayson WL, Ma T, Bunnell B, Lu WW (2006) Biomaterials 27:1859

670. Lin HR, Yeh YJ (2004) J Biomed Mater Res B Appl Biomater 71B:52

671. Gelinsky M, Eckert M, Despang F (2007) Int J Mater Res (Z Metallkd) 98:749
672. Yamaguchi I, Tokuchi K, Fukuzaki H, Koyama Y, Takakuda K, Monma H, Tanaka J (2001) J Biomed Mater Res 55:20

673. Zhao F, Yin YJ, Lu WW, Leong JC, Zhang WJ, Zhang JY, Zhang MF, Yao KD (2002) Biomaterials 23:3227

674. Shen X, Tong H, Jiang T, Zhu Z, Wan P, Hu J (2007) Compos Sci Technol 67:2238

675. Murugan R, Ramakrishna S (2004) Biomaterials 25:3829

676. Yoshida A, Miyazaki T, Ishida E, Ashizuka M (2004) Mater Trans 45:994

677. Zhang Y, Ni M, Zhang MQ, Ratner B (2003) Tissue Eng 9:337

678. Zhang Y, Zhang MQ (2001) J Non-Cryst Solids 282:159

679. Zhang Y, Zhang MQ (2002) J Biomed Mater Res 62:378

680. Tachaboonyakiat W, Ogomi D, Serizawa T, Akashi M (2006) J Bioact Compat Polym 21:579

681. Sreedhar B, Aparna Y, Sairam M, Hebalkar N (2007) J Appl Polym Sci 105:928

682. Rusu VM, Ng CH, Wilke M, Tiersch B, Fratzl P, Peter MG (2005) Biomaterials 26:5414

683. Pinheiro AG, Pereira FFM, Santos MRP, Freire FNA, Góes JC, Sombra ASB (2007) Polym Compos 28:582

684. Wan ACA, Khor E, Hastings GW (1998) J Biomed Mater Res $41: 541$

685. Wan ACA, Khor E, Hastings GW (1997) J Biomed Mater Res 38:235

686. Geçer A, Yldz N, Erol M, Çalml A (2008) Polymer Composites 29:84

687. Dong H, Ye JD, Wang XP, Yang JJ (2007) J Inorg Mater 22:1007

688. Wang X, Ma J, Feng Q, Cui FZ (2002) Biomaterials 23:4591

689. Wen HB, de Wijn JR, van Blitterswijk CA, de Groot K (1999) J Biomed Mater Res 46:245

690. Liu TY, Chen SY, Liu DM, Liou SC (2005) J Controlled Release 107:112

691. Liu Y, Hunziker E, Randall N, de Groot K, Layrolle P (2003) Biomaterials 24:65

692. Dorozhkin SV, Dorozhkina EI (2003) Colloids Surf A Physiochem Eng Asp 215:191

693. Fu HH, Hu YH, McNelis T, Hollinger JO (2005) J Biomed Mater Res A 74A:40

694. Bisht S, Bhakta G, Mitra S, Maitra A (2005) Int J Pharm 288:157

695. Kakizawa Y, Miyata K, Furukawa S, Kataoka K (2004) Adv Mater 16:699

696. Singh R, Saxena A, Mozumdar S (2008) Int J Appl Ceram Technol 5:1

697. Taguchi T, Kishida A, Akashi M (1998) Chem Lett 8:711

698. Tachaboonyakiat W, Serizawa T, Akashi M (2001) Polym J 33:177

699. Schnepp ZAC, Gonzalez-McQuire R, Mann S (2006) Adv Mater 18:1869

700. Bigi A, Boanini E, Gazzano M, Kojdecki MA, Rubini K (2004) J Mater Chem 14:274

701. Bigi A, Boanini E, Gazzano M, Rubini K, Torricelli P (2004) Biomed Mater Eng 14:573

702. Boanini E, Fini M, Gazzano M, Bigi A (2006) Eur J Inorg Chem 4821

703. Boanini E, Torricelli P, Gazzano M, Giardino R, Bigi A (2006) Biomaterials 27:4428

704. Sánchez-Salcedo S, Nieto A, Vallet-Regi M (2005) Chem Eng J 137:62

705. Román J, Cabañas MV, Peña J, Doadrio JC, Vallet-Regi M (2008) J Biomed Mater Res A 84A:99

706. Abiraman S, Varma H, Umashankar P, John A (2002) Biomaterials 23:3023

707. Bagot d'Arc M, Daculsi G (2003) J Mater Sci Mater Med $14: 229$ 
708. Bonucci E, Marini E, Valdinucci F, Fortunato G (1997) Eur J Oral Sci 105:557

709. Fortunato G, Marini E, Valdinucci F, Bonucci E (1997) J Cranio Maxillofac Surg 25:124

710. Jegoux F, Goyenvalle E, Bagot d'Arc M, Aguado E, Daculsi G (2005) Arch Orthop Trauma Surg 125:153

711. Le Guehennec L, Goyenvalle E, Aguado E, Pilet P, Bagot d'Arc M, Daculsi G (2005) J Mater Sci Mater Med 16:29

712. Wittkampf A (1989) J Cranio Maxillofac Surg 17:179

713. Le Nihouannen D, Guehennec LL, Rouillon T, Pilet P, Bilban M, Layrolle P, Daculsi G (2006) Biomaterials 27:2716

714. Le Nihouannen D, Saffarzadeh A, Aguado E, Goyenvalle E, Gauthier O, Moreau F, Pilet P, Spaethe R, Daculsi G, Layrolle P (2007) J Mater Sci Mater Med 18:225

715. Le Guehennec L, Goyenvalle E, Aguado E, Pilet P, Spaethe R, Daculsi G (2007) J Mater Sci Mater Med 18:1489

716. Le Nihouannen D, Goyenvalle E, Aguado E, Pilet P, Bilban M, Daculsi G, Layrolle P (2007) J Biomed Mater Res A 81A:399

717. Le Nihouannen D, Saffarzadeh A, Gauthier O, Moreau F, Pilet P, Spaethe R, Layrolle P, Daculsi G (2008) J Mater Sci Mater Med 19:667

718. Yoh R, Matsumoto T, Sasaki JI, Sohmura T (2008) J Biomed Mater Res A 87(1):222

719. Boanini E, Torricelli P, Gazzano M, Giardino R, Bigi A (2008) Biomaterials 29:790

720. Li L, Wei KM, Lin F, Kong XD, Yao JM (2008) J Mater Sci Mater Med 19:577

721. Wang L, Nemoto R, Senna M (2004) J Mater Sci Mater Med 15:261

722. Wang L, Nemoto R, Senna M (2002) J Nanoparticle Res 4:535

723. Wang L, Nemoto R, Senna M (2004) J Nanoparticle Res 6:91

724. Nemoto R, Wang L, Ikoma T, Tanaka J, Senna M (2004) J Nanoparticle Res 6:259

725. Wang L, Li CZ, Senna M (2007) J Nanoparticle Res 9:919

726. Wang L, Li CZ (2007) Carbohydr Polym 68:740

727. Sogo Y, Ito A, Matsuno T, Oyane A, Tamazawa G, Satoh T, Yamazaki A, Uchimura E, Ohno T (2007) Biomed Mater 2:116

728. Cross KJ, Huq NL, Palamara JE, Perich JW, Reynolds EC (2005) J Biol Chem 280:15362

729. Shchukin DG, Sukhorukov GB, Möhwald H (2003) Chem Mater 15:3947

730. Weiss P, Gauthier O, Bouler JM, Grimandi G, Daculsi G (1999) Bone 25(2 Suppl):67S

731. Daculsi G, Weiss P, Bouler JM, Gauthier O, Millot F, Aguado E (1999) Bone 25(2 Suppl):59S

732. Turczyn R, Weiss P, Lapkowski M, Daculsi G (2000) J Biomater Sci Polym Ed 11:217

733. Bennett S, Connolly K, Lee DR, Jiang Y, Buck D, Hollinger JO, Gruskin EA (1996) Bone 19:101S

734. Daculsi G, Rohanizadeh R, Weiss P, Bouler JM (2000) J Biomed Mater Res 50:1

735. Grimande G, Weiss P, Millot F, Daculsi G (1998) J Biomed Mater Res 39:660

736. Weiss P, Lapkowski M, LeGeros RZ, Bouler JM, Jean A, Daculsi G (1997) J Mater Sci Mater Med 8:621

737. Weiss P, Bohic S, Lapkowski M, Daculsi G (1998) J Biomed Mater Res 41:167

738. Schmitt M, Weiss P, Bourges X, del Valle GA, Daculsi G (2002) Biomaterials 23:2789

739. Gauthier O, Müller R, von Stechow D, Lamy B, Weiss P, Bouler JM, Aguado E, Daculsi G (2005) Biomaterials 26:5444

740. Weiss P, Layrolle P, Clergeau LP, Enckel B, Pilet P, Amouriq Y, Daculsi G, Giumelli B (2007) Biomaterials 28:3295

741. Trojani C, Boukhechba F, Scimeca JC, Vandenbos F, Michiels JF, Daculsi G, Boileau P, Weiss P, Carle GF, Rochet N (2006) Biomaterials 27:3256
742. Iooss P, Le Ray AM, Grimandi G, Daculsi G, Merle C (2001) Biomaterials 22:2785

743. Evis Z, Ergun C, Doremus RH (2005) J Mater Sci 40:1127. doi: 10.1007/s10853-005-6928-y

744. Rao RR, Kannan TS (2002) Mater Sci Eng C 20:187

745. Mansur C, Pope M, Pascucci MR, Shivkumar S (1998) Ceram Int 24:77

746. Kim HW, Kim HE, Salih V, Knowles JC (2004) J Biomed Mater Res A 68A:522

747. Milella E, Cosentino F, Licciulli A, Massaro C (2001) Biomaterials $22: 1425$

748. Goller G, Demirkiran H, Oktar FN, Demirkesen E (2003) Ceram Int 29:721

749. Tancred DC, Carr AJ, McCormack BA (2001) J Mater Sci Mater Med 12:81

750. Lopes MA, Silva RF, Monteiro FJ, Santos JD (2000) Biomaterials $21: 749$

751. Juang HY, Hon MH (1994) Mater Sci Eng C 2:77

752. Li J, Forbreg S, Hermansson L (1991) Biomaterials 12:438

753. Noma T, Shoji N, Wada S, Suzuki T (1993) J Ceram Soc Japan 101:923

754. Gautier S, Champion E, Bernache-Assollant D (1999) J Mater Sci Mater Med 10:533

755. Fang Y, Roy DM, Cheng J, Roy R, Agrawal DK (1993) Ceram Trans 36:397

756. Park K, Vasilosa T (1997) Mater Lett 32:229

757. de With G, Corbijn AT (1989) J Mater Sci 24:3411. doi: 10.1007/BF01139073

758. Ruys AJ, Simpson SA, Sorrell CC (1994) J Mater Sci Lett $13: 1323$

759. Miao X, Ruys AJ, Milthorpe BK (2001) J Mater Sci 36:3323. doi:10.1023/A:1017915226015

760. Li J, Liao H, Hermansson L (1996) Biomaterials 17:1787

761. Takagi M, Mochida M, Uchida N, Saito K, Uematsu K (1992) J Mater Sci Mater Med 3:199

762. Silva VV, Domingues RZ (1997) J Mater Sci Mater Med 8:907

763. Silva VV, Lameiras FS, Domingues RZ (2001) Ceram Int 27:615

764. Rapacz-Kmita A, Slosarczyk A, Paszkiewicz Z, Paluch D (2004) J Mater Sci 39:5865. doi:10.1023/B:JMSC.0000040104. $64482.4 \mathrm{a}$

765. Rapacz-Kmita A, Slosarczyk A, Paszkiewicz Z (2005) Ceram Int 31:567

766. Sung YM, Kim DH (2003) J Crystal Growth 254:411

767. Silva VV, Lameiras FS (2000) Mater Charact 45:51

768. Shen Z, Adolfsson E, Nygren M, Gao L, Kawaoka H, Niihara K (2001) Adv Mater 13:214

769. Adolfsson E, Alberiushenning P, Hermansson L (2000) J Am Ceram Soc 83:2798

770. Kim HW, Noh YJ, Koh YH, Kim HE, Kim HM (2002) Biomaterials 23:4113

771. Li W, Gao L (2003) Biomaterials 24:937

772. Kim HW, Knowles JC, Li LH, Kim HE (2005) J Biomed Mater Res A 72A:258

773. Xiao XF, Liu RF, Zheng YZ (2006) J Mater Sci 41:3417. doi: 10.1007/s10853-005-5340-y

774. Kumar BR, Prakash KH, Cheang P, Khor KA (2005) Acta Mater 53:2327

775. Ahn ES, Gleason NJ, Nakahira A, Ying JY (2001) Nano Lett $1: 149$

776. Silva VV, Lameiras FS, Domingues RZ (2001) Compos Sci Technol 61:301

777. Khor KA, Fu L, Lim JP, Cheang P (2001) Mater Sci Eng A 316:160

778. Fu L, Khor KA, Lim JP (2002) J Am Ceram Soc 85:800 
779. Chou BY, Chang E, Yao SY, Chen JM (2002) J Am Ceram Soc 85:661

780. Wang Q, Ge S, Zhang D (2005) Wear 259:952

781. Murugan R, Ramakrishna S (2003) Mater Lett 58:230

782. Fu L, Khor KA, Lim JP (2000) Mater Sci Eng A 276:46

783. Nagarajan VS, Rao KJ (1993) J Mater Chem 3:43

784. Tamari N, Kondo I, Mouri M, Kinoshita M (1988) J Ceram Soc Japan 96:1200

785. Evis Z, Doremus RH (2007) J Mater Sci 42:2426. doi:10.1007/ s10853-006-1299-6

786. Evis Z, Doremus RH (2007) J Mater Sci 42:3739. doi:10.1007/ s10853-006-0485-x

787. Ahn ES, Gleason NJ, Ying JY (2005) J Am Ceram Soc 88:3374

788. Erkmen ZE, Genç Y, Oktar FN (2007) J Am Ceram Soc 90:2885

789. Rapacz-Kmita A, Slosarczyk A, Paszkiewicz Z (2006) J Eur Ceram Soc 26:1481

790. Sung YM, Shin YK, Ryu JJ (2007) Nanotechnology 18:065602 (6 pp)

791. Quan R, Yang D, Wu X, Wang H, Miao X, Li W (2008) J Mater Sci Mater Med 19:183

792. Khalil KA, Kim SW, Kim HY (2007) Mater Sci Eng A 456:368

793. Kong YM, Kim S, Kim HE, Lee IS (1999) J Am Ceram Soc $82: 2963$

794. Choi JW, Kong YM, Kim HE, Lee IS (1998) J Am Ceram Soc $81: 1743$

795. Adolfsson E, Hermansson L (2000) J Mater Sci 35:5719. doi: 10.1023/A:1004814726021

796. Li J, Fartash B, Hermansson L (1995) Biomaterials 16:417

797. Kim S, Kong YM, Kim HE, Lee IS (2002) J Mater Sci Mater Med 13:307

798. Chiba A, Kimura S, Raghukandan K, Morizono Y (2003) Mater Sci Eng A 350:179

799. Pang YX, Bao X, Weng L (2004) J Mater Sci 39:6311. doi: 10.1023/B:JMSC.0000043601.46284.a0

800. Jun YK, Kim WH, Kweon OK, Hong SH (2003) Biomaterials 24:3731

801. Epure LM, Dimitrievska S, Merhi Y, Yahia LH (2007) J Biomed Mater Res A 83A:1009

802. Evis Z, Doremus RH (2007) Mater Sci Eng C 27:421

803. Lu YP, Li MS, Li ST, Wang ZG, Zhu RF (2004) Biomaterials 25:4393

804. Li H, Khor KA, Cheang P (2003) Biomaterials 24:949

805. Zheng XB, Ding CX (2000) J Therm Spray Technol 9:520

806. Lee SH, Kim HW, Lee EJ, Li LH, Kim HE (2006) J Biomater Appl 20:195

807. Lin C, Yen S (2004) J Mater Sci Mater Med 15:1237

808. Balamurugan A, Balossier G, Kannan S, Michel J, Rajeswari S (2007) Mater Sci Eng C 27:162

809. Gaona M, Limab RS, Marple BR (2007) Mater Sci Eng A 458:141

810. Boyd AR, Duffy H, McCann R, Meenan BJ (2008) Mater Sci Eng C 28:228

811. Fidancevska E, Ruseska G, Bossert J, Linc YM, Boccaccini AR (2007) Mater Chem Phys 103:95

812. Harle J, Kim HW, Mordan N, Knowles JC, Salih V (2006) Acta Biomater 2:547

813. Kim HW, Kim HE, Salih V, Knowles JC (2005) J Biomed Mater Res B Appl Biomater 72B:1

814. Pushpakanth S, Srinivasan B, Sreedhar B, Sastry TP (2008) Mater Chem Phys 107:492

815. Sato M, Aslani A, Sambito MA, Kalkhoran NM, Slamovich EB, Webster TJ (2008) J Biomed Mater Res 84A:265

816. Ramires PA, Romito A, Cosentino F, Milella E (2001) Biomaterials 22:1467

817. Sun R, Li M, Lu Y, An X (2006) Mater Sci Eng C 26:28
818. Lee BT, Lee CW, Gain AK, Song HY (2007) J Eur Ceram Soc 27:157

819. Kong YM, Bae CJ, Lee SH, Kim HW, Kim HE (2005) Biomaterials 26:509

820. Oktar FN, Agathopoulos S, Ozyegin LS, Gunduz O, Demirkol N, Bozkurt Y, Salman S (2007) J Mater Sci Mater Med 18:2137

821. Gunduz O, Erkan EM, Daglilar S, Salman S, Agathopoulos S, Oktar FN (2008) J Mater Sci 43:2536. doi:10.1007/s10853008-2497-1

822. Li XW, Yasuda HY, Umakoshi Y (2006) J Mater Sci Mater Med $17: 573$

823. Ragel CV, Vallet-Regi M, Rodríguez-Lorenzo LM (2002) Biomaterials 23:1865

824. Padilla S, Sánchez-Salcedo S, Vallet-Regi M (2005) J Biomed Mater Res A 75A:63

825. Lopes MA, Monterio FJ, Santos JD (1999) Biomaterials 20:2085

826. Fu Q, Zhou N, Huang W, Wang D, Zhang L, Li H (2004) J Mater Sci Mater Med 15:1333

827. Fu Q, Zhou N, Huang W, Wang D, Zhang L, Li H (2005) J Biomed Mater Res A 74A:156

828. Oktar FN, Goller G (2002) Ceram Int 28:617

829. Padilla S, Román J, Sánchez-Salcedo S, Vallet-Regi M (2006) Acta Biomater 2:331

830. Kokubo T, Shigematsu M, Nagashima Y, Tashiro M, Nakamura T, Yamamuro T, Higashi S (1982) Bull Inst Chem Res Kyoto Univ 60:260

831. Kitsugi T, Yamamuro T, Nakamura T, Higashi S, Kakutani Y, Hyakuna K, Ito S, Kokubo T, Takagi M, Shibuya T (1986) J Biomed Mater Res 20:1295

832. Kokubo T, Ito S, Shigematsu M, Sakka S, Yamamuro T (1987) J Mater Sci 22:4067. doi:10.1007/BF01133359

833. Kokubo T, Ito S, Shigematsu M, Sakka S, Yamamuro T (1985) J Mater Sci 20:2001. doi:10.1007/BF01112282

834. Kokubo T (1991) Biomaterials 12:155

835. Kokubo T, Ito S, Huang ZT, Hayashi T, Sakka S, Kitsugi T, Yamamuro T (1990) J Biomed Mater Res 24:331

836. Nishio K, Neo M, Akiyama H, Okada Y, Kokubo T, Nakamura T (2001) J Biomed Mater Res 55:164

837. Zhang D, Chang J, Zeng Y (2008) J Mater Sci Mater Med $19: 443$

838. Chaki TK, Wang PE (1994) J Mater Sci Mater Med 5:533

839. Zhang X, Gubbels GHM, Terpstra RA, Metselaar R (1997) J Mater Sci 32:235. doi:10.1023/A:1018568308926

840. Chu C, Lin P, Dong Y, Xue X, Zhu J, Yin Z (2002) J Mater Sci Mater Med 13:985

841. Shi W, Kamiya A, Zhu J, Watazu A (2002) Mater Sci Eng A 337:104

842. Ning CQ, Zhou Y (2002) Biomaterials 23:2909

843. Karanjai M, Sundaresan R, Rao GVN, Rama Mohan TR, Kashyap BP (2007) Mater Sci Eng A 447:19

844. Karanjai M, Manoj Kumar BV, Sundaresan R, Basu B, Rama Mohan TR, Kashyap BP (2008) Mater Sci Eng A 475:299

845. Ning CQ, Zhou Y (2004) Biomaterials 25:3379

846. Chu C, Xue X, Zhu J, Yin Z (2004) J Mater Sci Mater Med $15: 665$

847. Smirnov VV, Egorov AA, Barinov SM, Shvorneva LI (2007) Dokl Chem 413:82

848. Chu C, Xue X, Zhu J, Yin Z (2006) J Mater Sci Mater Med $17: 245$

849. Li J, Habibovic P, Yuan H, van den Doel M, Wilson CE, de Wijn JR, van Blitterswijk CA, de Groot K (2007) Biomaterials 28:4209

850. Pattanayak DK, Mathur V, Rao BT, Rama Mohan TR (2003) Trends Biomater Artif Organs 17:8 
851. Ding Y, Liu J, Wang H, Shen G, Yu R (2007) Biomaterials 28:2147

852. Damien CJ, Parsons JR, Benedict JJ, Weisman DS (1990) J Biomed Mater Res 24:639

853. Rauschmann MA, Wichelhaus TA, Stirnal V, Dingeldein E, Zichner L, Schnettler R, Alt V (2005) Biomaterials 26:2677

854. Urban RM, Turner TM, Hall DJ, Inoue N, Gitelis S (2007) Clin Orthop Relat Res 459:110

855. Gittings JP, Bowena CR, Turner IG, Baxter F, Chaudhuri J (2007) J Eur Ceram Soc 27:4187

856. Watanabe Y, Ikoma T, Suetsugu Y, Yamada H, Tamura K, Komatsu Y, Tanaka J, Moriyoshi Y (2006) J Eur Ceram Soc $26: 481$

857. Agathopoulos S, Tulyaganov DU, Marques PAAP, Ferro MC, Fernandes MHV, Correia RN (2003) Biomaterials 24:1317

858. Khor KA, Gu YW, Pan D, Cheang P (2004) Biomaterials 25:4009

859. Gu YW, Khor KA, Pan D, Cheang P (2004) Biomaterials 25:3177

860. Best SM, Porter AE, Thian ES, Huang J (2008) J Eur Ceram Soc 28:1319

861. de Aza PN, Guitián F, de Aza S (1997) Biomaterials 18:1285

862. Huang X, Jiang D, Tan S (2004) J Biomed Mater Res B Appl Biomater 69B:70

863. Zhang F, Chang J, Lin K, Lu J (2008) J Mater Sci Mater Med 19:167

864. Juhasz JA, Best SM, Kawashita M, Miyata N, Kokubo T, Nakamura T, Bonfield W (2003) J Biomed Mater Res A 67A:952

865. Juhasz JA, Best SM, Bonfield W, Kawashita M, Miyata N, Kokubo T, Nakamura T (2003) J Mater Sci Mater Med 14:489

866. Juhasz JA, Best SM, Brooks R, Kawashita M, Miyata N, Kokubo T, Nakamura T, Bonfield W (2004) Biomaterials 25:949

867. Rea SM, Brooks RA, Best SM, Kokubo T, Bonfield W (2004) Biomaterials 25:4503

868. Greish YE, Brown PW (2001) J Biomed Mater Res 55:618. Erratum in: J Biomed Mater Res 2001;56:459

869. Greish YE, Brown PW (2000) J Biomed Mater Res 52:687

870. Kangasniemi I, de Groot K, Wolke J, Andersson O, Luklinska Z, Becht JGM, Lakkisto M, Yli-Urpo A (1991) J Mater Sci Mater Med 2:133

871. Kangasniemi IMO, de Groot K, Becht JGM, Yli-Urpo A (1992) J Biomed Mater Res 26:663

872. Kangasniemi IMO, Vedel E, de Blick-Hogerworst J, Yli-Urpo A, de Groot K (1993) J Biomed Mater Res 27:1225

873. Maruno S, Ban S, Wang YF, Iwata H, Itoh H (1992) J Ceram Soc Jpn 100:362

874. White AA, Best SM, Kinloch IA (2007) Int J Appl Ceram Technol 4:1

875. Chlopek J, Czajkowska B, Szaraniec B, Frackowiak E, Szostak K, Beguin F (2006) Carbon 44:1106

876. Price RL, Waid MC, Haberstroh KM, Webster TJ (2003) Biomaterials $24: 1877$

877. Zanello LP, Zhao B, Hu H, Haddon RC (2006) Nano Lett 6:562

878. Saito N, Usui Y, Aoki K, Narita N, Shimizu M, Ogiwara N, Nakamura K, Ishigaki N, Kato H, Taruta S (2008) Curr Med Chem 15:523

879. Kobayashi S, Kawai W (2007) Composites A 38:114

880. Balani K, Anderson R, Laha T, Andara M, Tercero J, Crumpler E, Agarwal A (2007) Biomaterials 28:618

881. Chen Y, Gan CH, Zhang TH, Yu G, Bai P, Kaplan A (2005) Appl Phys Lett 86:251905 (3 pp)

882. Chen Y, Zhang TH, Gan CH, Yu G (2007) Carbon 45:998

883. Chen Y, Zhang YQ, Zhang TH, Gan $\mathrm{CH}$, Zheng $\mathrm{CY}$, Yu G (2006) Carbon 44:37

884. Ding Y, Liu J, Jin X, Lu H, Shen G, Yu R (2008) Analyst 133:184
885. Slosarcyk A, Klisch M, Blazewicz M, Piekarczyk J, Stobierski L, Rapacz-Kmita A (2000) J Eur Ceram Soc 20:1397

886. Dorner-Reisel A, Berroth K, Neubauer R, Nestler K, Marx G, Scislo M, Müller E, Slosarcyk A (2004) J Eur Ceram Soc 24:2131

887. Fu T, Zhao JL, Wei JH, Han Y, Xu KW (2004) J Mater Sci 39:1411. doi:10.1023/B:JMSC.0000013906.60034.e8

888. Yoshimura M (1988) Am Ceram Soc Bull 67:1950

889. Thompson I, Rawlings RD (1990) Biomaterials 11:505

890. Monma H (1987) J Ceram Soc Jpn 96:60

891. Suchanek W, Yashima M, Kakihana M, Yoshimura M (1996) Biomaterials 17:1715

892. Suchanek W, Yashima M, Kakihana M, Yoshimura M (1997) J Am Ceram Soc 80:2805

893. Kaito T, Mukai Y, Nishikawa M, Ando W, Yoshikawa H, Myoui A (2006) J Biomed Mater Res B Appl Biomater 78B:378

894. Ramay HR, Zhang M (2004) Biomaterials 21:5171

895. Watari F, Yokoyama A, Saso F, Uo M, Kawasaki T (1997) Composites B 28B:5

896. Watari F, Yokoyama A, Omori M, Hirai T, Kondo H, Uo M, Kawasaki T (2004) Compos Sci Technol 64:893

897. Chenglim C, Jingchuan Z, Zhongda Y, Shidong W (1999) Mater Sci Eng A 271:95

898. Inagaki M, Yokogawa Y, Kameyama T (2006) J Eur Ceram Soc 26:495

899. Ban S, Hasegawa J, Maruno S (1999) Mater Sci Forum 308311:350

900. Stojanovic D, Jokic B, Veljovic DJ, Petrovic R, Uskokovic PS Janackovic Dj (2007) J Eur Ceram Soc 27:1595

901. Nonami T, Kamiya A, Naganuma K, Kameyana T (1998) Mater Sci Eng C 6:281

902. Wong LH, Tio B, Miao X (2002) Mater Sci Eng C 20:111

903. Peltola T, Patsi M, Rahiala H, Kangasniemi I, Yli-Urpo A (1998) J Biomed Mater Res 41:504

904. Heilmann F, Standard OC, Müller FA, Hoffman M (2007) J Mater Sci Mater Med 18:1817

905. Cavalcanti A, Shirinzadeh B, Zhang M, Kretly LC (2008) Sensors 8:2932

906. Wypych G (1999) Handbook of fillers, 2nd edn. ChemTec Publishing, New York

907. Rhee SH, Lee JD, Tanaka J (2000) J Am Ceram Soc 83:2890

908. Lin X, Li X, Fan H, Wen X, Lu J, Zhang X (2004) Mater Lett 58:3569

909. Zhang W, Liao SS, Cui FZ (2003) Chem Mater 15:3221

910. Liu Q, de Wijn JR, van Blitterswijk CA (1998) J Biomed Mater Res 40:257

911. Li J, Chen YP, Yin Y, Yao F, Yao K (2007) Biomaterials 28:781

912. Boanini E, Gazzano M, Rubini K, Bigi A (2007) Adv Mater 19:2499

913. Tjandra W, Yao J, Ravi P, Tam KC, Alamsjah A (2005) Chem Mater 17:4865

914. Misra DN (1985) J Dent Res 12:1405

915. Liu Q, de Wijn JR, van Blitterswijk CA (1998) J Biomed Mater Res 40:358

916. Grossman RF (1996) In: Edenbaum J (ed) Plastics additives and modifiers handbook, 2nd edn. Chapman \& Hall, New York

917. Chang MC, Ikoma T, Kikuchi M, Tanaka J (2001) J Mater Sci Lett 20:1199

918. Sousa RA, Reis RL, Cunha AM, Bevis MJ (2003) J Mater Sci Mater Med 14:475

919. Wang M, Deb S, Bonfield W (2000) Mater Lett 44:119

920. Wang M, Bonfield W (2001) Biomaterials 22:1311

921. Dupraz AMP, de Wijn JR, van der Meer SAT, Goedemoed JH (1996) J Mater Sci Mater Med 7:731

922. Dupraz AMP, de Wijn JR, van der Meer SAT, de Groot K (1996) J Biomed Mater Res 30:231 
923. Liao JG, Wang XJ, Zuo Y, Zhang L, Wen JQ, Li Y (2008) J Inorg Mater 23:145

924. Sousa RA, Reis RL, Cunha AM, Bevis MJ (2002) J Appl Polym Sci 86:2866

925. Morita S, Furuya K, Ishihara K, Nakabayashi N (1998) Biomaterials 19:1601

926. Shinzato S, Nakamura T, Tamura J, Kokubo T, Kitamura Y (2001) J Biomed Mater Res 56:571

927. Dorozhkin SV (2001) Biomed Mater Res 54:247

928. Omori M, Okubo A, Otsubo M, Hashida T, Tohji K (2004) Key Eng Mater 254-256:395

929. Zhao B, Hu H, Mandal SK, Haddon RC (2005) Chem Mater 17:3235

930. Kasuga T, Yoshida M, Ikushima AJ, Tuchiya M, Kusakari H (1992) J Am Ceram Soc 75:1884
931. Dorozhkin SV (1999) Comments Inorg Chem 20:285

932. Dorozhkin SV (2002) Prog Cryst Growth Charact 44:45

933. Furukawa T, Matsusue Y, Yasunaga T, Shikinami Y, Okuno M, Nakamura T (2000) Biomaterials 21:889

934. Furukawa T, Matsusue Y, Yasunaga T, Nakagawa Y, Okada Y, Shikinami Y, Okuno M, Nakamura T (2000) J Biomed Mater Res 50:410

935. Yasunaga T, Matsusue Y, Furukawa T, Shikinami Y, Okuno M, Nakamura T (1999) J Biomed Mater Res 47:412

936. Marques AP, Reis RL, Hunt JA (2002) Biomaterials 6:1471

937. Mendes SC, Bovell YP, Reis RL, Cunha AM, de Bruijn JD, van Blitterswijk CA (2001) Biomaterials 22:2057

938. Meyers MA, Lin AYM, Seki Y, Chen PY, Kad BK, Bodde S (2006) JOM 58:36 